Cochrane Database of Systematic Reviews

\title{
Circuit class therapy for improving mobility after stroke (Review)
}

English C, Hillier SL, Lynch EA

English C, Hillier SL, Lynch EA.

Circuit class therapy for improving mobility after stroke.

Cochrane Database of Systematic Reviews 2017, Issue 6. Art. No.: CD007513.

DOI: 10.1002/14651858.CD007513.pub3.

www.cochranelibrary.com 
TABLE OF CONTENTS

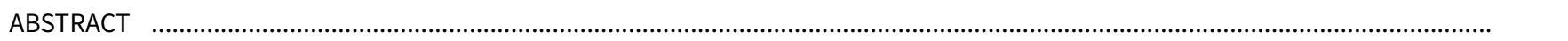

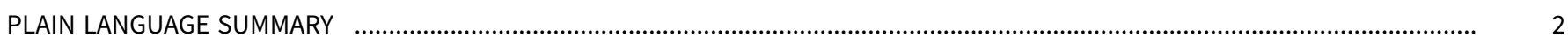

SUMMARY OF FINDINGS

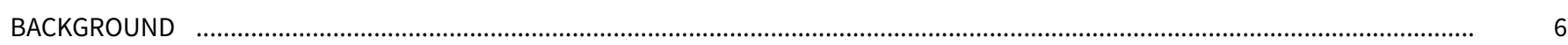

OBJECTIVES

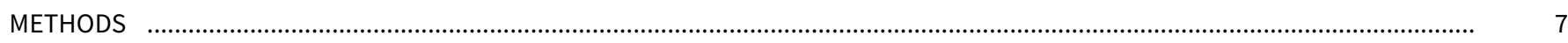

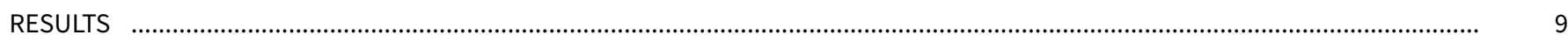

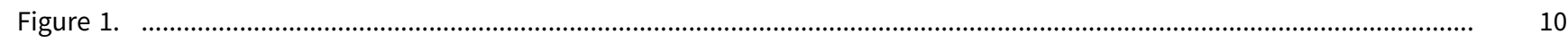

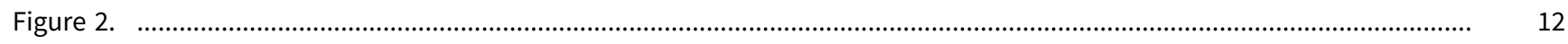

Figure 3.

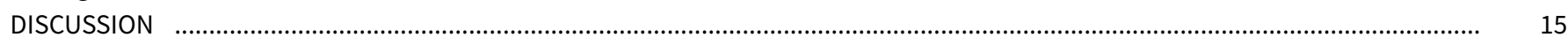

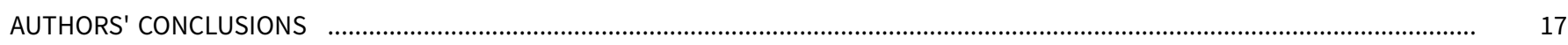

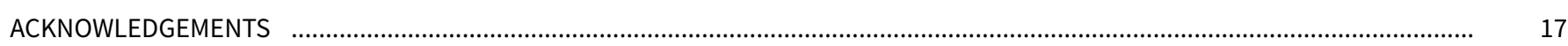

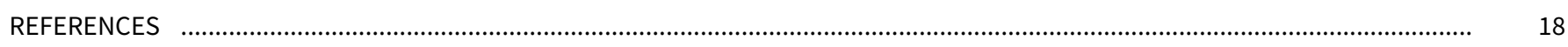

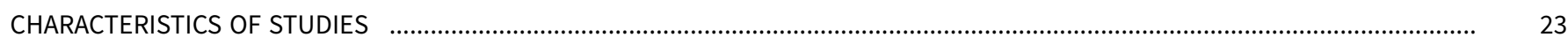

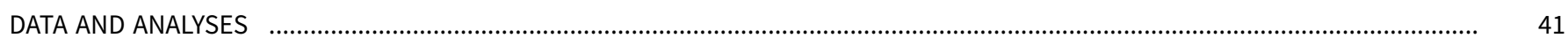

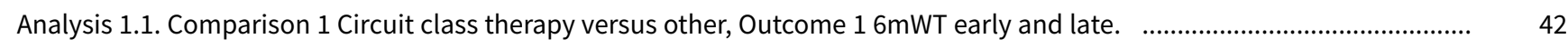

Analysis 1.2. Comparison 1 Circuit class therapy versus other, Outcome 2 Gait speed early and late. ......................................... 43

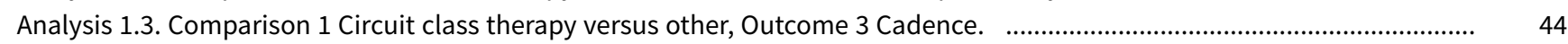

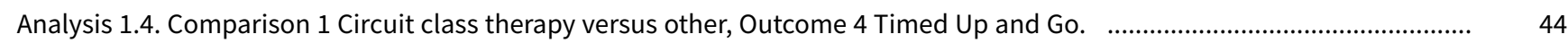

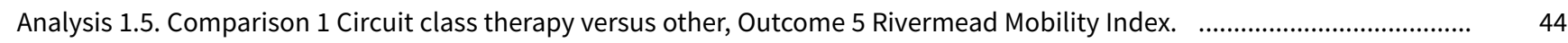

Analysis 1.6. Comparison 1 Circuit class therapy versus other, Outcome 6 Functional Ambulation Classification. ....................

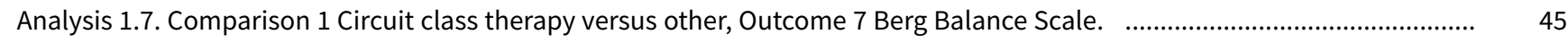

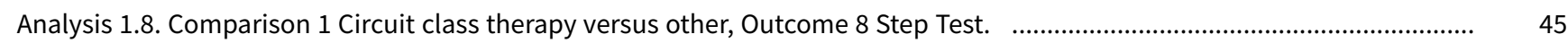

Analysis 1.9. Comparison 1 Circuit class therapy versus other, Outcome 9 Activities-specific Balance Confidence Scale. .......... 45

Analysis 1.10. Comparison 1 Circuit class therapy versus other, Outcome 10 Stroke Impact Scale (physical). ............................... 46

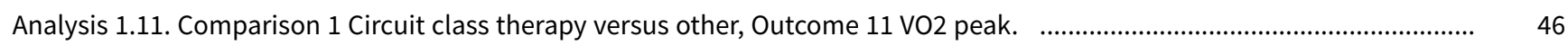

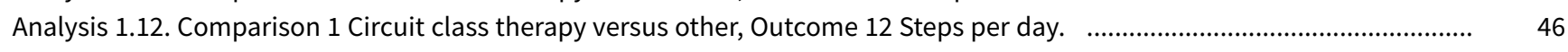

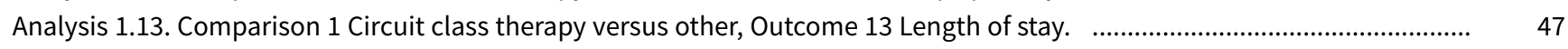

Analysis 1.14. Comparison 1 Circuit class therapy versus other, Outcome 14 Sensitivity: 6mWT. ................................................ 47

Analysis 2.1. Comparison 2 CCT + education versus no therapy, Outcome 1 Timed Up and Go. . ...................................................

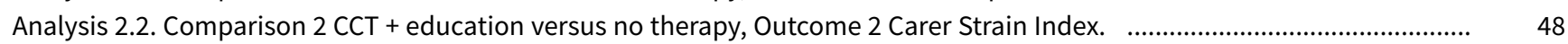

Analysis 3.1. Comparison 3 CCT +/- education versus any other intervention, Outcome 1 Adverse events (falls). ........................ 48

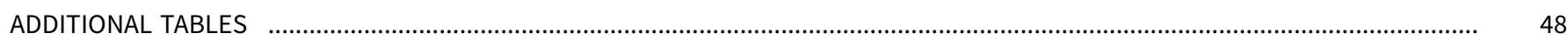

APPENDICES

WHAT'S NEW

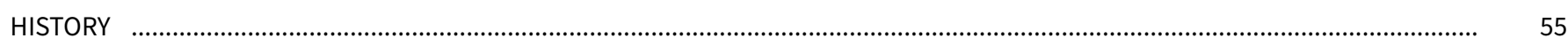

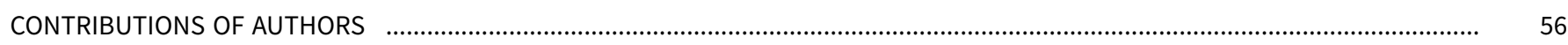

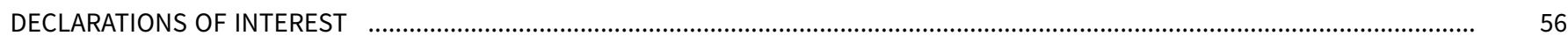

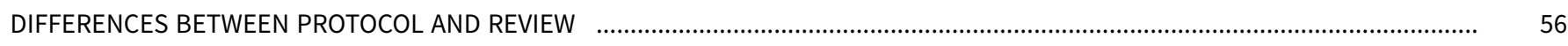

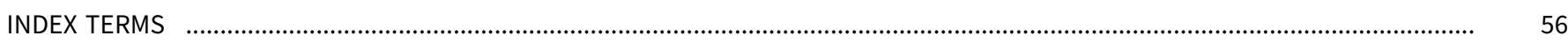


[Intervention Review]

\section{Circuit class therapy for improving mobility after stroke}

Coralie English1,2, Susan L Hillier ${ }^{3}$, Elizabeth A Lynch²,4

1School of Health Sciences and Priority Research Centre for Stroke and Brain Injury, University of Newcastle, Callaghan, Australia. 2NHMRC Centre of Research Excellence in Stroke Rehabilitation and Brain Recovery, Florey Institute of Neuroscience and Mental Health \& Hunter Medical Research Institute, Melbourne and Newcastle, Australia. ${ }^{3}$ Sansom Institute for Health Research, University of South Australia (City East), Adelaide, Australia. ${ }^{4}$ Adelaide Nursing School, The University of Adelaide, Adelaide, Australia

Contact: Susan L Hillier, Sansom Institute for Health Research, University of South Australia (City East), North Terrace, Adelaide, SA, 5000, Australia.Susan.Hillier@unisa.edu.au.

Editorial group: Cochrane Stroke Group.

Publication status and date: Edited (no change to conclusions), published in Issue 6, 2017.

Citation: English C, Hillier SL, Lynch EA. Circuit class therapy for improving mobility after stroke. Cochrane Database of Systematic Reviews 2017, Issue 6. Art. No.: CD007513. DOI: 10.1002/14651858.CD007513.pub3.

Copyright ( 2017 The Cochrane Collaboration. Published by John Wiley \& Sons, Ltd.

\section{A B S T R A C T}

\section{Background}

Circuit class therapy (CCT) offers a supervised group forum for people after stroke to practise tasks, enabling increased practice time without increasing staffing. This is an update of the original review published in 2010.

\section{Objectives}

To examine the effectiveness and safety of CCT on mobility in adults with stroke.

\section{Search methods}

We searched the Cochrane Stroke Group Trials Register (last searched January 2017), CENTRAL (the Cochrane Library, Issue 12, 2016), MEDLINE (1950 to January 2017), Embase (1980 to January 2017), CINAHL (1982 to January 2017), and 14 other electronic databases (to January 2017). We also searched proceedings from relevant conferences, reference lists, and unpublished theses; contacted authors of published trials and other experts in the field; and searched relevant clinical trials and research registers.

\section{Selection criteria}

Randomised controlled trials (RCTs) including people over 18 years old, diagnosed with stroke of any severity, at any stage, or in any setting, receiving CCT.

\section{Data collection and analysis}

Review authors independently selected trials for inclusion, assessed risk of bias in all included studies, and extracted data.

\section{Main results}

We included 17 RCTs involving 1297 participants. Participants were stroke survivors living in the community or receiving inpatient rehabilitation. Most could walk 10 metres without assistance. Ten studies (835 participants) measured walking capacity (measuring how far the participant could walk in six minutes) demonstrating that CCT was superior to the comparison intervention (Six-Minute Walk Test: mean difference (MD), fixed-effect, $60.86 \mathrm{~m}, 95 \%$ confidence interval (CI) 44.55 to 77.17 , GRADE: moderate). Eight studies (744 participants) measured gait speed, again finding in favour of CCT compared with other interventions (MD $0.15 \mathrm{~m} / \mathrm{s}, 95 \% \mathrm{Cl} 0.10$ to 0.19 , GRADE: moderate). Both of these effects are considered clinically meaningful. We were able to pool other measures to demonstrate the superior effects of CCT for aspects of walking and balance (Timed Up and Go: five studies, 488 participants, MD -3.62 seconds, $95 \% \mathrm{Cl}-6.09$ to -1.16 ; Activities of Balance Confidence scale: two studies, 103 participants, MD 7.76, 95\% Cl 0.66 to 14.87). Two other pooled balance measures 
failed to demonstrate superior effects (Berg Blance Scale and Step Test). Independent mobility, as measured by the Stroke Impact Scale, Functional Ambulation Classification and the Rivermead Mobility Index, also improved more in CCT interventions compared with others. Length of stay showed a non-significant effect in favour of CCT (two trials, 217 participants, MD -16.35, 95\% Cl -37.69 to 4.99). Eight trials (815 participants) measured adverse events (falls during therapy): there was a non-significant effect of greater risk of falls in the CCT groups (RD $0.03,95 \% \mathrm{Cl}-0.02$ to 0.08 , GRADE: very low). Time after stroke did not make a difference to the positive outcomes, nor did the quality or size of the trials. Heterogeneity was generally low; risk of bias was variable across the studies with poor reporting of study conduct in several of the trials.

\section{Authors' conclusions}

There is moderate evidence that CCT is effective in improving mobility for people after stroke - they may be able to walk further, faster, with more independence and confidence in their balance. The effects may be greater later after the stroke, and are of clinical significance. Further high-quality research is required, investigating quality of life, participation and cost-benefits, that compares CCT with standard care and that also investigates the influence of factors such as stroke severity and age. The potential risk of increased falls during CCT needs to be monitored.

\section{PLAIN LANGUAGE SUMMARY}

\section{Circuit class therapy for improving mobility after stroke}

\section{Review question}

Is circuit class therapy better than conventional physiotherapy for improving people's walking after a stroke?

\section{Background}

After stroke, people can have difficulty walking. They may become slower, only manage short distances, and may need assistance. They may lose balance more easily and be more fatigued. This can mean they walk even less, and so walking ability can worsen. Rehabilitation can help improve walking, but it is hard to access, particularly later after stroke. Circuit class therapy involves working in groups (rather than individually with a therapist), and doing specific practice of meaningful tasks, and may offer a solution that is more accessible.

\section{Study characteristics}

This is an update of the original review in 2010. We considered studies comparing circuit class therapy with conventional therapy for people with stroke, and included only high-quality studies with a low risk of being biased. We were interested in studies that compared these two approaches and their effects on the way people walk, how far, how fast, and how independently. We also looked for studies that investigated if the circuit classes were more or less likely to be harmful than conventional approaches. The evidence is current to January 2017.

\section{Main results}

We found seventeen studies, involving 1297 participants, that compared circuit class rehabilitation with usual care or sham rehabilitation. Most trials reported the benefits of circuit classes for improving walking ability. More specifically, we combined the results from the studies and found moderate evidence that circuit classes were more effective in improving the person's ability to walk further, more independently, and faster and, in some cases, to balance more easily and confidently when compared with other types of therapy. There was a suggestion that people might fall more often in the circuit classes, and that they may be able to get home from rehabilitation hospital more quickly, but these two aspects were not confirmed using statistics. We also found that the positive effects of the circuit classes were experienced equally by people who had had their stroke more than a year ago compared with people who had had their stroke within the year. This means people can continue to improve longer after their stroke than was previously reported. More research is needed to see if it works for all people with any severity of stroke and if some tasks are better to practise than others.

\section{Quality of the evidence}

The quality of the studies overall was acceptable, given it is difficult to keep some aspects tightly controlled in rehabilitation studies. However, we have downgraded the quality rating to 'moderate' to acknowledge that some trials have the potential for bias. 
SUMMARY OF FINDINGS

Summary of findings for the main comparison. Circuit class therapy compared with other intervention for improving mobility

Circuit class therapy compared with other intervention for improving mobility

Patient or population: people with stroke

Settings: in hospital or community

Intervention: mobility-related circuit class therapy

Comparison: any other intervention

\begin{tabular}{|c|c|c|c|c|c|c|}
\hline \multirow[t]{3}{*}{ Outcomes } & \multicolumn{2}{|c|}{$\begin{array}{l}\text { Illustrative comparative effects ( } 95 \% \\
\mathrm{Cl} \text { ) }\end{array}$} & \multirow[t]{3}{*}{$\begin{array}{l}\text { Relative effect } \\
(95 \% \mathrm{CI})\end{array}$} & \multirow{3}{*}{$\begin{array}{l}\text { No of partici- } \\
\text { pants } \\
\text { (studies) }\end{array}$} & \multirow{3}{*}{$\begin{array}{l}\text { Quality of the } \\
\text { evidence } \\
\text { (GRADE) }\end{array}$} & \multirow[t]{3}{*}{ Comments } \\
\hline & Assumed effect & Absolute effect & & & & \\
\hline & $\begin{array}{l}\text { Other interven- } \\
\text { tion }\end{array}$ & $\begin{array}{l}\text { Mobility-related } \\
\text { circuit class thera- } \\
\text { py }\end{array}$ & & & & \\
\hline & & & & & & $\begin{array}{l}\text { Some studies have unclear risk of bias (down- } \\
\text { graded) }\end{array}$ \\
\hline $\begin{array}{l}\text { Walking speed } \\
\text { Continuous measure } \\
\text { of walking speed } \\
\text { measured over a } \\
\text { short distance in } \mathrm{m} / \mathrm{s}\end{array}$ & $\begin{array}{l}\text { The mean gait } \\
\text { speed ranged } \\
\text { across control } \\
\text { groups from } 0.43 \\
\mathrm{~m} / \mathrm{s} \text { to } 1.3 \mathrm{~m} / \mathrm{s}\end{array}$ & $\begin{array}{l}\text { The mean gait } \\
\text { speed in the in- } \\
\text { tervention groups } \\
\text { was } 0.15 \mathrm{~m} / \mathrm{s} \text { faster } \\
(0.10 \text { to } 0.19)\end{array}$ & & $744(8)$ & $\begin{array}{l}\oplus \oplus \oplus \ominus \\
\text { moderate }\end{array}$ & $\begin{array}{l}\text { Applicable: difference greater than MDC = } \\
0.06 \mathrm{~m} / \mathrm{s} \text { Perera } 2006, \text { and } 95 \% \mathrm{Cl} \text { of differ- } \\
\text { ence does not cross MDC } \\
\text { Some studies have unclear risk of bias (down- } \\
\text { graded) }\end{array}$ \\
\hline $\begin{array}{l}\text { Balance and mobil- } \\
\text { ity }\end{array}$ & $\begin{array}{l}\text { The mean speed } \\
\text { ranged across } \\
\text { control groups }\end{array}$ & $\begin{array}{l}\text { The mean speed } \\
\text { in the interven- } \\
\text { tion group was } 3.62\end{array}$ & & $488(5)$ & $\begin{array}{l}\oplus \oplus \ominus \ominus \\
\text { low }\end{array}$ & $\begin{array}{l}\text { Applicable: somewhat as difference is not } \\
\text { greater than MDC (8 s or } 28 \% \text { ) (downgraded). }\end{array}$ \\
\hline
\end{tabular}




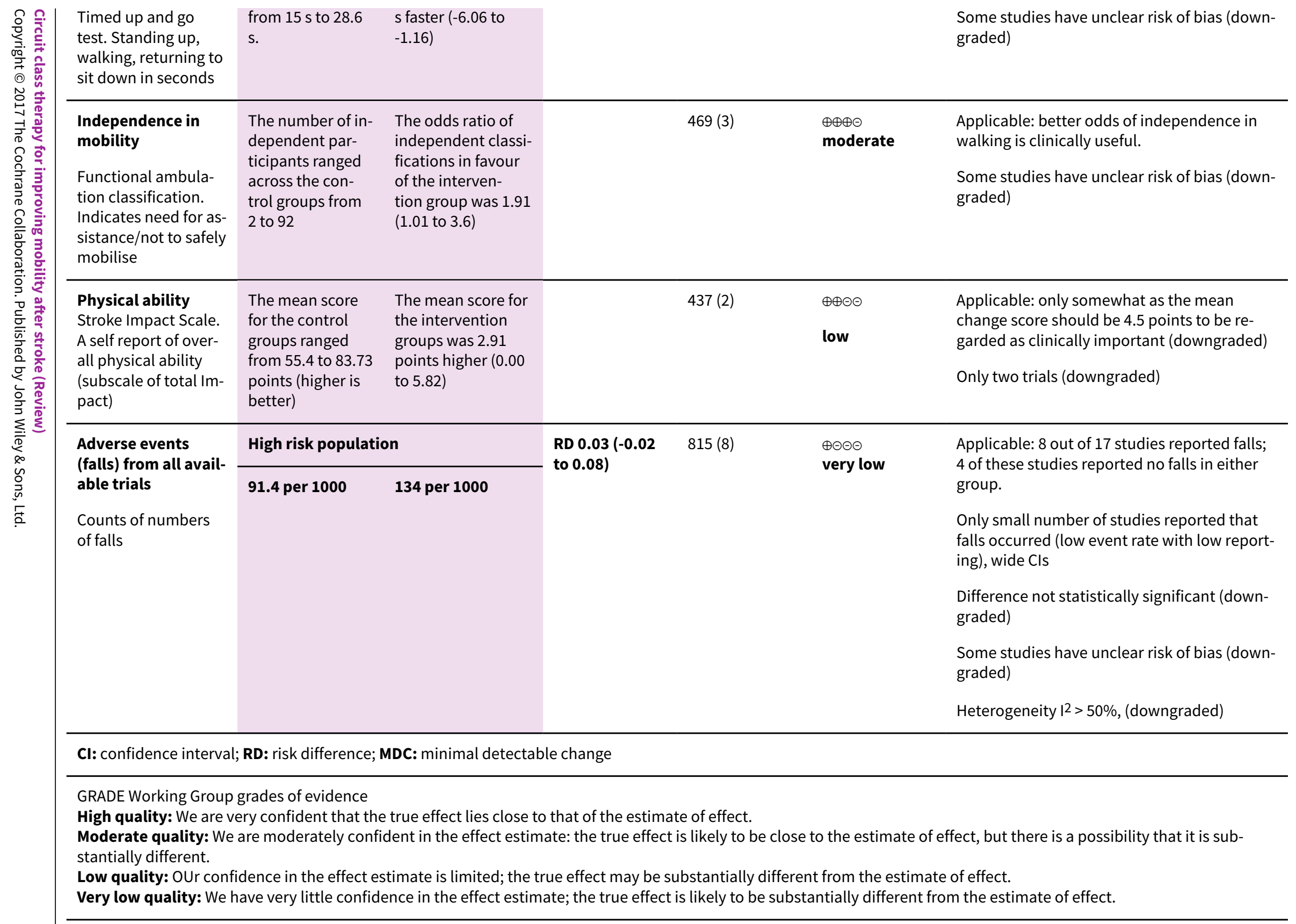




\section{B A C K G R O U N D}

\section{Description of the condition}

Stroke is the second most common cause of death globally, and was the third most common cause of disability-adjusted life-years worldwide in 2010 (Feigin 2014). The absolute numbers of people with stroke and the overall global burden of stroke are high and, despite medical advances in high-income countries, these numbers are increasing steadily (Feigin 2014). Disability from stroke can negatively affect people's relationships (Lynch 2008a), the ability to live in the community, and the ability to participate in work and leisure activities. Stroke rehabilitation has been described as a holistic management plan, which is directed towards "enabling a person with impairment to reach their optimal physical, cognitive, emotional, communicative and/or social functional level" (Dawson 2013, p4). In terms of physical function, there are clear benefits from the provision of physical rehabilitation after stroke (Pollock 2014). With increasing numbers of people having strokes, poststroke rehabilitation services are in high demand.

Rehabilitation after stroke can be provided in inpatient settings, in peoples' homes, or in community clinics. The financial costs associated with stroke are substantial: for instance, the average per-person costs of stroke in 2012 in Australia was AUD 27,709 (Deloitte Access Economics 2013), and the burden of disease costs in the USA has been estimated at USD 34 billion per year (Mozaffarian 2015). While there is evidence that rehabilitation at home may be more cost-effective than other models of service delivery (Hillier 2010), this is not a feasible service for many people with stroke. Given the high demand for services and high costs associated with delivering post-stroke care, there is pressure on rehabilitation services to provide evidence-based therapies that are also cost effective.

\section{Description of the intervention}

Group circuit class therapy (CCT) is a model of physical therapy delivery wherein participants are given the opportunity to practice active task-specific exercises (i.e. functional activities) in an intensive manner. The first trials investigating the feasibility of providing physical therapy to patients in groups rather than the traditional one-therapist-to-one-patient model were published in the late 1990s (Taskinen 1999; Teixeira-Salmela 1999). The key components of CCT are that physical therapy is provided in groups (more than two participants per therapist) and there is a focus on repetitive practise of functional tasks and exercises that are continually progressed as the participant's function improves (English 2007; Van de Port 2012; Wevers 2009). CCT may comprise either a series of workstations arranged in a circuit (Van de Port 2012; Wevers 2009) or a series of individualised activities within a group setting (English 2007; English 2015). CCT differs from physiological exercise programmes designed to improve strength or aerobic fitness because, although many CCT exercises may have a strength or fitness component, the primary focus is on specific training of everyday motor tasks.

CCT can be directed towards a range of post-stroke impairments and has been used to improve the use of hemiparetic upper limbs (Blennerhassett 2004), or to improve both mobility and upper limb impairments within the one circuit class session (English 2007; English 2015). However, the majority of studies have investigated the use of CCT for improving mobility (the ability to stand, walk, or run) so mobility-tailored CCT is the focus of this review.

\section{How the intervention might work}

Physical therapy provided to people with stroke for 30 minutes to 60 minutes per day, five to seven days per week, results in significant improvements in independence and motor function compared with no therapy (Pollock 2014). Accordingly, many national clinical guidelines for stroke recommend that people with stroke spend a minimum of between 30 minutes and three hours per day in therapy during inpatient rehabilitation (Intercollegiate Stroke Working Party 2012; Jauch 2013; Lindsay 2010; National Stroke Foundation 2010; Stroke Foundation of New Zealand 2010). Data modelling work has demonstrated that increased time scheduled for therapy is associated with significant post-stroke improvements in function (Lohse 2014). Further evidence regarding the benefits of increased time in therapy was provided from a recently updated meta-analysis of clinical trials of physiotherapy after stroke (Verbeek 2014). The meta-analysis included 80 trials that investigated the effect of providing increased intensity (hours spent) of physiotherapy, and found that increasing time in therapy after stroke is associated with significant, positive effects on walking speed, balance, and activities of daily living. In order to achieve significant positive effects at the body-function level as well as the activities and participation level, an increase of 17 hours of therapy provided over 10 weeks is necessary (Verbeek 2014). The group nature of CCT interventions potentially allows a greater amount of therapy to be provided to patients within a finite period of time without increasing staffing requirements.

A recent Cochrane Review on physiotherapy for improving mobility after stroke reported that no approach of physiotherapy is clearly more effective than other approaches (Pollock 2014). The review also found that physiotherapy appears to be most beneficial when a mixture of different approaches are provided that are tailored for each patient. Interventions that have proven effectiveness in improving mobility outcomes for people with stroke include balance training (Verbeek 2014), combined strength and cardiovascular training (Verbeek 2014), and treadmill training for people who are able to walk independently (Mehrholz 2014). CCT can potentially improve mobility outcomes as the aforementioned interventions can be incorporated into CCT, and all activities prescribed within CCT are routinely tailored to each participant.

There may be benefits of CCT related to the peer support and social interaction provided by the group environment. Depression after stroke is common, affecting one third of people in the first year following stroke (Hackett 2008). Several small qualitative studies have found benefits to stroke survivors from participating in group activities with peers in terms of learning new coping mechanisms (Morris 2012), experiencing an increased sense of independence and well-being (Morris 2012), and reducing post-stroke depression (Stroke Recovery Canada 2009).

The format of CCT is conducive for optimal motor learning after stroke. Given the group nature of the CCT format, participants will usually be prescribed certain activities to perform semi-supervised or independently, and other activities to perform with assistance of a therapist. When participants are performing the independent activities, the nature of the task-specific exercise should ensure their attention is on the overall movement outcome (external focus) 
rather than the individual body part or joint movements (internal focus). Attention to external foci has been associated with better motor-learning outcomes (Van Vliet 2006; Wulf 2010). The presence of a therapist at each CCT session allows for extrinsic feedback to be given to participants, which is an important contributor for optimal motor learning (Sigrist 2013; Wulf 2010). Further, CCT allows participants to observe other stroke survivors who are learning new motor tasks, which is another mechanism to facilitate motor learning (Wulf 2010).

\section{Why it is important to do this review}

Given the fiscal constraints of healthcare systems, rehabilitation services cannot simply increase the amount of therapy provided to people with stroke by scheduling more frequent or longer oneto-one therapy sessions, because this involves significant increases in staffing costs. Instead, it is important that novel cost-effective models of providing increased intensity of therapy are developed, researched, and implemented. CCT has the potential to be an effective means of providing a greater amount of physical therapy for people with stroke both in hospital and community settings. When the clinical effectiveness of CCT is established, then cost implications of this model of therapy provision can be investigated. This is an update of the original review in 2010 which found that there was evidence to support the use of CCT for improving mobility after stroke.

\section{OB JECTIVES}

To examine the effectiveness and safety of CCT on mobility in adults with stroke.

\section{ME T HO D S}

\section{Criteria for considering studies for this review}

\section{Types of studies}

Randomised controlled trials (RCTs) comparing CCT with no therapy, sham therapy, or another therapy modality. The earlier review included quasi-randomised trials due to the paucity of studies. This was not necessary in this update.

\section{Types of participants}

We included studies of adults (18 years and older) with stroke (all types, severity, and stages of stroke/rehabilitation).

\section{Types of interventions}

We defined CCT as an intervention that involves participants receiving physical rehabilitation in a group environment, with a staff-to-client ratio of no greater than 1:3 (that is, no more than one staff member per three clients). We included studies that provided a minimum of once-weekly CCT sessions for a minimum of four weeks. We only included studies that reported interventions with a focus on repetitive (within session) practise of functional tasks arranged in a circuit, with the aim of improving mobility. We excluded studies of interventions that included exercises solely aimed at improving impairment (such as strengthening, range of motion, or cardiovascular fitness).

\section{Types of outcome measures}

We evaluated outcome measures at post-intervention and at follow-up wherever available (e.g. three to six months post- intervention). We did not consider outcomes taken after a single circuit class.

\section{Primary outcomes}

In this update the primary outcome of interest was walking capacity as measured using the Six Minute Walk Test (distance walked in six minutes: 6mWT). This is a clinically-sensitive measure with demonstrated functional benefit for the person with stroke.

\section{Secondary outcomes}

Other measures of walking and standing ability including:

- walking speed measured over a short distance (e.g. 5 m or $10 \mathrm{~m}$ walk test);

- functional mobility measures such as the Timed Up and Go (TUG) or the Rivermead Mobility Index (RMI);

- measures of standing balance, including the Step Test, Berg Balance Scale or Functional Reach Test.

Measures of impairment, such as:

- lower limb strength; and

- range of motion.

Measures of activity limitation, such as:

- instrumental activities of daily living; and

- personal care.

Measures of participation restriction, such as:

- health-related quality of life.

Other measures, such as:

- length of hospital stay;

- adverse events (including mortality);

- self-reported satisfaction;

- locus of control

- economic indicators.

\section{Summary of inclusion criteria}

- Human participants diagnosed with stroke (haemorrhage or infarct), of any severity/stage/setting (e.g. early: less than six months; or later: more than six months)

- Eighteen years of age or older

- Receiving CCT as defined

- Outcomes evaluated in domains as defined

- RCT

\section{Search methods for identification of studies}

See the 'Specialized register' section in the Cochrane Stroke Group module. We included all languages, and did not impose any date limits. To improve sensitivity we did not include a trials filter. We arranged for the translation of articles where necessary.

\section{Electronic searches}

We searched the Cochrane Stroke Group Trials Register, which was last searched by the Managing Editor in January 2017. We searched for additional articles published since the previous Cochrane 
systematic review on this topic from January 2008 onwards. Databases searched include the Cochrane Central Register of Controlled Trials (CENTRAL) (in the Cochrane Library 2016, Issue 12, Appendix 1), MEDLINE (in OVID, 1950 to January 2017, Appendix 2), Embase (1980 to January 2017, Appendix 3), CINAHL (1982 to January 2017, Appendix 4), PsycINFO (last searched January 2017, Appendix 5), AMED (1985 to January 2017, Appendix 6), SPORTDiscus (1949 to January 2017, Appendix 7), AGELINE (1978 to March 2015), Current Contents (last searched January 2017), Australasian Medical Index (AMI, 1968 to June 2016), NLM GATEWAY (gateway.nlm.nih.gov, last searched June 2016 for 2014 update), Latin American \& Caribbean Health Sciences Literature (LILACS, 1982 to June 2016), IndMed (1985 to January 2017), Educational Resources Information Center (ERIC, 1967 to June 2016), and the Physiotherapy Evidence Database (PEDro, www.pedro.org.au, last searched January 2017). Unique search strings are included in the Appendices, and where not included are adaptations.

\section{Searching other resources}

We used the MEDLINE (Ovid) search developed by the Cochrane Stroke Group Information Specialist and adapted it to search the other databases. We included all languages, and imposed no date limits. As the subject area of this review is quite specific we did not include a trials filter. This increased the sensitivity of the search.

In an effort to identify further published, unpublished and ongoing studies, we:

- searched for proceedings from stroke-related conferences that were peer-reviewed and published in the above databases until 2016;

- searched reference lists (from salient articles, journals and books) and unpublished theses;

- contacted authors of published trials and other experts in the field;

- searched the following clinical trials and research registers:

- World Health Organization (WHO) International Clinical Trials Registry Platform (ICTRP) (apps.who.int/trialsearch/);

- US National Institutes of Health Ongoing Trials Register, ClinicalTrials.gov (www.clinicaltrials.gov/);

- Computer Retrieval of Information on Scientific Projects (commons.era.nih.gov/common);

- ISRCTN Registry www.isrctn.com/ (formerly the Current Controlled Trials);

- National Institute of Neurological Disorders and Stroke (www.ninds.nih.gov/);

- National Rehabilitation Information Centre (Naric) (including REHABDATA) (www.naric.com/);

- Stroke Trials Directory - the Internet Stroke Center (www.strokecenter.org/trials).

\section{Data collection and analysis}

\section{Selection of studies}

We retrieved papers from the identified lists on the basis of title/abstract, reviewing them against the established criteria for inclusion. If all criteria were met (that is, answers to the five criteria were 'yes' or 'unsure') we retrieved the study in full and reviewed it for final inclusion and then for methodological quality and data extraction. If we disagreed on any aspect of study inclusion we reached consensus through discussion and had a third review author available for consultation if consensus could not be reached.

\section{Data extraction and management}

We independently entered data into the Review Manager software, RevMan 5.3 (RevMan 2014), and included full citation details of the study, objectives, design, length, assessment time points, number and characteristics of participants (inclusion and exclusion criteria), description of the intervention, outcome measures, intention-to-treat analysis, withdrawals and loss to follow-up, and adverse events. If we disagreed on any aspect of data extraction or quality evaluation, we reached consensus through discussion and had a third review author available for consultation if consensus could not be reached.

\section{Assessment of risk of bias in included studies}

We independently assessed the quality of the studies to be included. We assessed the methodological quality of the included studies for risk of bias using the criteria recommended in section 8 of the Cochrane Handbook for Systematic Reviews of Interventions (Higgins 2011) in six domains: sequence generation, allocation concealment, blinding of participants, personnel and outcome assessors, incomplete outcome data, selective reporting and 'other'. We defined 'other' as adequate sample size, based on supplied power calculations. We gave studies an overall summary of the risk of bias for each important outcome (across domains), as well as within and across studies using three levels: low, unclear, or high risk of bias. We also gave a descriptive report on the overall risk of bias in relation to the findings from the meta-analyses.

\section{Measures of treatment effect}

We extracted and analysed data to calculate risk ratio (RR) or mean difference (MD) and 95\% confidence intervals (CI). This required the identification of the number of participants in each group in each trial and the total number (for dichotomous data), and the number of participants plus the mean and standard deviations for each group (for continuous data).

\section{Unit of analysis issues}

We considered studies with non-standard designs, for example, cluster randomised trials, if they were assessed as having a low risk of bias. We only considered randomised cross-over trials prior to cross over (irrespective of wash-out periods as the changes are assumed to be permanent) and if the study authors provided an analysis of results for the first phase.

\section{Dealing with missing data}

We contacted study authors to request appropriate data for metaanalyses if these were not adequately reported in the retrieved paper. We considered intention-to-treat analysis as part of the risk of bias assessment and recorded loss to follow-up.

\section{Assessment of heterogeneity}

We assessed statistical heterogeneity both visually and using the $1^{2}$ statistic (Higgins 2003). Where $1^{2}$ was greater than $50 \%$ we used random-effects rather than a fixed-effect analysis. We also evaluated clinical heterogeneity (clinical and methodological diversity). 


\section{Assessment of reporting biases}

We minimised reporting biases by the comprehensive search strategies, which had no date or language limits. However, where appropriate we could also examine this statistically via funnel plots and tests for asymmetry if there were sufficient studies (recommended more than 10; Sterne 2011).

\section{Data synthesis}

We conducted a meta-analysis with appropriate data. We considered the degree of heterogeneity to determine whether to use fixed-effect or random-effects analyses.

\section{Subgroup analysis and investigation of heterogeneity}

We considered performing subgroup analyses to establish effectiveness relative to gender, chronicity, age or stroke severity (respectively men versus women; early (less than one year poststroke) versus late (more than one year post-stroke); young adults versus older; mild/moderate versus severe stroke, if sufficient data were available.

\section{Sensitivity analysis}

We conducted sensitivity analyses to determine if pooling results from large trials (more than 100 participants) led to different results compared with pooling data from small trials (fewer than 100 participants), or if trials with low versus high risk of bias influenced the results, when a sufficient number of trials were available.

\section{GRADE assessment and 'Summary of findings' tables}

We presented the main results of the review in Summary of findings for the main comparison for the comparison of CCT versus 'other' interventions. We reported the outcome measure of walking capacity (6mWT) as the primary outcome; we also included other secondary outcomes in the table that had a sufficient body of evidence (number of trials/number of participants) in recognition that low numbers in either or both of these inevitably leads to a 'very low' GRADE designation.

A 'Summary of findings' table presents information about the certainty of the evidence, the size of the effect of the intervention examined, and the sum of available data for the main outcomes. The 'Summary of findings' table also includes an overall grading of the evidence related to each of the main outcomes using the GRADE approach (GRADE 2013). This defines the certainty or confidence in a body of evidence that an estimate of effect or association is close to the true quantity of specific interest. This certainty involves consideration of within-trial risk of bias (methodological quality), applicability of evidence, heterogeneity, precision of effect estimates, and risk of publication bias (Higgins 2011). When making decisions for the risk of bias, we downgraded only when we had classed studies as being at high risk of bias for one or more domains or they were classed as being at unclear risk of bias for both domains that contribute to selection bias, or both (GRADE 2013).

\section{RES U LTS}

\section{Description of studies}

See Characteristics of included studies and Characteristics of excluded studies

\section{Results of the search}

We retrieved 101 potential trials in full from the search, of which we included 17 in this review (Figure 1). Twelve were new studies published between 2010 and 2015. Five studies were included from the previous review (Blennerhassett 2004; Dean 2000; Marigold 2005; Mudge 2009a; Pang 2005). We excluded one study from the previous review in this update as it was a pseudo-randomised trial (English 2007). 
Figure 1. PRISMA flow diagram

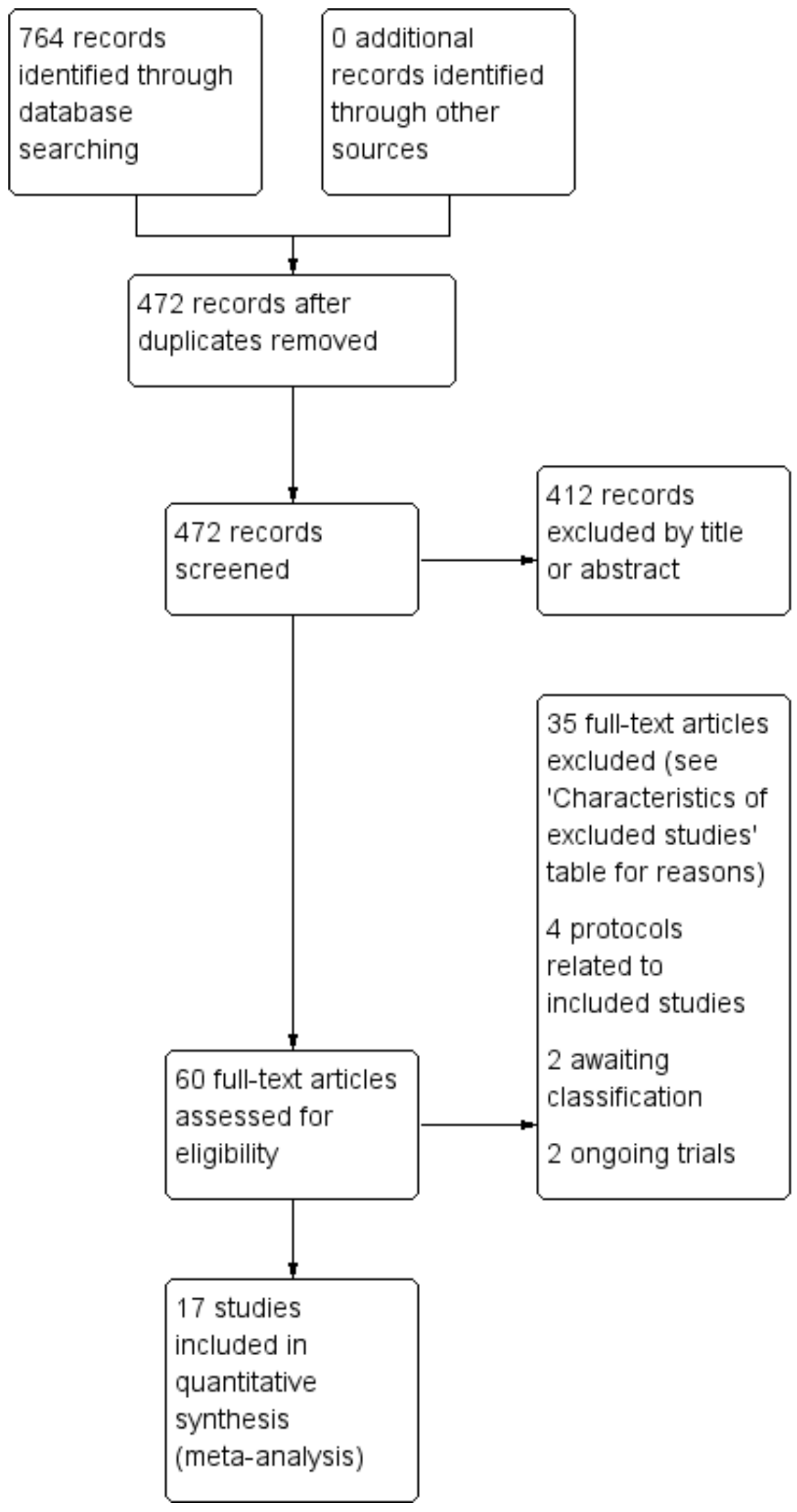




\section{Included studies}

The 17 included trials were all conducted between 2000 and 2015; four in Australia (Blennerhassett 2004; English 2015; Dean 2012; Marsden 2010), four in Canada (Dean 2000; Marigold 2005; Pang 2005; Tang 2014), two in Korea (Song 2015; Kim 2016a) and the UK (Harrington 2010; Moore 2015) , and one each in Germany (Outermans 2010), India (Verma 2011), , the Netherlands (Van de Port 2012), New Zealand (Mudge 2009a), and Sweden (Holmgren 2010). Four trials were conducted in an inpatient hospital setting (Blennerhassett 2004; English 2015; Song 2015; Verma 2011). The remaining 13 trials were conducted in community settings. A total of 1297 participants were included with sample sizes varying from 12 to 250 participants. Time since stroke onset varied with studies including participants within one month (three trials: Blennerhassett 2004; English 2015; Outermans 2010), three months (three trials: Kim 2016a, Van de Port 2012; Verma 2011), six months (one trial: Holmgren 2010), one year (one trial: Harrington 2010), and more than one year post stroke (eight trials: Dean 2012; Moore 2015; Tang 2014; Dean 2000; Marigold 2005; Marsden 2010; Mudge 2009a; Pang 2005). One trial did not report the exact time since stroke (Song 2015). Only two studies collected objective measures of stroke severity, both of which used the National Institutes of Stroke Scale (Tang 2014; Verma 2011). For the majority of the other studies, stroke severity could be inferred as being mild to moderate, as their inclusion criteria for functional ability was only participants who were able to walk at least $5 \mathrm{~m}$ (Tang 2014) or $10 \mathrm{~m}$ independently, with or without a walking aid. Two studies included people living at home in the community with no reference to walking ability (Harrington 2010; Marsden 2010), and one included people in the moderate band of stroke severity according to score ranges on the Functional Independence Measure (FIM) (English 2015).

All studies investigated the effects of CCT (workstation-based, taskspecific practise in a group with a ratio of staff to client of $1: 3$ or higher) with the aim of improving mobility in people post stroke. Two studies also explicitly aimed to improve cardiorespiratory fitness and included a target heart rate zone within their intervention (Outermans 2010; Tang 2014). Three studies combined CCT with education sessions (Harrington 2010; Holmgren 2010; Marsden 2010) and one combined CCT with mental imagery (Verma 2011). The length of therapy sessions, frequency (sessions per week), and duration of the intervention period varied somewhat between studies but were relatively homogeneous in terms of staffing and content - see Table 1 for a summary of all CCT formats. Five studies reported the percentage of therapy sessions attended and this ranged from 63\% (Dean 2012) to 92\% (Mudge 2009a), with Harrington 2010 reporting that $61 \%$ of participants attended at least $75 \%$ of therapy sessions. English 2015 reported the mean total amount of therapy time received per participant ( 37.3 hours) and Van de Port 2012 reported the total number and average duration of therapy sessions delivered to intervention participants (4461 sessions, mean 72 minutes' duration).

Twelve studies had a comparison group involving alternate 'other interventions', which was matched for length of sessions, frequency, and duration of intervention for eight studies. The description of the comparison 'other interventions' ranged from usual care (English 2015; Kim 2016a; Song 2015; Van de Port 2012; Verma 2011), CCT involving upper limb training only (Blennerhassett 2004; Dean 2000; Dean 2012; Pang 2005), nonspecific exercises such as stretching (Marigold 2005; Moore 2015) or education/social groups (Mudge 2009a). Three studies compared CCT combined with education versus no therapy (Harrington 2010; Holmgren 2010; Marsden 2010). In two studies the comparison group also received mobility-related CCT but at a lower intensity (without a target heart rate) (Outermans 2010; Tang 2014).

All studies used a composite of measures related to mobility including tests of walking ability (gait speed and capacity), and balance (TUG, Berg Balance Scale (BBS), Step test). Some studies used measures of quality of life, upper limb function, balance selfefficacy, tests for impairment (strength, $\mathrm{VO}_{2} \mathrm{max}$, kinematic data), free-living walking ability (steps per day using an activity monitor), numbers of adverse events (falls during therapy), satisfaction, and length of stay. Only one study included measures of economic indicators (Harrington 2010). A total of 62 different outcome measures were reported in the included studies.

\section{Excluded studies}

We excluded the remaining studies for a variety of reasons including inappropriate methods, or interventions that were either not taskspecific (that is to say the interventions addressed impairments not functional tasks) or not in a group (staff-to-client ratio was less than 1:3). See Characteristics of excluded studies for individual reasons for exclusions.

\section{Risk of bias in included studies}

Figure 2 summarises the trials together with risk of bias in the six domains, with the most likely risk in the area of selective reporting of outcome data, which was frequently rated as unclear because the majority of included studies did not publish a trial protocol or register their trials. Figure 3 shows the trials individually across the six domains. Three of the 17 trials demonstrated adequate control of risk across all six domains (Dean 2012; English 2015; Mudge 2009a). 
Figure 2. Risk of bias graph: review authors' judgements about each risk of bias item presented as percentages across all included studies.

Random sequence generation (selection bias)

Allocation concealment (selection bias)

Blinding (performance bias and detection bias)

Incomplete outcome data (attrition bias)

Selective reporting (reporting bias)

Other bias
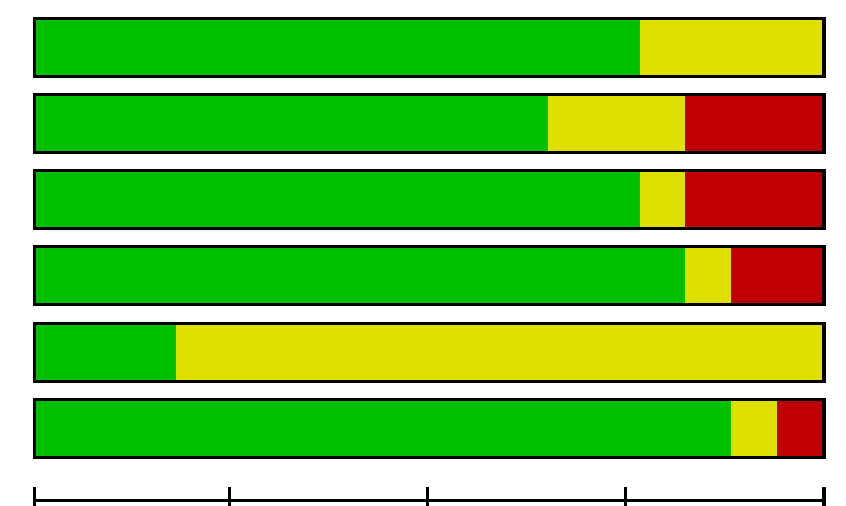

\begin{tabular}{lllll|}
\hline $0 \%$ & 1 & 1 & 1 & \\
\hline & $25 \%$ & $50 \%$ & $75 \%$ & $100 \%$
\end{tabular}


Figure 3. Methodological quality summary: review authors' judgements about each methodological quality item for each included study.

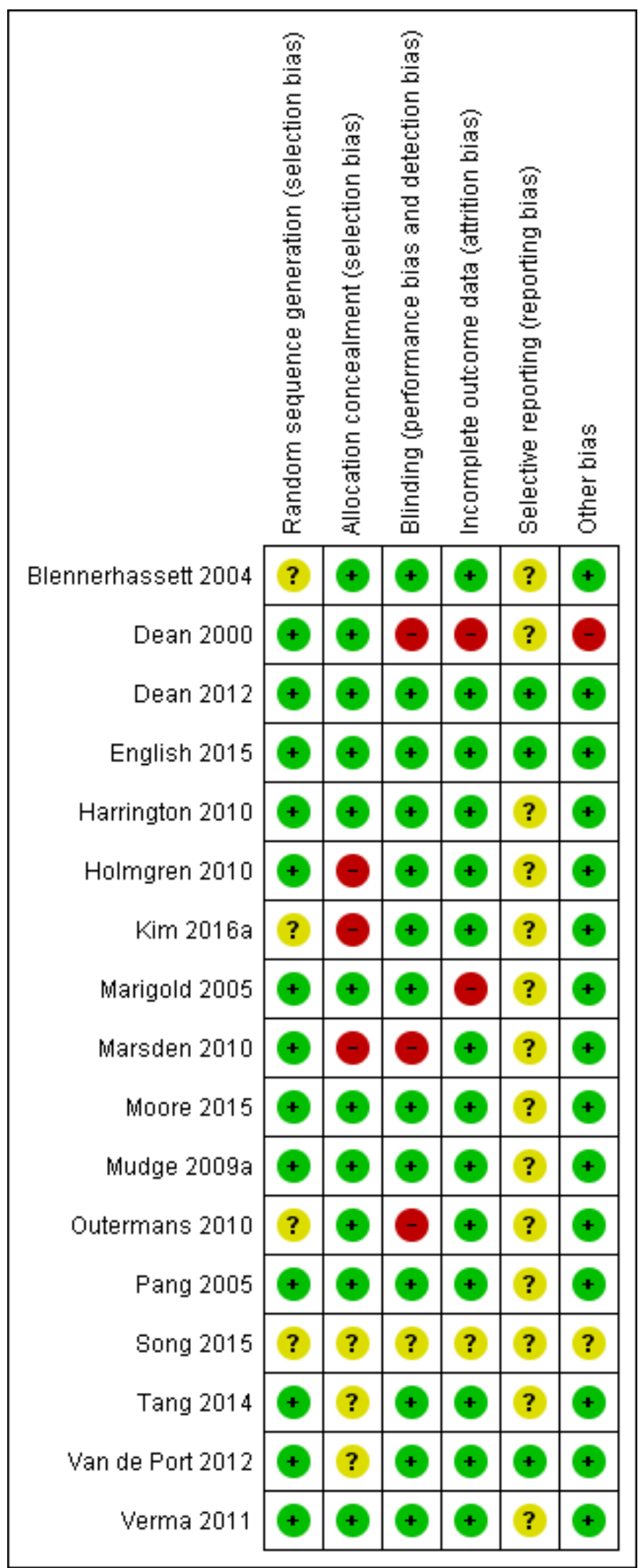




\section{Allocation}

Thirteen studies stated the allocation method for randomising, with the remaining four studies stating that random allocation occurred but not how (Blennerhassett 2004; Kim 2016a; Outermans 2010; Song 2015). Six studies either did not conceal or did not state whether or how allocation was concealed to the administrator of the randomisation process (Holmgren 2010; Kim 2016a; Marsden 2010; Song 2015; Tang 2014; Van de Port 2012).

\section{Blinding}

Four studies did not report blinding of assessors involved in the trial (Dean 2000; Marsden 2010; Outermans 2010; Song 2015).

\section{Incomplete outcome data}

Three studies did not adequately report and/or account for attrition across the trial groups (Dean 2000; Marigold 2005; Song 2015).

\section{Selective reporting}

Only three studies provided a reference to the trial registration or study protocol with all three studies demonstrating complete reporting (Dean 2012; English 2015; Van de Port 2012).

\section{Other potential sources of bias}

We noted other potential sources of bias, such as small numbers (Dean 2000), and cursory reporting across all aspects of trial conduct (Song 2015).

\section{Effects of interventions}

See: Summary of findings for the main comparison Circuit class therapy compared with other intervention for improving mobility

\section{CCT versus 'other interventions'}

Sufficient clinical homogeneity allowed us to pool study data, comparing CCT for mobility versus 'other intervention(s)'.

\section{Primary outcome}

Ten studies (835 participants, $64 \%$ of total sample) measured walking capacity using the 6mWT (Blennerhassett 2004; Dean 2000; Dean 2012; English 2015; Kim 2016a; Moore 2015; Mudge 2009a; Pang 2005; Van de Port 2012; Verma 2011). Meta-analysis demonstrated that overall CCT was superior to the comparison intervention (MD $60.86,95 \% \mathrm{Cl} 44.55$ to $77.17 ; \mathrm{I}^{2}=27 \%$, Analysis 1.1). Subgroup analysis between trials with participants who were early versus late after stroke onset showed a greater mean difference (improvement) for the later group but failed to reach a significant difference between these subgroups $(P=0.14)$.

Using the GRADE criteria based on the number of participants, the significant effect and relatively narrow $\mathrm{Cls}$, we applied an overall rating of 'moderate', however we downgraded due to uncertain risk of bias across several studies.

\section{Secondary outcomes}

Eight studies (744 participants, $57 \%$ of total sample) measured gait speed (Dean 2000; Dean 2012; English 2015; Moore 2015; Mudge 2009a; Song 2015; Van de Port 2012; Verma 2011), with metaanalysis showing a difference between the two groups that reached significance in favour of CCT (MD $0.15,95 \% \mathrm{Cl} 0.10$ to $0.19 ; 1^{2}=$ $14 \%$, Analysis 1.2). Using the GRADE criteria based on the number of participants, the significant effect and relatively narrow Cls, we applied an overall rating of 'moderate', however we downgraded due to uncertain risk of bias across several studies.

Two studies (50 participants) measured cadence in steps per minute and found a significant effect in favour of CCT (Song 2015; Verma 2011: MD 13.57, $95 \% \mathrm{Cl} 7.52$ to $19.62 ;\left.\right|^{2}=0 \%$, Analysis 1.3 ).

Five studies (488 participants) used the TUG test to measure the ability to stand up, walk, and turn around, and metaanalysis showed a difference between the two groups that reached significance in favour of CCT ((Blennerhassett 2004; Dean 2000; Dean 2012; Marigold 2005; Van de Port 2012: MD -3.62, 95\% Cl -6.09 to $-1.16 ; 1^{2}=0 \%$, Analysis 1.4). Two studies (296 participants) measured mobility using the Rivermead Mobility Index (Mudge 2009a; Van de Port 2012). The meta-analysis showed a significant effect in favour of CCT (MD $0.56,95 \% \mathrm{Cl} 0.17$ to $0.95 ; \mathrm{I}^{2}=7 \%$, Analysis 1.5). Three studies (469 participants) measured independence in walking using the Functional Ambulation Classification (English 2015; Van de Port 2012; Verma 2011) and found a significant effect in favour of CCT (OR 1.91, 95\% Cl 1.01 to $3.62 ;\left.\right|^{2}=34 \%$, Analysis 1.6 ).

Four studies (171 participants) applied the Berg Balance Scale with meta-analysis showing no significant between-group differences (Kim 2016a; Moore 2015; Marigold 2005; Pang 2005: MD 1.21, 95\% Cl -0.62 to $3.04 ; 1^{2}=30 \%$, Analysis 1.7 ). Three studies (190 participants) used the Step Test to measure balance with no significant betweengroup differences (Blennerhassett 2004; Dean 2000; Dean 2012: MD $0.98,95 \% \mathrm{Cl}-0.40$ to $2.37 ; \mathrm{I}^{2}=21 \%$, Analysis 1.8 ). Two studies (103 participants) measured balance self-efficacy using the Activities-specific Balance Confidence Scale (ABC) with metaanalysis showing a significant effect in favour of CCT ((Marigold 2005; Mudge 2009a: MD 7.76, 95\% Cl 0.66 to $14.87 ; 1^{2}=0 \%$, Analysis 1.9).

Two studies (437 participants) used the Stroke Impact Scale - physical sub-scale to measure self-reported physical ability (English 2015; Van de Port 2012). The meta-analysis demonstrated a favourable effect for CCT that just met significance (MD 2.91, 95\% $\mathrm{Cl} 0.00$ to $5.82 ; \mathrm{I}^{2}=0 \%$, Analysis 1.10 ).

Two studies measured fitness using VO2 peak (Moore 2015; Pang 2005, 103 participants). A significant favourable effect was found for CCT participants (MD 2.81, 95\% Cl 0.90 to $4.72 ; \mathrm{I}^{2}=0 \%$, Analysis 1.11). Two studies (206 participants) included measures of average daily step counts and found significant effect in favour of CCT (Mudge 2009a; Dean 2012: MD 1325.66, 95\% Cl 411.09 to 2240.22; $\left.\right|^{2}$ $=29 \%$, Analysis 1.12 ).

Two trials (217 participants) measured length of stay (Blennerhassett 2004; English 2015). A shorter length of stay was reported for participants receiving CCT (MD - 16.35, 95\% Cl -37.69 to 4.99; $12=51 \%$ ), but this was not significant when random effects were applied (given the high heterogeneity) (Analysis 1.13).

\section{CCT + education versus no intervention}

Sufficient clinical homogeneity allowed us to pool study data, comparing CCT + education versus no intervention. Two studies measured balance using the TUG (269 participants) with no significant between group differences found (Harrington 2010; Marsden 2010: MD $0.90,95 \% \mathrm{Cl}-0.94$ to $2.75 ; 1^{2}=0 \%$, Analysis 2.1). The same two studies measured carer burden using the Carer 
Strain Index (Harrington 2010; Marsden 2010, 174 participants). The meta-analysis showed a negative effect of the intervention with higher Carer Strain Index (worse functioning) reported by carers of participants in the CCT + education group (MD 1.06, 95\% Cl 0.39 to $1.73 ; 1^{2}=0 \%$, Analysis 2.2 .

\section{CCT versus a different $\mathrm{CCT}$}

Two studies compared mobility-related CCT provided at high intensity (with target heart rate zones) versus the same exercises at low intensity (Outermans 2010; Tang 2014). The 6mWT was the only outcome in common between these trials, but due to the differences in the duration of the intervention there was insufficient clinical homogeneity to pool data (six months in Tang 2014 versus four weeks in Outermans 2010).

\section{All comparisons}

Eight studies (836 participants) reported monitoring adverse events including falls. Of these, four studies reported that there were no falls, and the other four reported between six falls (Pang 2005) and 55 falls (Van de Port 2012). There was a higher risk of falls in the CCT groups (risk difference $0.03,95 \% \mathrm{Cl}-0.02,0.08 ; \mathrm{I}^{2}=60 \%$ ) but this did not reach significance (Analysis 3.1).

\section{Sensitivity analyses: primary outcome}

We conducted a sensitivity analysis based on the size of the trial, considering large trials to be those with 100 or more participants (Dean 2012; English 2015; Harrington 2010; Van de Port 2012) and small trials to be those with fewer than 100 participants (Blennerhassett 2004; Dean 2000; Holmgren 2010; Kim 2016a; Marigold 2005; Marsden 2010; Moore 2015; Mudge 2009a; Outermans 2010; Pang 2005; Song 2015; Tang 2014; Verma 2011). The size of effect for the $6 \mathrm{mWT}$ was smaller but still significant when pooling only data from large trials (MD $46.31,95 \%$ CI 22.90 to 69.72 ; participants $=588$; studies $\left.=3 ; 1^{2}=11 \%\right)$ compared with small trials (MD 74.59, 95\% Cl 51.85 to 97.32; participants $=247$; studies $=7 ; 1^{2}$ $=17 \%)$.

We also conducted a sensitivity analysis based on risk of bias where the three studies with no/low assessed risk of bias in the six domains confirmed a positive effect in favour of CCT for the $6 \mathrm{mWT}$ (Dean 2012; English 2015; Mudge 2009a: MD 46.32, 95\% Cl 17.40 to $75.24 ; 1^{2}=38 \%$ ) (Analysis 1.14).

\section{DISCUSSION}

\section{Summary of main results}

The primary aim of this review was to investigate the effectiveness of group CCT for improving mobility after stroke. For our primary outcome measure of gait capacity, we found CCT to be superior to other interventions for improving the distance walked on the $6 \mathrm{mWT}$. The minimal clinically-meaningful improvement on the $6 \mathrm{mWT}$ has been estimated at $34.4 \mathrm{~m}$ for people later after stroke (Eng 2004) and $61 \mathrm{~m}$ for people early after stroke (Perera 2006). Thus, we can be confident that the mean improvement found in the meta-analysis of $60.86 \mathrm{~m}$ represents a real and applicable clinical change. The positive finding for the $6 \mathrm{mWT}$ is of functional relevance as it has been shown to be a stronger predictor of the community walking ability than measures of walking speed (Fulk 2010; Mudge 2009b; Rand 2009), which may overestimate community ambulatory ability (Taylor 2006). Furthermore, the
$6 \mathrm{mWT}$ has been shown to correlate significantly with quality of life after stroke (Muren 2008). We also confirmed that the positive effects were present for people both early and late after stroke suggesting potential for improvement does not necessarily decline. A further positive feature of the primary outcome analyses was that heterogeneity was low. However, we downgraded the GRADE designation to 'moderate' because of the potential for risk of bias in some included studies.

We also found a small favourable effect of CCT in regards to improvements in walking speed, with the magnitude of the between-group difference ( $0.15 \mathrm{~m}$ per second) being greater than the estimated smallest worthwhile effect of $0.06 \mathrm{~m}$ per second (Perera 2006). Perera 2006 suggest that a difference of greater than $0.14 \mathrm{~m}$ per second represents a substantial meaningful change for people after stroke. Thus, we can be confident that our results represent real clinical change. Our results suggest that CCT as an intervention has a positive effect on improving independence in walking, with the odds of being fully independent in walking (Functional Ambulation Scale score of 5) after the intervention being significantly greater for intervention participants compared with people allocated to the control intervention.

The evidence for the effectiveness of CCT in improving walking ability after stroke can be considered robust as it is consistently positive across a range of clinic-based walking measures (6mWT, walking speed, Functional Ambulation Classification) and selfreported physical function (Stroke Impact Scale - Physical, Rivermead Mobiity Index). The intervention across all studies included a strong emphasis on continuous walking practice. Therefore, the positive results are in line with evidence for intensity and task-specificity of training, that is to say 'what is trained is what is gained' (Verbeek 2014).

There is some evidence that improvements in walking capacity and ability gained through CCT may also translate into behaviour change. In this updated review, two studies included measures of daily step counts, measured using either a pedometer (Dean 2012) or an ankle-worn accelerometer (Mudge 2009a). Both trials found that participants who received CCT increased their daily step count to a significantly greater degree than control participants. This is important, as lack of adequate physical activity is linked to increased all-cause morbidity and mortality (Lollgen 2009) and cardiovascular disease-specific morbidity and mortality (Thompson 2003), as well as increased risk of stroke (Feigin 2014; McDonnell 2013).

Importantly, CCT may also be an effective method of training for improving cardiorespiratory fitness for people later after stroke. Many studies (Marsden 2013; Marsden 2016; Smith 2012) have reported fitness levels of stroke survivors at less than the minimum requirement for activities of daily living in older adults, that is, 15 $\mathrm{mL} / \mathrm{kg} / \mathrm{min}$ to $18 \mathrm{~mL} / \mathrm{kg} / \mathrm{min}$ (Shephard 2009). An improvement in fitness in the order of magnitude found in our meta-analysis $(2.8$ $\mathrm{mL} / \mathrm{kg} / \mathrm{min}$ ) is similar to that conferred by exercise interventions with an aerobic component (Marsden 2013). This amount is clinically important as it can improve the exercise reserve of stroke survivors (Ivey 2006) and has the potential to reduce the risk of death (Kodama 2009).

The effectiveness of CCT for improving postural control is less clear. We found significant between-group differences in favour of CCT for the Activities-specific Balance Confidence scale and the 
TUG that exceeded the minimal detectable difference on these measures (Flansbjer 2005; Salbach 2006). However, between-group differences were non-significant for the step test, and too small to be clinically worthwhile on the Berg Balance Scale: MD of 1.36 points compared with minimal detectable change of 6.9 points early after stroke (Stevenson 2001), and 4.13 points later after stroke (Flansbjer 2012).

There is some suggestion that providing CCT to people receiving inhospital rehabilitation after stroke may reduce length of hospital stay with a mean between-group difference of 16.35 days. However, the heterogeneity in the study results was higher $(12=51 \%)$ and the difference just failed to reach significance using random effects in the analysis. There are many factors that influence length of hospital stay. A recent individual patient meta-analysis was conducted where data were pooled from two large multicentre trials investigating the effect of additional weekend therapy for people with stroke. The meta-analysis identified a range of factors that significantly contributed to length of rehabilitation hospital stay, including age and degree of disability at admission (English 2016). Interestingly, this paper also reported considerable variability in length of stay between individual hospital sites, highlighting the complexity of factors that influence how long people with stroke spend in inpatient rehabilitation. However, a secondary analysis of data from the CIRCIT trial (English 2015) found that when controlling for other influencing factors, receiving CCT as the sole method of physiotherapy service delivery (as compared to usual care physiotherapy) was an independent predictor of a shorter length of stay, in the order of -11.6 days (95\% $\mathrm{Cl}-21.3$ to $-1.9, \mathrm{P}=0.019$ ) (Abstracts Asian Pacific Stroke Congress p6). Reducing length of stay has the potential for significant savings to the healthcare system, but we currently lack highquality economic data to establish the cost effectiveness of such an approach.

With regards to adverse events, there were more falls (albeit not statistically different) reported among participants receiving CCT compared with other interventions. Any intervention aimed at improving mobility and balance after stroke carries an inherent risk of causing falls because it is necessary for participants to undertake activities at the limits of their abilities for the interventions to be effective. The greater falls rate in the intervention group is perhaps not surprising considering that the control group was either undertaking interventions that did not expose the participants to an increased risk of falls; for example, seated upper extremity exercise programmes (Blennerhassett 2004; Dean 2000; Pang 2005), stretching (Marigold 2005; Moore 2015), education (Holmgren 2010; Mudge 2009a), or had significantly less risk exposure because they spent significantly less time engaged in physical therapy sessions (English 2015). Nevertheless, it would be pertinent for future studies to more closely examine the link between CCT and falls in therapy.

Carer burden was reported as increased in two studies comparing CCT plus education against no intervention (Harrington 2010; Marsden 2010). It is unknown how the burden was generated and whether it was simply because of receipt of an intervention per se this requires clarification in future studies.

Based on the results of the two available trials, there is currently no evidence for superior effectiveness of CCT when combined with education. Similarly, there is insufficient evidence for the relative effectiveness of CCT delivered at higher versus lower intensity (based on heart rate targets).

\section{Overall completeness and applicability of evidence}

The content of the intervention provided was similar across all studies with many of the same exercises and activities included (see Characteristics of included studies and Table 1). The majority (11) of the trials were conducted with participants later after stroke (more than one year), compared with earlier after stroke (less than one year, six trials) and whilst our subgroup analyses failed to show a significant difference in effect between the two time frames, there was a larger improvement noted in the later group for several measures. The influence of time alone on recovery after stroke remains largely unknown, although it has been estimated to account for between $16 \%$ and $42 \%$ of improvements in function in the first six to 10 weeks after stroke (Kwakkel 2004). This may mask any potential benefits of CCT over and above usual care in studies conducted with people earlier after stroke.

There were insufficient data available to examine the impact of CCT on sensorimotor impairment after stroke. No studies included measures of movement kinematics or stroke recovery biomarkers such as imaging. Therefore, we cannot determine the degree to which improvements in mobility measures are related to recovery of motor function, specifically 'true neurological recovery' (Levin 2009) versus compensation and overcoming deconditioning.

This updated review included four trials with sample sizes greater than 100 participants. When we pooled data from only these trials, the magnitude of effect for CCT was smaller, but remained statistically significant for the $6 \mathrm{mWT}$. Smaller trials tend to overestimate treatment effects (Pereira 2012). The implications of population heterogeneity across large and small trials need to be considered. Furthermore, our $6 \mathrm{mWT}$ results were upheld after a sensitivity analysis for trials with low versus unclear/high risk of bias.

The ability to pool data across trials was somewhat limited by the diversity in outcome measures used. Across the 17 included trials, a total of 62 different outcome measures were used. Lack of commonality in outcome measures is a major issue hampering the progress of stroke rehabilitation and recovery research. An analysis of 38 trials in the Virtual International Stroke Archives in 2012 found at least 44 reported outcome measures, with age being the only common metric across trials (Ali 2013). A group of international experts is currently working on addressing this issue with consensus statements being produced as a result (Bernhardt 2016).

\section{Quality of the evidence}

The trials were of varying levels of assessed risk of bias. Most commonly, failure to report one or two domains led to a greater overall risk and it remains to be seen if standards of trial conduct and reporting improve in the future. We cannot differentiate between failure to report versus failure to control the risk and this is a potential source of bias in the review process. Hence we downgraded all GRADE determinations as a result of this uncertainty. Three studies achieved 'low' risk ratings in all six domains, confirming that stroke rehabilitation studies can be conducted and reported in an acceptable manner. 


\section{Potential biases in the review process}

Potential biases in the review process need to be considered in that the three review authors are stroke rehabilitation trialists and take a pragmatic stand on trial design. For example, we did not assess trials as having a risk of bias where the therapist or the participants were not blinded, as we did not consider this possible in these kinds of clinical trials (other than to maintain the participant naive as to which arm of the trial was of interest to the researchers). The definition of CCT was relatively prescriptive and it may be that studies using an alternate circuit format were not included. For example, Kim 2016b compared group CCT with individualised CCT - however their definition of individualised CCT met the criteria for this review's group CCT, thus not offering a useful comparator. It is important that studies such as this are considered in future, as they may help ascertain which aspects of CCT are effective.

\section{Agreements and disagreements with other studies or reviews}

This updated review strengthens the findings of our previous review and the systematic review of Wevers 2009, that CCT is an effective intervention for improving walking ability in people after stroke. The updated findings highlight that the benefit of CCT is reported regardless of time after stroke. This update also provides new evidence that CCT may be an effective method of improving cardiorespiratory fitness and increased daily physical activity (step counts).

\section{AUTHORS' CONCLUSIONS}

\section{Implications for practice}

Based on the existing moderate evidence, circuit class therapy (CCT) is effective in improving walking ability in people after stroke, and this effect was found when delivered in early and late periods after stroke. There is insufficient evidence to determine whether providing physiotherapy using the CCT format for people receiving inpatient rehabilitation may reduce length of hospital stay. Relative to other interventions, there is insufficient evidence to determine whether CCT was associated with an increased risk of falls Therapists should use strategies to reduce the risk of falls while trying to maintain the integrity of the intervention.

\section{Implications for research}

The evidence is becoming clearer and more consistent for the effectiveness of CCT for improving mobility in people after stroke who are able to walk independently. It will be important in future trials to include different subgroups of people with stroke, as well as measurement of changes at the impairment level to help to determine the effect of CCT on true neurological recovery versus compensation. Other aspects of the mechanism of effect are also not clear and likely to be a combination of increased motivation, amount and intensity of practice, as well as the specificity of the practice. Mechanism pathways need further investigation. Further investigation is also needed into the mitigation of risk of falls and the potential strain on carers.

\section{ACKNOWLEDGEMENTS}

Anthea Worley and Debbie Booth for assisting with searches. Ashlee Dunn and Gary Crowfoot for assistance with data extraction and editing. Staff of the Cochrane Stroke Group. 


\section{R E F E R E N C E S}

\section{References to studies included in this review}

\section{Blennerhassett 2004 \{published data only\}}

Blennerhassett J, Dite W. Additional task-related practice improves mobility and upper limb function early after stroke: a randomised controlled trial. Australian Journal of Physiotherapy 2004;50:219-24.

\section{Dean 2000 \{published data only\}}

Dean C, Richards C, Malouin F. Task-related circuit training improves performance of locomotor tasks in chronic stroke: a randomised controlled pilot trial. Archives of Physical Medicine and Rehabilitation 2000;81:409-17.

\section{Dean 2012 \{published data only\}}

Dean CM, Rissel C, Sharkey M, Sherrington C, Cumming RG, Barker RN, et al. Exercise intervention to prevent falls and enhance mobility in community dwellers after stroke: a protocol for a randomised controlled trial. BMC Neurology 2009;9:38.

* Dean CM, Rissel C, Sherrington C, Sharkey M, Cumming RG, Lord SR, et al. Exercise to enhance mobility and prevent falls after stroke: the community stroke club randomized trial. Neurorehabilitation and Neural Repair 2012;26(9):1046-57.

\section{English 2015 \{published data only\}}

* English C, Bernhardt J, Crotty M, Esterman A, Segal L, Hillier S. Circuit class therapy or seven-day week therapy for increasing rehabilitation intensity of therapy after stroke (CIRCIT): a randomized controlled trial. International Journal of Stroke 2015;10(4):594-602.

Hillier S, English C, Crotty M, Segal L, Bernhardt J, Esterman A. Circuit class or seven-day therapy for increasing intensity of rehabilitation after stroke: protocol of the CIRCIT trial. International Journal of Stroke 2011;6:560-5.

\section{Harrington 2010 \{published data only\}}

Harrington R, Taylor G, Hollinghurst S, Reed M, Kay H, Wood VA. A community-based exercise and education scheme for stroke survivors: a randomized controlled trial and economic evaluation. Clinical Rehabilitation 2010;24(1):3-15

\section{Holmgren 2010 \{published data only\}}

Holmgren E, Gosman-Hedstroem G, Lindstroem B, Wester P. What is the benefit of a high-intensive exercise program on health-related quality of life and depression after stroke? A randomised controlled trial. Advances in Physiotherapy 2010;12:125-33.

\section{Kim 2016a \{published data only\}}

Kim SM, Han EY, Kim BR, Hyun CW. Clinical application of circuit training for subacute stroke patients: a preliminary study. Journal of Physical Therapy Science 2016;28(1):169-74.

\section{Marigold 2005 \{published data only\}}

Marigold D, Eng J, Dawson A, Inglis J, Harris J, Gylfadóttir S. Exercise leads to faster postural reflexes, improved balance and mobility, and fewer falls in older persons with chronic stroke. Journal of the American Geriatrics Society 2005;53:426-3.
Marsden 2010 \{published data only\}

Marsden D, Quinn R, Pond N, Golledge R, Neilson C, White J, et al. A multidisciplinary group programme in rural settings for community-dwelling chronic stroke survivors and their carers: a pilot randomized controlled trial. Clinical Rehabilitation 2010;24(4):328-41.

\section{Moore 2015 \{published data only\}}

Moore SA, Hallsworth K, Jakovljevic DG, Blamire AM, He J, Ford GA, et al. Effects of community exercise therapy on metabolic, brain, physical, and cognitive function following stroke: a randomized controlled pilot trial. Neurorehabilitation and Neural Repair 2015;29(7):623-35.

\section{Mudge 2009a \{published data only\}}

Mudge S, Stott N, Barber P. Circuit-based rehabilitation improves gait endurance but not usual walking activity in chronic stroke: a randomised clinical trial. Archives of Physical Medicine and Rehabilitation 2009;90(12):1989-96.

\section{Outermans 2010 \{published data only\}}

Outermans JC, Van Peppen RP, Wittink H, Takken T, Kwakkel G. Effects of a high-intensity task-oriented training on gait performance early after stroke: a pilot study. Clinical Rehabilitation 2010;24(11):979-87.

Pang 2005 \{published data only\}

* Pang M, Eng J, Dawson A, McKay H, Harris J. A communitybased fitness and mobility exercise program for older adults with chronic stroke: a randomised controlled trial. Journal of the American Geriatrics Society 2005;53:1667-74.

Pang MY, Harris JE, Eng JJ. A community-based upperextremity group exercise program improves motor function and performance of functional activities in chronic stroke: a randomised controlled trial. Archives of Physical Medicine and Rehabilitation 2006;87:1-9.

\section{Song 2015 \{published data only\}}

Song HS, Kim JY, Park SD. Effect of the class and individual applications of task-oriented circuit training on gait ability in patients with chronic stroke. Journal of Physical Therapy Science 2015;27(1):187-9. [0915-5287: (Print)]

* Song HS, Kim JY, Park SD. The effect of class-based taskoriented circuit training on the self-satisfaction of patients with chronic stroke. Journal of Physical Therapy Science 2015:27:127-9.

\section{Tang 2014 \{published data only\}}

Tang A, Eng JJ, Krassioukov AV, Madden KM, Mohammadi A, Tsang MY, et al. Exercise-induced changes in cardiovascular function after stroke: a randomized controlled trial. International Journal of Stroke 2014;9(7):883-9.

\section{Van de Port 2012 \{published data only\}}

Van de Port IG, Wevers L, Roelse H, Van Kats L, Lindeman E, Kwakkel G. Cost-effectiveness of a structured progressive taskoriented circuit class training programme to enhance walking 
competency after stroke: the protocol of the FIT-Stroke trial. BMC Neurology 2009;9:43.

* Van de Port IG, Wevers LE, Lindeman E, Kwakkel G. Effects of circuit training as alternative to usual physiotherapy after stroke: randomised controlled trial. BMJ 2012;344:e2672.

\section{Verma 2011 \{published data only\}}

Verma R, Arya KN, Garg RK, Singh T. Task-oriented circuit class training program with motor imagery for gait rehabilitation in poststroke patients: a randomized controlled trial. Topics in Stroke Rehabilitation 2011;18 Suppl 1:620-32.

\section{References to studies excluded from this review}

Altin 2009 \{published data only\}

Altin Ertekin O, Gelecek N, Yildirim Y, Akdal G. Supervised versus home physiotherapy outcomes in stroke patients with unilateral visual neglect: a randomized controlled follow-up study. Journal of Neuroscience 2009;26(3):325-34.

\section{Arya 2012 \{published data only\}}

Arya KN, Verma R, Garg RK, Sharma VP, Agarwal M, Aggarwal GG. Meaningful task-specific training (MTST) for stroke rehabilitation: a randomized controlled trial. Topics in Stroke Rehabilitation 2012;19(3):193-211.

\section{Boss 2014 \{published data only\}}

Boss HM, Van Schaik SM, Deijle IA, De Melker EC, Van den Berg BT, Scherder EJ, et al. Safety and feasibility of poststroke care and exercise after minor ischemic stroke or transient ischemic attack: MotiveS \& MovelT. NeuroRehabilitation 2014;34(3):401-7.

\section{Bustamante Valles 2016 \{published data only\}}

Bustamante Valles K, Montes S, de Jesus Madrigal M, Burciaga A, Martinez M, Johnson M. Technology-assisted stroke rehabilitation in Mexico: a pilot randomised trial comparing tradition therapy to circuit training in robot/ technology-assisted therapy gym. Journal of Neuroengineering and Rehabilitation 2016; Vol. 13:83. [DOI: 10.1186/

s12984-016-0190-1]

\section{Chu 2004 \{published data only\}}

Chu KS, Eng JJ, Dawson AS, Harris JE, Ozkaplan A, Gylfadóttir S. Water-based exercise for cardiovascular fitness in people with chronic stroke: a randomised controlled trial. Archives of Physical Medicine and Rehabilitation 2004;85:870-4.

\section{Dickstein 2014 \{published data only\}}

Dickstein R, Levy S, Shefi S, Holtzman S, Peleg S, Vatine JJ. Motor imagery group practice for gait rehabilitation in individuals with post-stroke hemiparesis: a pilot study. NeuroRehabilitation 2014;34(2):267-76.

\section{English 2007 \{published data only\}}

English C, Hillier S, Stiller K, Warden-Flood A. Circuit class therapy versus individual physiotherapy sessions during inpatient stroke rehabilitation: a controlled trial. Archives of Physical Medicine and Rehabilitation 2007;88:955-63.

\section{English 2014 \{published data only\}}

English C, Hillier S, Kaur G, Hundertmark L. People with stroke spend more time in active task practice, but similar time in walking practice, when physiotherapy rehabilitation is provided in circuit classes compared to individual therapy sessions: an observational study. Journal of Physiotherapy 2014;60(1):50-4.

Faulkner 2014 \{published data only\}

Faulkner J, Lambrick D, Woolley B, Stoner L, Wong LK, McGonigal G. The long-term effect of exercise on vascular risk factors and aerobic fitness in those with transient ischaemic attack: a randomized controlled trial. Journal of Hypertension 2014;32(10):2064-70.

\section{Kim 2010 \{published data only\}}

Kim MC, Ahn CS, Lee HS, Jang SH, You YY. Change in C-Reactive protein level according to amounts of exercise in chronic hemiparetic patients with cerebral infarct. Journal of Physical Therapy Science 2010;22(3):279-84.

Kim 2012 \{published data only\}

Kim BH, Lee SM, Bae YH, Yu JH, Kim TH. The effect of a task-oriented training on trunk control ability, balance and gait of stroke patients. Journal of Physical Therapy Science 2012;24(6):519-22.

\section{Kim 2014 \{published data only\}}

Kim M, Cho K, Lee W. Community walking training program improves walking function and social participation in chronic stroke patients. Tohoku Journal of Experimental Medicine 2014;234(4):281-6.

\section{Kim 2016b \{published data only\}}

Kim B, Park Y, Seo Y, Park S, Cho H, Moon H, et al. Effects of individualised versus group task-oriented circuit training on balance ability and gait endurance in chronic stroke inpatients. Journal of Physical Therapy Science 2016;28:1872-5.

\section{Kowalczewski 2007 \{published data only\}}

Kowalczewski J, Gritsenko V, Ashworth N, Ellaway P, Prochazka A. Upper-extremity functional electric stimulationassisted exercises on a workstation in the sub-acute phase of stroke recovery. Archives of Physical Medicine and Rehabilitation 2007;88:833-9.

\section{Langhammer 2008 \{published data only\}}

Langhammer B, Stanghelle JK, Lindmark B. Exercise and healthrelated quality of life during the first year following acute stroke. A randomised controlled trial. Brain Injury 2008;22(2):135-45.

\section{Lee 2012 \{published data only\}}

Lee Y, Lee J, Shin S, Lee S. The effect of dual motor task training while sitting on trunk control ability and balance of patients with chronic stroke. Journal of Physical Therapy Science 2012;24(4):345-9.

\section{Lee 2015 \{published data only\}}

Lee YH, Park SH, Yoon ES, Lee CD, Wee SO, Fernhall B, et al. Effects of combined aerobic and resistance exercise on central arterial stiffness and gait velocity in patients with chronic 
poststroke hemiparesis. American Journal of Physical Medicine and Rehabilitation 2015;94(9):687-95.

\section{McDonnell 2014 \{published data only\}}

McDonnell MN, Mackintosh SF, Hillier SL, Bryan J. Regular group exercise is associated with improved mood but not quality of life following stroke. PeerJ 2014;2:e331.

Mead 2007 \{published data only\}

Mead GE, Greig CA, Cunningham I, Lewis SJ, Dinan S, Saunders DH, et al. Stroke: a randomised trial of exercise or relaxation. Journal of the American Geriatrics Society 2007;55:892-9.

\section{Olney 2006 \{published data only\}}

Olney SJ, Nymark J, Brouwer B, Culham E, Day A, Heard J, et al. A randomised controlled trial of supervised versus unsupervised exercise programs for ambulatory stroke survivors. Stroke 2006;37:476-81.

\section{Park 2016 \{published data only\}}

Park KT, Kim HJ. Effect of the a circuit training program using obstacles on the walking and balance abilities of stroke patients. Journal of Physical Therapy Science 2016;28(4):1194-8.

\section{Puckree 2014 \{published data only\}}

Puckree T, Naidoo P. Balance and stability-focused exercise program improves stability and balance in patients after acute stroke in a resource-poor setting. $P M \& R$ : the Journal of Injury, Function, and Rehabilitation 2014;6(12):1081-7.

\section{Pyöriä 2007 \{published data only\}}

Pyöriä O, Talvitie U, Nyrkkö H, Kautiainen H, Pohjolainen T, Kasper V. The effect of two physiotherapy approaches on physical and cognitive functions and independent coping at home in stroke rehabilitation. A preliminary follow-up study. Disability and Rehabilitation 2007;29(6):503-11.

\section{Quaney 2009 \{published data only\}}

Quaney BM, Boyd LA, McDowd JM, Zahner LH, He J, Mayo MS, et al. Aerobic exercise improves cognition and motor function poststroke. Neurorehabilitation and Neural Repair 2009;23(9):879-85.

\section{Rimmer 2000 \{published data only\}}

Rimmer J, Riley B, Creviston T, Nicola T. Exercise training in a predominantly African-American group of stroke survivors. Medicine and Science in Sports and Exercise 2000;32(12):1990-6.

\section{Saeys 2012 \{published data only\}}

Saeys W, Vereeck L, Truijen S, Lafosse C, Wuyts FP, Heyning PV. Randomized controlled trial of truncal exercises early after stroke to improve balance and mobility. Neurorehabilitation and Neural Repair 2012;26(3):231-8.

\section{Salbach 2004 \{published data only\}}

Salbach NM, Mayo NE, Wood-Dauphinee S, Hanley JA, Richards CL, Côté R. A task-orientated intervention enhances walking distance and speed in the first year post stroke: a randomised controlled trial. Clinical Rehabilitation 2004; 18:509-15.
Scianni 2010 \{published data only\}

Scianni A, Teixeira-Salmela LF, Ada L. Effect of strengthening exercise in addition to task-specific gait training after stroke: a randomised trial. International Journal of Stroke 2010;5(4):329-35.

\section{Sherrington 2008 \{published data only\}}

Sherrington C, Pamphlett PI, Jacka JA, Olivetti LM, Nugent JA, Hall JM, et al. Group exercise can improve participants' mobility in an outpatient rehabilitation setting: a randomised controlled trial. Clinical Rehabilitation 2008;22:493-502.

Shin 2011 \{published data only\}

Shin WS, Lee SW, Lee YW, Choi SB, Song CH. Effects of combined exercise training on balance of hemiplegic stroke patients. Journal of Physical Therapy Science 2011;23(4):639-43.

Sullivan 2007 \{published data only\}

Sullivan KJ, Brown DA, Klassen T, Mulroy S, Ge T, Azen SP, et al. Effects of task-specific locomotor and strength training in adults who were ambulatory after stroke: results of the STEPS randomised clinical trial. Physical Therapy 2007;87:1580-602.

Sunnerhagen 2007 \{published data only\}

Sunnerhagen S. Circuit training in community-living "younger" men after stroke. Journal of Stroke and Cerebrovascular Diseases 2007;16(3):122-9.

Tanne 2008 \{published data only\}

Tanne D, Tsabari R, Chechik O, Toledano A, Orion D, Schwammenthal $\mathrm{Y}$, et al. Improved exercise capacity in patients after minor ischaemic stroke undergoing a supervised exercise training program. Israeli Medical Association Journal 2008;10:113-6.

Teixeira-Salmela 1999 \{published data only\}

Teixeira-Salmela LF, Olney SJ, Nadeau S, Brouwer B. Muscle strengthening and physical conditioning to reduce impairment and disability in chronic stroke survivors. Archives of Physical Medicine and Rehabilitation 1999;80:1211-8.

Yang 2006 \{published data only\} Yang Y-U, Wang R-Y, Lin K-H, Chu M-Y, Chan R-C. Task-oriented progressive resistance strength training improves muscle strength and functional performance in individuals with stroke. Clinical Rehabilitation 2006;20(20):860-70.

\section{References to studies awaiting assessment}

Mota 2011 \{published data only\}

Mota RS, Bitencourt JS, Conceicao TMA, Cardoso FB, Silva IL, Beresford $\mathrm{H}$. Evaluation of the effectiveness of aerobic exercise in hemiparetic gait [Avaliação do efeito do exercício aeróbico na marcha de indivíduos hemiparéticos]. Revista Brasileira de Ciência e Movimento 2011;19(2):108-18.

\section{Scholten 2014 \{published data only\}}

Scholten RJPM. Fitness training after a stroke is effective [Fitness training ne een beroerte is effectief]. Nederlands Tijdschrift voor Geneeskunde 2014;158(A7429):864. 


\section{References to ongoing studies}

\section{Floel 2014 \{published data only\}}

Floel A, Werner C, Grittner U, Hesse S, Jöbges M, Knauss J, et al. Physical fitness training in Subacute Stroke (PHYSSTROKE) - study protocol for a randomised controlled trial. Trials 2014;15:45.

\section{Lawal 2015 \{published data only\}}

Lawal IU, Hillier SL, Hamzat TK, Rhoda A. Effectiveness of a structured circuit class therapy model in stroke rehabilitation: a protocol for a randomised controlled trial. BMC Neurology 2015;15:88.

\section{Additional references}

\section{Abstracts Asian Pacific Stroke Congress}

Abstracts Asian Pacific Stroke Congress. Australia, July 14-17, 2016: Abstracts. Cerebrovascular Diseases 2016;42 Suppl 1:1-157.

\section{Ali 2013}

Ali M, English C, Bernhardt J, Sunnerhagen KS, Brady M. More outcomes than trials: a call for consistent data collection across stroke rehabilitation trials. International Journal of Stroke 2013;8(1):18-24. [1747-4930]

\section{Bernhardt 2016}

Bernhardt J, Borschmann K, Boyd L, Carmichael ST, Corbett D, Cramer SC, et al. Moving rehabilitation research forward: developing consensus statements for rehabilitation and recovery research. International Journal of Stroke 2016;11(4):454-8. [1747-4930]

\section{Dawson 2013}

Dawson AS, Knox J, McClure A, Foley N, Teasell R: Stroke Rehabilitation Writing Group. Chapter 5: Stroke rehabilitation. Canadian Best Practice Recommendations For Stroke Care. Ottawa: Heart and Stroke Foundation and the Canadian Stroke Network, 2013.

\section{Deloitte Access Economics 2013}

Deloitte Access Economics. The economic impact of stroke in Australia. Deloitte Access Economics 13 March 2013; Vol. strokefoundation.com.au/What-we-do/Research/Economicimpact-of-stroke-in-Australia:1-20.

\section{Eng 2004}

Eng JJ, Dawson AS, Chu KS. Submaximal exercise in persons with stroke: test-retest reliability and concurrent validity with maximal oxygen consumption. Archives of Physical Medicine and Rehabilitation 2004;85(1):113-8. [0003-9993]

\section{English 2016}

English C, Shields N, Brusco NK, Taylor NF, Watts JJ, Peiris C, et al. Additional weekend therapy may reduce length of rehabilitation stay after stroke: a meta-analysis of individual patient data. Journal of Physiotherapy 2016;62(3):124-9.

\section{Feigin 2014}

Feigin VL, Forouzanfar MH, Krishnamurthi R, Mensah GA, Connor M, Bennett DA, Global Burden of Diseases Injuries and Risk Factors Study 2010 Stroke Experts Group. Global and regional burden of stroke during 1990-2010: findings from the Global Burden of Disease Study 2010. Lancet 2014;383(9913):245-54.

\section{Flansbjer 2005}

Flansbjer UB, Holmback AM, Downham D, Patten C, Lexell J. Reliability of gait performance in men and women with hemiparesis after stroke. Journal of Rehabilitation Medicine 2005;37:75-82.

\section{Flansbjer 2012}

Flansbjer UB, Blom J, Brogardh C. The reproducibility of Berg Balance Scale and the Single-leg Stance in chronic stroke and the relationship between the two tests. $P M \& R:$ the Journal of Injury, Function, and Rehabilitation 2012;4(3):165-70. [1934-1482]

\section{Fulk 2010}

Fulk GD, Reynolds C, Mondal S, Deutsch JE. Predicting home and community walking activity in people with stroke. Archives of Physical Medicine and Rehabilitation 2010;91(10):1582-6. [0003-9993]

\section{GRADE 2013}

Schünemann H, Brożek J, Guyatt G, Oxman A, editor(s), GRADE working group. GRADE Handbook. gdt.guidelinedevelopment.org/central_prod/_design/client/ handbook/handbook.html (accessed December 2016).

\section{Hackett 2008}

Hackett ML, Anderson CS, House A, Halteh C. Interventions for preventing depression after stroke. Cochrane Database of Systematic Reviews 2008, Issue 3. [DOI: 10.1002/14651858.CD003689.pub3]

\section{Higgins 2003}

Higgins JPT, Thompson SG, Deeks JJ, Altman DG. Measuring inconsistency in meta-analyses. BMJ 2003;327:557-60.

\section{Higgins 2011}

Higgins JPT, Altman DG, Sterne JAC (editors). Chapter 8: Assessing risk of bias in included studies. In: Higgins JPT, Green $\mathrm{S}$ (editors). Cochrane Handbook for Systematic Reviews of Interventions Version 5.1.0 (updated March 2011). The Cochrane Collaboration, 2011. Available from handbook.cochrane.org.

\section{Hillier 2010}

Hillier S, Inglis-Jassiem G. Rehabilitation for communitydwelling people with stroke: home or centre based? A systematic review. International Journal of Stroke 2010;5(3):178-86.

\section{Intercollegiate Stroke Working Party 2012}

Intercollegiate Stroke Working Party. National Clinical Guidelines for Stroke. 4th Edition. London: Royal College of Physicians, 2012. 


\section{Ivey 2006}

Ivey FM, Hafer-Macko CE, Macko RF. Exercise rehabilitation after stroke. NeuroRx 2006;3(4):439-50.

\section{Jauch 2013}

Jauch E, Saver JL, Adams HP Jr, Bruno A, Connors JJ, Demaerschalk BM, the American Heart Association Stroke Council, Council on Cardiovascular Nursing, Council on Peripheral Vascular Disease and Council on Clinical Cardiology. Guidelines for the early management of patients with acute ischaemic stroke: a guideline for healthcare professionals from the American Heart Association/American Stroke Association. Stroke 2013;44:870-947.

\section{Kodama 2009}

Kodama S, Saito K, Tanaka S, Maki M, Yachi Y, Asumi M, et al. Cardiorespiratory fitness as a quantitative predictor of allcause mortality and cardiovascular events in healthy men and women: a meta-analysis. JAMA 2009;301(19):2024-35.

\section{Kwakkel 2004}

Kwakkel G, Van Peppen R, Wagenaar R, Wood-Dauphinee S, Richards C, Ashburn A, et al. Effects of augmented exercise therapy time after stroke. A meta-analysis. Stroke 2004;35:2529-36.

\section{Levin 2009}

Levin MF, Kleim JA, Wolf SL. What do motor "recovery" and "compensation" mean in patients following stroke? Neurorehabilitation and Neural Repair 2009;23(4):313-9. [1545-9683: (Print)]

\section{Lindsay 2010}

Lindsay MP, Gubitz G, Bayley M, Hill MD, Davies-Schinkel C, Singh S: Canadian Stroke Strategy Best Practices and Standards Writing Group. Canadian Best Practice Recommendations For Stroke Care. Ottawa: Canadian Stroke Network, 2010.

\section{Lohse 2014}

Lohse KR, Lang CE, Boyd LA. Is more better? Using meta-data to explore dose-response relationships in stroke rehabilitation. Stroke 2014;45:2053-8.

\section{Lollgen 2009}

Lollgen H, Bockenhoff A, Knapp G. Physical activity and allcause mortality: an updated meta-analysis with different intensity categories. International Journal of Sports Medicine 2009;30(3):213-24. [0172-4622]

\section{Lynch 2008a}

Lynch EB, Butt Z, Heinemann A, Victorson D, Nowinski CJ, Perez $L$, et al. A qualitative study of quality of life after stroke: the importance of social relationships. Journal of Rehabiltiation Medicine 2008;40(7):518-23.

\section{Marsden 2013}

Marsden DL, Dunn A, Callister R, Levi CR, Spratt NJ. Characteristics of exercise training interventions to improve cardiorespiratory fitness after stroke: a systematic review with meta-analysis. Neurorehabilitation and Neural Repair 2013;27(9):775-88. [1545-9683]

\section{Marsden 2016}

Marsden DL, Dunn A, Callister R, McElduff P, Levi CR, Spratt NJ. A home- and community-based physical activity program can improve the cardiorespiratory fitness and walking capacity of stroke survivors. Journal of Stroke and Cerebrovascular Diseases 2016;25(10):2386-98. [1052-3057]

\section{McDonnell 2013}

McDonnell MN, Hillier SL, Hooker SP, Le A, Judd SE, Howard VJ. Physical activity frequency and risk of incident stroke in a national US study of blacks and whites. Stroke 2013;44(9):2519-24. [0039-2499]

\section{Mehrholz 2014}

Mehrholz J, Pohl M, Elsner B. Treadmill training and body weight support for walking after stroke. Cochrane Database of Systematic Reviews 2014, Issue 1. [DOI: 10.1002/14651858.CD002840.pub3]

\section{Morris 2012}

Morris R, Morris P. Participants/experiences of hospital-based peer support groups for stroke patients and carers. Disability and Rehabilitation 2012;34:347-54.

\section{Mozaffarian 2015}

Mozaffarian D, Benjamin EJ, Go AS, Arnett DK, Blaha MJ, Cushman M, American Heart Association Statistics Committee and Stroke Statistics Subcommittee. Heart disease and stroke statistics - 2015 update: a report from the American Heart Association. Circulation 2015;131:e29-322.

\section{Mudge 2009b}

Mudge S, Stott S. Timed walking tests correlate with daily step activity in person with stroke. Archives of Physical Medicine and Rehabilitation 2009;90:296-301.

\section{Muren 2008}

Muren MA, Hutler M, Hooper J. Functional capacity and healthrelated quality of life in individuals post-stroke. Topics in Stroke Rehabilitation 2008;15(1):51-8.

\section{National Stroke Foundation 2010}

National Stroke Foundation. Clinical Guidelines for Stroke Management. Melbourne: National Stroke Foundation, 2010.

\section{Pereira 2012}

Pereira TV, Horwitz RI, loannidis JP. Empirical evaluation of very large treatment effects of medical interventions. JAMA 2012;308(16):1676-84. [0098-7484]

\section{Perera 2006}

Perera S, Mody SH, Woodman RC, Studenski SA. Meaningful change and responsiveness in common physical performance measures in older adults. Journal of the American Geriatric Society 2006;54(5):743-9. [0002-8614: (Print)]

\section{Pollock 2014}

Pollock A, Baer G, Campbell P, Choo P, Forster A, Morris J, et al. Physical rehabilitation approaches for the recovery of function and mobility following stroke. Cochrane Database of Systematic Reviews 2014, Issue 4. [DOI: 10.1002/14651858.CD001920.pub3] 


\section{Rand 2009}

Rand D, Eng J, Tang P-F, Jeng J-S, Hung C. How active are people with stroke? Use of accelerometers to assess physical activity. Stroke 2009;40:163-8.

\section{RevMan 2014 [Computer program]}

Nordic Cochrane Centre, The Cochrane Collaboration. Review Manager 5 (RevMan 5). Version 5.3. Copenhagen: Nordic Cochrane Centre, The Cochrane Collaboration, 2014.

\section{Salbach 2006}

Salbach N, Mayo N, Hanley J, Richards C, Wood-Dauphinee S. Psychometric evaluation of the original and Canadian French version of the activities-specific balance confidence scale among people with stroke. Archvies of Physical Medicine and Rehabilitation 2006;87(12):1597-604.

\section{Shephard 2009}

Shephard RJ. Maximal oxygen intake and independence in old age. British Journal of Sports Medicine 2009;43(5):342-6.

\section{Sigrist 2013}

Sigrist R, Rauter G, Riener R, Wolf P. Augmented visual, auditory, haptic, and multimodal feedback in motor learning: a review. Psychonomic Bulletin and Review 2013;20:21-53.

\section{Smith 2012}

Smith AC, Saunders DH, Mead G. Cardiorespiratory fitness after stroke: a systematic review. International Journal of Stroke 2012;7(6):499-510. [1747-4930]

\section{Sterne 2011}

Sterne JAC, Egger M, Moher D (editors). Chapter 10: Addressing reporting biases. In: Higgins JPT, Green S (editors). Cochrane Handbook for Systematic Reviews of Intervention. Version 5.1.0 (updated March 2011). The Cochrane Collaboration, 2011. Available from handbook.cochrane.org.

\section{Stevenson 2001}

Stevenson TJ. Detecting change in patients with stroke using the Berg Balance Scale. Australian Journal of Physiotherapy 2001;47(1):29-38. [0004-9514: (Print)]

\section{Stroke Foundation of New Zealand 2010}

Stroke Foundation of New Zealand and New Zealand Guidelines Group. Clinical Guidelines for Stroke Management 2010. Wellington: Stroke Foundation of New Zealand, 2010.

\section{Stroke Recovery Canada 2009}

Stroke Recovery Canada. Health Recovery Social Networks: Exploring the experiences of participants in stroke recovery peer support groups. Association for Non-Profit and Social Economy Research Annual Conference. Ottawa, 2009.

\section{CHARACTERISTICS OF STUDIES}

Characteristics of included studies [ordered by study ID]

\section{Taskinen 1999}

Taskinen P. The development of health enhancing exercise groups adapted for hemiplegic patients. A pilot study. Neurorehabilitation 1999;13:35-43.

\section{Taylor 2006}

Taylor DW, Stretton C, Mudge S, Garrett N. Does clinic measured gait speed differ from gait speed measured in the community in people with stroke. Clinical Rehabilitation 2006;20:438-44.

\section{Thompson 2003}

Thompson PD. Exercise and physical activity in the prevention and treatment of atherosclerotic cardiovascular disease. Arteriosclerosis, Thrombosis, and Vascular Biology 2003;23(8):1319-21. [1079-5642]

\section{Van Vliet 2006}

Van Vliet PM, Wulf G. Extrinsic feedback for motor learning after stroke: what is the evidence?. Disability and Rehabilitation 2006;28:831-40.

\section{Verbeek 2014}

Verbeek JM, Van Wegen E, Van Peppen R, Van der Wees PJ, Hendriks E, Rietberg M, et al. What is the evidence for physical therapy poststroke? A systematic review and meta-analysis. PLOS ONE 2014;9(2):e87987.

\section{Wevers 2009}

Wevers L, Van de Port I, Vermue M, Mead G, Kwakkel G. Effects of a task-oriented circuit class training on walking competency after stroke. Stroke 2009;40:2450-9.

\section{Wulf 2010}

Wulf G, Shea C, Lewthwaite R. Motor skill learning and performance: a review of influential factors. Medical Education 2010;44:75-84.

\section{References to other published versions of this review \\ English 2009}

English C, Hillier SL. Circuit class therapy for improving mobility after stroke. Cochrane Database of Systematic Reviews 2009, Issue 1. [DOI: 10.1002/14651858.CD007513]

\section{English 2010}

English C, Hillier SL. Circuit class therapy for improving mobility after stroke. Cochrane Database of Systematic Reviews 2010, Issue 7. [DOI: 10.1002/14651858.CD007513.pub2]

* Indicates the major publication for the study

Blennerhassett 2004

Methods RCT


Blennerhassett 2004 (Continued)

$$
\text { Mobility CCT versus upper limb CCT }
$$

Participants 30 participants (15 each group) receiving inpatient rehabilitation (mean of 43 days post-stroke), mean age 55.1 years, able to walk $10 \mathrm{~m}$ with close supervision with or without gait aids

Interventions Intervention: mobility-related CCT, 105 -minute workstations consisting of functional tasks including sit to stand, step ups, obstacle course walking, standing balance, stretching and strengthening exercises); $1 \mathrm{~h} /$ day, 5 days/week for 4 weeks

Comparison: upper limb-related CCT, 105 -minute workstations consisting of functional tasks to improve reach to grasp, hand eye co-ordination, stretching and strengthening exercises; $1 \mathrm{~h} /$ day, 5 days/ week for 4 weeks

Staff:participant ratio: 1:4

Both groups received additional CCT therapy in addition to usual care

Outcomes $\quad 6 \mathrm{mWT}$, Step Test, TUG, LOS, MAS upper arm and hand items, JTHFT

\section{Notes}

\section{Risk of bias}

\begin{tabular}{|c|c|c|}
\hline Bias & Authors' judgement & Support for judgement \\
\hline $\begin{array}{l}\text { Random sequence genera- } \\
\text { tion (selection bias) }\end{array}$ & Unclear risk & Card draw: unclear how cards were constructed \\
\hline $\begin{array}{l}\text { Allocation concealment } \\
\text { (selection bias) }\end{array}$ & Low risk & Sealed, opaque envelopes, independent person \\
\hline $\begin{array}{l}\text { Blinding (performance } \\
\text { bias and detection bias) } \\
\text { All outcomes }\end{array}$ & Low risk & Assessor blinded \\
\hline $\begin{array}{l}\text { Incomplete outcome data } \\
\text { (attrition bias) } \\
\text { All outcomes }\end{array}$ & Low risk & $100 \%$ data at 4 weeks \\
\hline $\begin{array}{l}\text { Selective reporting (re- } \\
\text { porting bias) }\end{array}$ & Unclear risk & No trial protocol \\
\hline Other bias & Low risk & Adequate sample size \\
\hline
\end{tabular}

\section{Dean 2000}

\begin{tabular}{|c|c|}
\hline Methods & $\begin{array}{l}\text { RCT } \\
\text { Mobility CCT versus upper limb CCT }\end{array}$ \\
\hline Participants & $\begin{array}{l}9 \text { participants (intervention }=5 \text {, comparison }=4 \text { ), mean } 1.3 \text { years post-stroke, mean age } 62.3 \text { years, able } \\
\text { to walk } 10 \mathrm{~m} \text { independently with or without gait aid }\end{array}$ \\
\hline Interventions & $\begin{array}{l}\text { Intervention: mobility-related CCT, } 10 \text { workstations functional tasks including seated reaching beyond } \\
\text { arms' reach, sit to stand, stepping activities, heel lifts, standing balance, strengthening exercises, walk- } \\
\text { ing activities; } 1 \text { h, } 3 \text { times/week for } 4 \text { weeks } \\
\text { Comparison: upper limb-related CCT, workstations consisting of upper limb tasks; } 1 \text { h, } 3 \text { times/week } \\
\text { for } 4 \text { weeks }\end{array}$ \\
\hline
\end{tabular}


Dean 2000 (Continued)

Staff:participant ratio: 1:6

Outcomes $\quad 6 \mathrm{mWT}$, Step Test, TUG, gait speed, peak vertical ground reaction force through affected lower limb during sit-to-stand, laboratory measures of gait kinematics and kinetics

Notes

\section{Risk of bias}

\begin{tabular}{lll}
\hline Bias & Authors' judgement & Support for judgement \\
\hline $\begin{array}{l}\text { Random sequence genera- } \\
\text { tion (selection bias) }\end{array}$ & Low risk & $\begin{array}{l}\text { Randomisation by lottery: "drawing two cards, one with subject's name and } \\
\text { one with group allocation from two separate boxes" }\end{array}$ \\
\hline $\begin{array}{l}\text { Allocation concealment } \\
\text { (selection bias) }\end{array}$ & Low risk & Cards drawn by a person independent of the study \\
\hline $\begin{array}{l}\text { Blinding (performance } \\
\text { bias and detection bias) } \\
\text { All outcomes }\end{array}$ & High risk & $\begin{array}{l}\text { Clinical assessments, with exception of } 6 \text { mWT, conducted by independent } \\
\text { rater; however, this blinding may have been unmasked as the result of this ob- } \\
\text { server inadvertently observing } 1 \text { training session }\end{array}$ \\
\hline $\begin{array}{l}\text { Incomplete outcome data } \\
\text { (attrition bias) } \\
\text { All outcomes }\end{array}$ & High risk & $\begin{array}{l}\text { Missing data balanced across groups (1 in experimental and 2 in control) for } \\
\text { transport or unrelated illness reasons, but no intention-to-treat analysis un- } \\
\text { dertaken }\end{array}$ \\
\hline $\begin{array}{l}\text { Selective reporting (re- } \\
\text { porting bias) }\end{array}$ & Unclear risk & No trial protocol \\
\hline \begin{tabular}{l} 
Other bias \\
\hline
\end{tabular} & High risk & Very small sample size \\
\hline
\end{tabular}

Dean 2012

\begin{tabular}{ll}
\hline Methods & RCT \\
& Mobility CCT + home exercise programme versus upper limb CCT + home exercise programme \\
\hline Participants & $\begin{array}{l}151 \text { participants (intervention }=76, \text { comparison }=75), \text { mean } 6.0 \text { years post-stroke, mean age } 67.1 \text { years, } \\
\text { able to walk } 10 \text { m independently with or without gait aid }\end{array}$ \\
\hline Interventions & $\begin{array}{l}\text { Intervention: mobility-related CCT, task-related training with progressive balance, strengthening, } \\
\text { standing, walking and stair climbing exercises, home programme and advice to increase walking }\end{array}$ \\
& $\begin{array}{l}\text { Comparison: upper-limb related CCT, task-related strength and co-ordination training, cognitive train- } \\
\text { ing, home programme and advice to increase use of upper limb and engage in more cognitive tasks }\end{array}$ \\
& Staff:participant ratio: not reported \\
\hline Outcomes & $\begin{array}{l}\text { 6mWT, gait speed, TUG, } 5 \text { x sit-to-stand test, step test, timed single leg stance, co-ordinated stability } \\
\text { test, maximal balance range, choice stepping reaction time, number falls in } 12 \text { months, falls risk score, } \\
\text { knee extensor strength, Short Form-12, Adelaide Activity Profile, daily step counts }\end{array}$ \\
\hline Notes & Adverse events and attendance at classes also reported
\end{tabular}

\section{Risk of bias}


Dean 2012 (Continued)

Random sequence genera- Low risk Randomisation was computer-generated prior to commencement study tion (selection bias)

\begin{tabular}{ll}
\hline $\begin{array}{l}\text { Allocation concealment } \\
\text { (selection bias) }\end{array}$ Low risk & Sealed, opaque envelopes
\end{tabular}

$\begin{array}{ll}\begin{array}{l}\text { Blinding (performance } \\ \text { bias and detection bias) }\end{array} \quad \text { Low risk } & \begin{array}{l}\text { The participants and therapists delivering the intervention could not be } \\ \text { blinded to intervention group allocation." }\end{array}\end{array}$

and detection bias) blinded to intervention group allocation."

All outcomes

Apart from self-reported falls, "All other outcome measures were collected by an assessor who was blinded to group allocation."

Participants asked not to reveal details of the programme to the assessors

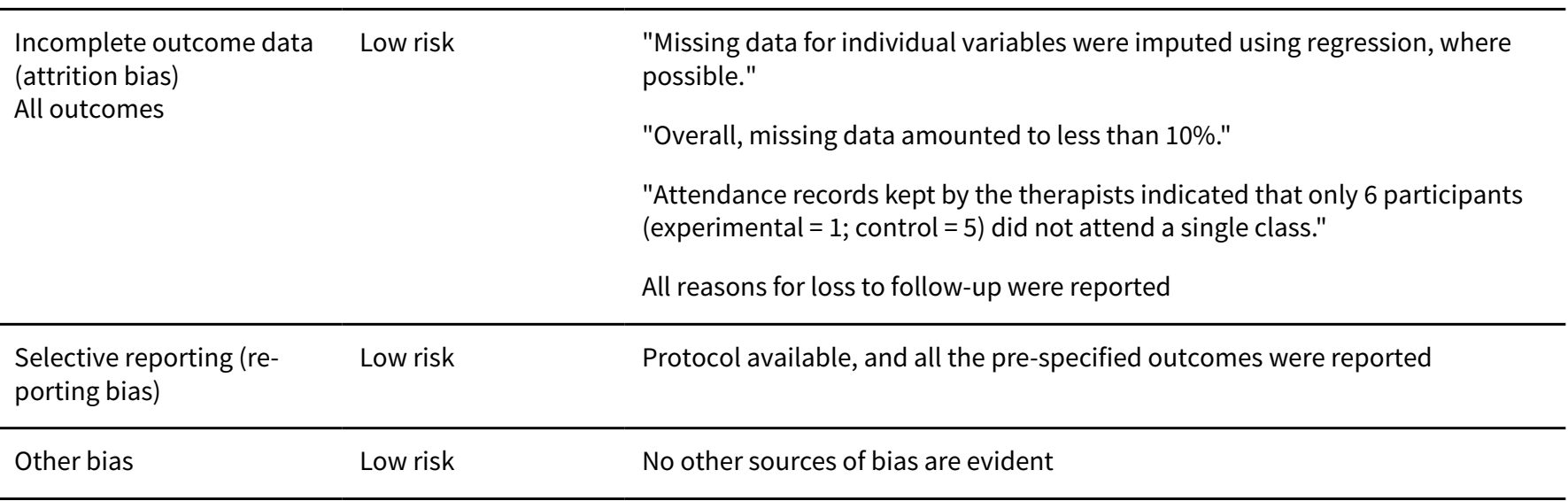

English 2015

Methods
RCT ( 3 arms)
CCT (mobility and upper-limb) versus usual care (one-to-one therapy, 5 days/week) versus 7-day/week
therapy (one-to-one). Only CCT and usual care arms included in this review

\begin{tabular}{ll}
\hline Participants & 283 participants in whole trial (intervention = 93, comparison $=94$ ), mean 29.8 days post-stroke, mean \\
age 69.1 years, moderate disability (FIM total score of 40-80 OR motor score of 38-62)
\end{tabular}

Interventions Intervention: physiotherapy service provided in twice daily 90-min CCT sessions, 5 days/week primarily focused on mobility. Included task-specific, individually progressed exercises focused on improving walking and standing activities

Comparision: physiotherapy services based on usual care; primarily provided in individual, one-to-one therapy sessions 5 days/week

Staff:participant ratio: between 1:3 and 1:6

\begin{tabular}{ll}
\hline Outcomes & 6mWT, gait speed, functional ambulation classification, FIM, Stroke Impact Scale, Wolf Motor Function \\
& Test, Australian Quality of Life score
\end{tabular}

Notes Data on therapy time provided and adverse events also available

\section{Risk of bias}

Bias

Authors' judgement Support for judgement 
English 2015 (Continued)

Random sequence genera- Low risk "A computer-generated randomization sequence was blocked to ensure equal tion (selection bias) numbers for each arm in each block of 15."

Allocation concealment Low risk
(selection bias)

(selection bias)
Blinding (performance Low risk

bias and detection bias)

All outcomes "Randomisation was concealed by use of a central telephone service adminis-
tered by staff not involved in the trial."

\begin{tabular}{|c|c|c|}
\hline $\begin{array}{l}\text { Incomplete outcome data } \\
\text { (attrition bias) } \\
\text { All outcomes }\end{array}$ & Low risk & $\begin{array}{l}\text { "Analyses were first conducted with no imputation of missing data (reported)." } \\
\text { The study found that when a multiple imputation was applied, it did not signif- } \\
\text { icantly influence the results }\end{array}$ \\
\hline
\end{tabular}

No mention of blinding participants or personnel. It would be unlikely that study participants and staff were blinded due to the nature of the trial. Unlikely to influence outcomes: "All outcomes were assessed by a trained assessor who was blinded to group allocation"

Figure 1 shows a flow of participants including reasons for participants lost to follow-up. Usual care therapy $=6 / 94,7$ days $/$ week $=8 / 96$, usual care $=8 / 93$

\begin{tabular}{lll}
\hline $\begin{array}{l}\text { Selective reporting (re- } \\
\text { porting bias) }\end{array}$ & Low risk & $\begin{array}{l}\text { Protocol available, and all the pre-specified outcomes were reported } \\
\text { Cost-effectiveness sub-study to be reported in a different paper }\end{array}$ \\
\hline Other bias & Low risk & No other sources of bias are evident \\
\hline
\end{tabular}

\section{Harrington 2010}

\begin{tabular}{ll}
\hline Methods & RCT \\
& Mobility CCT + education versus standard care and information sheet about support services \\
\hline Participants & $\begin{array}{l}243 \text { participants (intervention }=119, \text { comparison }=124), \text { minimum } 12 \text { months post, median } 10.3 \text { years } \\
\text { post-stroke, mean age } 70.5 \text { years, living in the community and able to participate in groups }\end{array}$
\end{tabular}

$\begin{array}{ll}\text { Interventions } & \text { Intervention: CCT with exercises adapted to ability aimed at improving balance, strength and en- } \\ \text { durance, plus home exercise programme, plus interactive self-management education sessions; } 1 \mathrm{~h} \text { ex- } \\ \text { ercise and } 1 \mathrm{~h} \text { of education twice a week for } 8 \text { weeks }\end{array}$

\section{Comparison: standard care and information sheet with list of local exercise classes}

Duration and frequency: not reported

Staff:participant ratio: 2:9

\begin{tabular}{ll}
\hline Outcomes & $\begin{array}{l}\text { TUG, RMI, Functional Reach, Frenchay Activities Index, Hosptial Anxiety and Depression Scale, Subjec- } \\
\text { tive Impact of Physical and Social Outcome, WHO-QoL, Carer Strain Index }\end{array}$ \\
\hline Notes &
\end{tabular}

\section{Risk of bias}

\begin{tabular}{lll}
\hline Bias & Authors' judgement & Support for judgement \\
\hline $\begin{array}{l}\text { Random sequence genera- } \\
\text { tion (selection bias) }\end{array}$ & Low risk & $\begin{array}{l}\text { "We used computer generated numbers in geographical blocks of 18 partici- } \\
\text { pants, with the unit of randomization being the patient." }\end{array}$ \\
\hline $\begin{array}{l}\text { Allocation concealment } \\
\text { (selection bias) }\end{array}$ & Low risk & "Randomization was carried out centrally by an independent assistant who \\
took no part in recruitment."
\end{tabular}


Harrington 2010 (Continued)

Blinding (performance Low risk "Due to the nature of the intervention it was not possible to blind either the bias and detection bias) participants or the individuals involved in running the schemes..."

All outcomes

"...outcome was assessed by a blinded assessor."

\begin{tabular}{lll}
\hline $\begin{array}{l}\text { Incomplete outcome data } \\
\text { (attrition bias) } \\
\text { All outcomes }\end{array}$ & Low risk & $\begin{array}{l}\text { Analysis was undertaken on an intention-to-treat basis } \\
\text { Figure 1 shows participant flow, with reasons for loss to follow-up available }\end{array}$ \\
\hline $\begin{array}{l}\text { Selective reporting (re- } \\
\text { porting bias) }\end{array}$ & Unclear risk & No study protocol \\
\hline Other bias & Low risk & No other source of bias evident \\
\hline
\end{tabular}

Holmgren 2010

\begin{tabular}{|c|c|}
\hline Methods & $\begin{array}{l}\text { RCT } \\
\text { Mobility CCT + education versus education only }\end{array}$ \\
\hline Participants & $\begin{array}{l}34 \text { participants (intervention }=15 \text {, comparison }=15 \text { ), mean time since stroke } 0.36 \text { years, mean age } 78.5 \\
\text { years, able to walk } 10 \mathrm{~m} \text { independently with or without gait aid (excluded if able to walk outdoors inde- } \\
\text { pendently) }\end{array}$ \\
\hline \multirow[t]{4}{*}{ Interventions } & $\begin{array}{l}\text { Intervention: mobility-related CCT, focus on physical activity and functional performance and educa- } \\
\text { tion about falls risk }\end{array}$ \\
\hline & СCT duration not specified, 7 sessions a week for 5 weeks; education $1 \mathrm{~h} /$ week for 5 weeks \\
\hline & Comparison: education about coping with hidden dysfunctions after stroke $1 \mathrm{~h} /$ week for 5 weeks \\
\hline & Staff:participant ratio: not reported \\
\hline Outcomes & Short-form 36, Geriatric Depression Scale \\
\hline Notes & $\begin{array}{l}\text { Secondary outcomes reported from original trial. Original trial not published suggesting possible publi- } \\
\text { cation bias }\end{array}$ \\
\hline
\end{tabular}

\section{Risk of bias}

\begin{tabular}{lll}
\hline Bias & Authors' judgement & Support for judgement \\
\hline $\begin{array}{l}\text { Random sequence genera- } \\
\text { tion (selection bias) }\end{array}$ & Low risk & $\begin{array}{l}\text { "...was conducted with a minimization software program, MiniM to avoid im- } \\
\text { balances at baseline between the two groups." }\end{array}$ \\
\hline $\begin{array}{l}\text { Allocation concealment } \\
\text { (selection bias) }\end{array}$ & High risk & Two main investigators responsible for randomisation \\
\hline $\begin{array}{l}\text { Blinding (performance } \\
\text { bias and detection bias) } \\
\text { All outcomes }\end{array}$ & Low risk & Single-blinded \\
& $\begin{array}{l}\text { Participants were instructed not to reveal anything about group allocation. } \\
\text { "All participants were blinded as for the content of the two different groups be- } \\
\text { fore randomization." No mention of blinding of staff, however unlikely due to } \\
\text { nature of trial. Unlikely to influence outcomes. }\end{array}$
\end{tabular}


"The nurses and physiotherapists who performed the clinical test assessments were blinded to group allocation."

\begin{tabular}{ll}
\hline $\begin{array}{l}\text { Incomplete outcome data } \\
\text { (attrition bias) }\end{array}$ & Intention-to-treat analysis \\
All outcomes & Figure 1 shows the participant flow including reasons for loss to follow-up \\
& All but 1 participant completed the 5-week intervention period \\
& 2 participants dropped out at follow-up due to health reasons
\end{tabular}

Selective reporting (re- Unclear risk No protocol available

porting bias)

Other bias Low risk No other sources of bias evident

Kim 2016a

\begin{tabular}{ll}
\hline Methods & RCT \\
& Mobility CCT versus usual care therapy \\
\hline Participants & $\begin{array}{l}20 \text { participants (intervention }=10, \text { comparison }=10), \text { mean time since stroke } 30.0 \text { days, mean age } 65.6, \\
\text { score } 3 \text { or } 4 \text { on Functional Ambulation Classification (able to walk with no more than } 1 \text { person assist- } \\
\text { ing), less than } 3 \text { months post-stroke }\end{array}$ \\
\hline
\end{tabular}

Interventions Intervention: mobility-related CCT, including trunk exercises, active sitting practice, sit-to-stand practice, standing and walking practice, aerobic exercise and strength training; $90 \mathrm{~min} /$ per day, 5 days/ week for 4 weeks

Comparison: usual care physiotherapy provided in $2 \times 30$-min sessions, 5 x per week for 4 weeks. Content based on neurodevelopmental approach and provided in one-to-one therapy sessions

Staff:participant ratio: at least 2 participants to 1 therapist

Outcomes 6mWT, BBS, modified Barthel Index (Korean version), lower limb score of the Fugl-Meyer assessment

$$
\text { Notes }
$$

\section{Risk of bias}

\begin{tabular}{lll}
\hline Bias & Authors' judgement & Support for judgement \\
\hline $\begin{array}{l}\text { Random sequence genera- } \\
\text { tion (selection bias) }\end{array}$ & Unclear risk & $\begin{array}{l}\text { Randomised via sealed envelope technique, random sequence generation not } \\
\text { stated }\end{array}$ \\
\hline $\begin{array}{l}\text { Allocation concealment } \\
\text { (selection bias) }\end{array}$ & High risk & No mention of allocation concealment \\
\hline $\begin{array}{l}\text { Blinding (performance } \\
\text { bias and detection bias) }\end{array}$ & Low risk & Assessors blinded to group allocation \\
$\begin{array}{l}\text { All outcomes } \\
\begin{array}{l}\text { Incomplete outcome data } \\
\text { (attrition bias) } \\
\text { All outcomes }\end{array}\end{array}$ & Low risk & No missing data \\
\hline
\end{tabular}


Kim 2016a (Continued)

Selective reporting (re- Unclear risk $\quad$ No trial protocol
porting bias)

Other bias Low risk No other sources of bias identified

\section{Marigold 2005}

\begin{tabular}{ll}
\hline Methods & $\begin{array}{l}\text { RCT } \\
\text { Mobility-related CCT versus general balance class }\end{array}$ \\
\hline Participants & $\begin{array}{l}59 \text { participants (Group } 1=28, \text { Group 2 = 31), mean 3.7 years post-stroke, mean age 67.8 years, able to } \\
\text { walk } 10 \text { m independently with or without gait aid }\end{array}$ \\
\hline Interventions & $\begin{array}{l}\text { Intervention: mobility-related CCT including walking, standing tasks focused on balance, sit to stand; } 1 \text { - } \\
\text { h sessions, } 3 \text { times/week for } 10 \text { weeks } \\
\text { Group 2: stretching and slow weight shifting exercises; } 1 \text {-h sessions, } 3 \text { times/week for } 10 \text { weeks }\end{array}$ \\
& Staff:participant ratio: not reported \\
\hline Outcomes & BBS, TUG, ABC, NHP, standing postural reflexes using force platform, self-reported prospective falls di- \\
ary
\end{tabular}

Notes

\section{Risk of bias}

\begin{tabular}{|c|c|c|}
\hline Bias & Authors' judgement & Support for judgement \\
\hline $\begin{array}{l}\text { Random sequence genera- } \\
\text { tion (selection bias) }\end{array}$ & Low risk & Computer-generated codes \\
\hline $\begin{array}{l}\text { Allocation concealment } \\
\text { (selection bias) }\end{array}$ & Low risk & Person independent of the study \\
\hline $\begin{array}{l}\text { Blinding (performance } \\
\text { bias and detection bias) } \\
\text { All outcomes }\end{array}$ & Low risk & All assessors were blinded to group assignment, study design and purpose \\
\hline $\begin{array}{l}\text { Incomplete outcome data } \\
\text { (attrition bias) } \\
\text { All outcomes }\end{array}$ & High risk & $\begin{array}{l}\text { Total of } 11 \text { lost before post-intervention testing, another } 6 \text { lost before fol- } \\
\text { low-up } \\
\text { No intention-to-treat analysis or imputation of missing data }\end{array}$ \\
\hline $\begin{array}{l}\text { Selective reporting (re- } \\
\text { porting bias) }\end{array}$ & Unclear risk & Protocol not published so unclear regarding whether all outcomes reported \\
\hline Other bias & Low risk & Adequate sample size \\
\hline
\end{tabular}

\section{Marsden 2010}

$\begin{array}{ll}\text { Methods } & \text { RCT cross-over design } \\ & \text { Mobility-related CCT plus education versus wait list control }\end{array}$


Marsden 2010 (Continued)

Participants 26 participants (Group $1=12$, Group $2=14$ ), mean 2.5 years post-stroke, mean age 71.7 years, clinical diagnosis of stroke

Interventions

Intervention: mobility-related CCT, $10 \times 5$-min workstations consisting of sit to stand, reaching, standing balance, walking figure 8, stationary bike; $1 \mathrm{~h}$ exercise and $1 \mathrm{~h}$ education, once a week for 7 weeks Comparison: wait list control

Staff:participant ratio: $1: 3$

Outcomes 6mWT, TUG, Short-form 36 (physical), Carer Strain Index

Notes Only first comparison (pre-cross over) included

\section{Risk of bias}

\begin{tabular}{lll}
\hline Bias & Authors' judgement & Support for judgement \\
\hline $\begin{array}{l}\text { Random sequence genera- } \\
\text { tion (selection bias) }\end{array}$ & Low risk & Toss of a coin by a team member \\
\hline $\begin{array}{l}\text { Allocation concealment } \\
\text { (selection bias) }\end{array}$ & High risk & Team member responsible for allocation \\
\hline $\begin{array}{l}\text { Blinding (performance } \\
\text { bias and detection bias) } \\
\text { All outcomes }\end{array}$ & High risk & $\begin{array}{l}\text { No mention of blinding of staff or participants, however unlikely due to nature } \\
\text { of trial. Unlikely to influence outcomes }\end{array}$ \\
$\begin{array}{l}\text { Primary outcomes assessor blinded } \\
\text { Incomplete outcome data } \\
\begin{array}{l}\text { (attrition bias) } \\
\text { All outcomes }\end{array}\end{array}$ & Low risk & $\begin{array}{l}\text { Secondary outcome assessors not blinded. Only secondary outcomes used in } \\
\text { the meta-analysis }\end{array}$ \\
\hline $\begin{array}{l}\text { Selective reporting (re- } \\
\text { porting bias) }\end{array}$ & $\begin{array}{l}\text { Intention-to-treat. "... but no values were imputed for survivors or carers who } \\
\text { did not attend an assessment session." }\end{array}$ \\
\hline $\begin{array}{l}\text { Other bias } \\
\text { Only } 1 \text { loss to follow-up (hospitalisation) for intervention group. Figure } 1 \text { flow } \\
\text { diagram }\end{array}$ \\
\hline
\end{tabular}

\section{Moore 2015}

\begin{tabular}{ll}
\hline Methods & RCT \\
& Mobility CCT vs home stretching (matched duration) \\
\hline Participants & $\begin{array}{l}40 \text { participants (intervention }=20, \text { comparison = 20), mean time since stroke } 1.5 \text { years, mean age } 69 \\
\text { years, able to complete } 6 \mathrm{mWT} \text { with or without gait aid }\end{array}$ \\
\hline Interventions & $\begin{array}{l}\text { Intervention: mobility CCT based on FAME programme including warm-up, stretching, functional } \\
\text { strengthening, balance, agility \& fitness, cool down; } 45 \text { - } 60 \text { minutes, } 3 \text { times/week for } 19 \text { weeks }\end{array}$ \\
& $\begin{array}{l}\text { Comparison: home stretching programme of matched duration; } 45 \text { to } 60 \text { minutes } 3 \text { times/week for } 19 \\
\text { weeks }\end{array}$
\end{tabular}


Moore 2015 (Continued)

Staff:participant ratio: not reported

Outcomes

6mWT, gait speed, BBS, SIS (physical), VO2 peak, peak work rate, Addenbrook's Cognitive Examination (revised, ACE-r), blood cholesterol, 2-hour glucose, HOMA index, blood pressure, BMI, fat mass, brain physiology (cerebral blood flow)

Notes Adverse events reported, not actual therapy time delivered

\section{Risk of bias}

\begin{tabular}{|c|c|c|}
\hline Bias & Authors' judgement & Support for judgement \\
\hline $\begin{array}{l}\text { Random sequence genera- } \\
\text { tion (selection bias) }\end{array}$ & Low risk & $\begin{array}{l}\text { "A computerized random number generator was used to allocate treatment by } \\
\text { an independent administrator after screening." }\end{array}$ \\
\hline $\begin{array}{l}\text { Allocation concealment } \\
\text { (selection bias) }\end{array}$ & Low risk & $\begin{array}{l}\text { "... the administrator was telephoned for the next number in the sequence to } \\
\text { enable participant randomisation." }\end{array}$ \\
\hline \multirow{3}{*}{$\begin{array}{l}\text { Blinding (performance } \\
\text { bias and detection bias) } \\
\text { All outcomes }\end{array}$} & Low risk & Single-blind RCT \\
\hline & & $\begin{array}{l}\text { No mention of blinding participants or personnel. It would be unlikely that } \\
\text { study participants and staff were blinded due to the nature of the trial. Unlike- } \\
\text { ly to influence outcomes }\end{array}$ \\
\hline & & Assessors were blinded \\
\hline \multirow{2}{*}{$\begin{array}{l}\text { Incomplete outcome data } \\
\text { (attrition bias) } \\
\text { All outcomes }\end{array}$} & Low risk & $\begin{array}{l}\text { States participants performed "...>90\% of outcome assessments and exercise } \\
\text { sessions." Although these were not defined }\end{array}$ \\
\hline & & All participants completed the intervention, none lost to follow-up \\
\hline $\begin{array}{l}\text { Selective reporting (re- } \\
\text { porting bias) }\end{array}$ & Unclear risk & No protocol available \\
\hline Other bias & Low risk & No other sources of bias evident \\
\hline
\end{tabular}

Mudge 2009a

\begin{tabular}{ll}
\hline Methods & $\begin{array}{l}\text { RCT } \\
\text { Mobility-related CCT versus education or social groups }\end{array}$ \\
\hline Participants & $\begin{array}{l}58 \text { participants (Group } 1=31 \text {, Group 2 = 27), mean } 4.9 \text { years post-stroke, mean age 69.1 years, able to } \\
\text { walk } 10 \text { m independently with or without gait aid }\end{array}$ \\
\hline Interventions & $\begin{array}{l}\text { Intervention: mobility CCT, 15 2-min workstations including walking, standing balance and strengthen- } \\
\text { ing; 50-60 min 3 times/week for } 4 \text { weeks } \\
\text { Comparison: } 4 \text { social and } 4 \text { educational sessions; duration not specified, twice a week for } 4 \text { weeks } \\
\text { Staff:participant ratio: 3:9 }\end{array}$ \\
\hline Outcomes & Gait speed, 6 mWT, RMI, ABC, steps per day using activity monitor, PADS \\
\hline Notes & Repetitions and details about exercise intensity recorded each station
\end{tabular}

\section{Risk of bias}


Mudge 2009a (Continued)

\begin{tabular}{lll} 
Bias & Authors' judgement & Support for judgement \\
\hline $\begin{array}{l}\text { Random sequence genera- } \\
\text { tion (selection bias) }\end{array}$ & Low risk & Computer-generated random numbers \\
\hline $\begin{array}{l}\text { Allocation concealment } \\
\text { (selection bias) }\end{array}$ & Low risk & Person independent of the study matched the participants to the codes \\
\hline $\begin{array}{l}\text { Blinding (performance } \\
\text { bias and detection bias) } \\
\text { All outcomes }\end{array}$ & Low risk & Unmasking occurred for 3 out of 58 participants (5\%) \\
\hline $\begin{array}{l}\text { Incomplete outcome data } \\
\text { (attrition bias) } \\
\text { All outcomes }\end{array}$ & Low risk & $\begin{array}{l}\text { 2 lost before randomisation, } 3 \text { withdrew before post-intervention assess- } \\
\text { ment and a further } 5 \text { lost before follow-up assessment; losses balanced across } \\
\text { groups } \\
\text { Intention-to-treat analysis undertaken with imputation of missing data using } \\
\text { carry forward method }\end{array}$
\end{tabular}

Selective reporting (re- Unclear risk No protocol available

porting bias)

Other bias Low risk Adequate sample size

Outermans 2010

Methods RCT

High-intensity, mobility-related CCT versus low-intensity, mobility-related CCT

$\begin{array}{ll}\text { Participants } & 44 \text { participants (intervention }=23 \text {, comparison }=21 \text { ), mean time since stroke } 0.75 \text { months, mean age } \\ 56.6 \text {, able to walk } 10 \text { m independently }\end{array}$

Interventions Intervention: high-intensity mobility CCT, workstations based on Dean 2000 with progressive target heart rate; 45-60 minutes, 3 times/week for 4 weeks in addition to $30 \mathrm{~min} /$ day usual care physiotherapy

Comparison: low-intensity mobility CCT, not clear if same exercises were included, no progression of heart rate; 45-60 minutes, 3 times/week for 4 weeks in addition to $30 \mathrm{~min} /$ day usual care physiotherapy

Staff:participant ratio: not reported

\begin{tabular}{ll}
\hline Outcomes & $6 \mathrm{mWT}$, gait speed, BBS, functional reach \\
\hline Notes & Adverse events, duration (number of days) of training
\end{tabular}

\section{Risk of bias}

\begin{tabular}{lll}
\hline Bias & Authors' judgement & Support for judgement \\
\hline $\begin{array}{l}\text { Random sequence genera- } \\
\text { tion (selection bias) }\end{array}$ & Unclear risk & Reported as "randomly generated" but description of how was not presented \\
\hline $\begin{array}{l}\text { Allocation concealment } \\
\text { (selection bias) }\end{array}$ & Low risk & $\begin{array}{l}\text { "Allocation was performed by drawing randomly generated lots enclosed in } \\
\text { opaque envelopes." }\end{array}$ \\
\hline $\begin{array}{l}\text { Blinding (performance } \\
\text { bias and detection bias) }\end{array}$ & High risk & $\begin{array}{l}\text { "All clinical assessments were conducted by one assessor, who was not blind- } \\
\text { ed for allocation. To minimize bias the assessor was not present at the group }\end{array}$ \\
\hline
\end{tabular}


Outermans 2010 (Continued)

All outcomes training at any time. Also previous assessments were not available during post-test assessment and all instructions were standardized."

\section{Incomplete outcome data Low risk}

(attrition bias)

All outcomes
Intention-to-treat. "Missing values were imputed using the assumption of a worst-case scenario in which the baseline value was carried forward."

Reasons for loss to follow-up are available: 6 lost in intervention group, 7 in control group

\begin{tabular}{lll}
\hline $\begin{array}{l}\text { Selective reporting (re- } \\
\text { porting bias) }\end{array}$ & Unclear risk & No protocol available \\
\hline Other bias & Low risk & No other sources of bias evident \\
\hline
\end{tabular}

\section{Pang 2005}

\begin{tabular}{ll}
\hline Methods & RCT \\
& Mobility CCT versus upper limb CCT \\
\hline Participants & $\begin{array}{l}63 \text { participants (Group } 1=32, \text { Group } 2=31 \text { ), mean } 5.1 \text { years post-stroke, mean age } 65.3 \text { years, able to } \\
\text { walk } 10 \text { m independently with or without gait aids }\end{array}$ \\
\hline
\end{tabular}

Interventions

Intervention: mobility-related CCT based on FAME programme including warm-up, stretching, functional strengthening, balance, agility \& fitness, cool down including target heart rate; 1-h session, 3 times/ week for 19 weeks

Comparison: upper-limb-related CCT including strengthening, range of motion, functional reach and manipulation tasks; 1-h session, 3 times/week for 19 weeks

Staff:participant ratio: not reported

Outcomes

$6 \mathrm{mWT}, \mathrm{BBS}, \mathrm{VO}_{2} \mathrm{max}$, knee extension strength (dynamometer), PASIPD, proximal femur BMD

\section{Notes}

\section{Risk of bias}

\begin{tabular}{|c|c|c|}
\hline Bias & Authors' judgement & Support for judgement \\
\hline $\begin{array}{l}\text { Random sequence genera- } \\
\text { tion (selection bias) }\end{array}$ & Low risk & Drawing ballots \\
\hline $\begin{array}{l}\text { Allocation concealment } \\
\text { (selection bias) }\end{array}$ & Low risk & $\begin{array}{l}\text { Ballots drawn by person not involved with enrolment, screening, or outcome } \\
\text { assessments }\end{array}$ \\
\hline $\begin{array}{l}\text { Blinding (performance } \\
\text { bias and detection bias) } \\
\text { All outcomes }\end{array}$ & Low risk & $\begin{array}{l}\text { Research personnel who performed outcome assessments were blinded to } \\
\text { group assignment }\end{array}$ \\
\hline $\begin{array}{l}\text { Incomplete outcome data } \\
\text { (attrition bias) } \\
\text { All outcomes }\end{array}$ & Low risk & $\begin{array}{l}\text { Similar small amount of missing data across groups } \\
\text { Missing data imputed from baseline values and intention-to-treat analysis } \\
\text { used }\end{array}$ \\
\hline $\begin{array}{l}\text { Selective reporting (re- } \\
\text { porting bias) }\end{array}$ & Unclear risk & $\begin{array}{l}\text { This study was reported in at least } 3 \text { separate papers all including different } \\
\text { outcome measures }\end{array}$ \\
\hline Other bias & Low risk & Adequate sample size \\
\hline
\end{tabular}


Song 2015

\begin{tabular}{ll} 
Methods & RCT \\
& Mobility CCT vs mobility CCT individually provided vs conventional therapy \\
\hline Participants & $\begin{array}{l}30 \text { participants (intervention }=11, \text { comparison (individual) }=10 \text {, comparison (conventional therapy) }= \\
\text { 9, more than } 6 \text { months post-stroke (mean and upper range not given), mean age } 56.2 \text {, able to walk } 10 \mathrm{~m} \\
\text { without assistance }\end{array}$
\end{tabular}

\begin{tabular}{ll}
\hline Interventions & Intervention: mobility CCT, provided in circuit \\
& Comparison (individual): mobility exercises, provided one-to-one \\
Comparison (conventional therapy): not described \\
30 min/day, 3 times/week for 4 weeks \\
Inpatient rehabilitation \\
Staff:participant ratio: not specified \\
\hline Outcomes & Gait speed, cadence, self-esteem scale, motivation of rehabilitation, relationship change scale \\
\hline Notes &
\end{tabular}

\section{Risk of bias}

\begin{tabular}{|c|c|c|}
\hline Bias & Authors' judgement & Support for judgement \\
\hline $\begin{array}{l}\text { Random sequence genera- } \\
\text { tion (selection bias) }\end{array}$ & Unclear risk & Insufficient information \\
\hline $\begin{array}{l}\text { Allocation concealment } \\
\text { (selection bias) }\end{array}$ & Unclear risk & Insufficient information \\
\hline $\begin{array}{l}\text { Blinding (performance } \\
\text { bias and detection bias) } \\
\text { All outcomes }\end{array}$ & Unclear risk & Insufficient information \\
\hline $\begin{array}{l}\text { Incomplete outcome data } \\
\text { (attrition bias) } \\
\text { All outcomes }\end{array}$ & Unclear risk & Insufficient information \\
\hline $\begin{array}{l}\text { Selective reporting (re- } \\
\text { porting bias) }\end{array}$ & Unclear risk & No protocol available \\
\hline Other bias & Unclear risk & $\begin{array}{l}\text { Study failed to report any of the above points. Only small sample sizes }(n=9 \text {, } \\
n=10, n=11 \text { ). Participant assignment was unclear: "Twelve patients were ex- } \\
\text { cluded due to health problems, so subjects were randomly assigned to ..." }\end{array}$ \\
\hline
\end{tabular}

Tang 2014

$\begin{array}{ll}\text { Methods } & \text { RCT } \\ & \begin{array}{l}\text { Mobility CCT (with aerobic exercise component) vs balance and stretching exercises without aerobic } \\ \text { stimulus }\end{array}\end{array}$


Tang 2014 (Continued)

Participants 50 participants (intervention $=25$, comparison $=25$ ), mean 4.2 years post-stroke, mean 66.4 years, able to walk $5 \mathrm{~m}$ independently with or without gait aids

Interventions

Intervention: aerobic training with target progressive heart rate using brisk walking, cycling, step ups, sit to stands

Comparison: balance and flexibility non-aerobic, including balance exercise progressed to be challenging

60-min sessions 3 times/week for 6 months

Staff:participant ratio: 3:12

\begin{tabular}{ll}
\hline Outcomes & $6 \mathrm{mWT}, \mathrm{VO}_{2}$ peak, arterial stiffness, cardiac function, cholesterol, triglycerides, fasting glucose \\
\hline Notes & Adverse events and adherence to class attendance reported \\
\hline
\end{tabular}

\section{Risk of bias}

\begin{tabular}{|c|c|c|}
\hline Bias & Authors' judgement & Support for judgement \\
\hline $\begin{array}{l}\text { Random sequence genera- } \\
\text { tion (selection bias) }\end{array}$ & Low risk & $\begin{array}{l}\text { "... performed the randomisation using a computer-generated } 1: 1 \text { allocation } \\
\text { sequence and permuted block sizes of } 2 \text { or } 4 . "\end{array}$ \\
\hline $\begin{array}{l}\text { Allocation concealment } \\
\text { (selection bias) }\end{array}$ & Unclear risk & States "concealed allocation" with no description \\
\hline $\begin{array}{l}\text { Blinding (performance } \\
\text { bias and detection bias) } \\
\text { All outcomes }\end{array}$ & Low risk & $\begin{array}{l}\text { Single-blinded trial. Unlikely to influence outcomes } \\
\text { "Blinded outcome assessors were used." }\end{array}$ \\
\hline $\begin{array}{l}\text { Incomplete outcome data } \\
\text { (attrition bias) } \\
\text { All outcomes }\end{array}$ & Low risk & $\begin{array}{l}\text { Intention-to-treat analysis } \\
\text { Dropouts described, with only } 3 \text { from } 1 \text { group and none from the other. Rea- } \\
\text { sons unrelated to the programme }\end{array}$ \\
\hline $\begin{array}{l}\text { Selective reporting (re- } \\
\text { porting bias) }\end{array}$ & Unclear risk & No protocol available \\
\hline Other bias & Low risk & No other sources of bias evident \\
\hline
\end{tabular}

Van de Port 2012

\begin{tabular}{ll}
\hline Methods & RCT \\
& Mobility CCT versus conventional (one-to-one) therapy \\
\hline Participants & $\begin{array}{l}250 \text { participants (intervention }=126, \text { comparison }=124), \text { mean } 3.2 \text { months post-stroke, mean age } 57 \\
\text { years able to walk } 10 \text { m independently with or without walking aid, discharged from inpatient therapy }\end{array}$ \\
\hline Interventions & $\begin{array}{l}\text { Intervention: mobility related CCT, 8 } \times 3 \text {-min workstations activities designed to improve walking com- } \\
\text { petency }\end{array}$ \\
Comparison: individual (one-to-one) conventional therapy according to Dutch Guidelines \\
90 min twice a week for 12 weeks
\end{tabular}


Van de Port 2012 (Continued)

Staff:participant ratio: $1: 1.8$

Outcomes $6 \mathrm{mWT}$, gait speed, Functional Ambulation Classification, modified stairs test, TUG, timed balance test, RMI, Nottingham Extended Activities of Daily Living, Stroke Impact Scale (mobility), Fatigue Severity Scale, Falls Efficacy Scale, Hospital Anxiety and Depression Scale, motricity index (arm and leg)

Notes Adverse events and actual therapy time delivered (in minutes) reported

\section{Risk of bias}

\begin{tabular}{|c|c|c|}
\hline Bias & Authors' judgement & Support for judgement \\
\hline $\begin{array}{l}\text { Random sequence genera- } \\
\text { tion (selection bias) }\end{array}$ & Low risk & "....and randomisation took place using an online minimization procedure." \\
\hline $\begin{array}{l}\text { Allocation concealment } \\
\text { (selection bias) }\end{array}$ & Unclear risk & $\begin{array}{l}\text { The randomisation scheme was developed and held by an offsite company } \\
\text { that provided the online randomisation program. When participants were re- } \\
\text { cruited, members of research team would be notified of group allocation by } \\
\text { text message }\end{array}$ \\
\hline \multirow{2}{*}{$\begin{array}{l}\text { Blinding (performance } \\
\text { bias and detection bias) } \\
\text { All outcomes }\end{array}$} & Low risk & Single-blinded trial. Unlikely to influence outcomes \\
\hline & & $\begin{array}{l}\text { "Three trained RAs who were blinded to treatment allocation, measured all } \\
\text { outcomes before randomisation ..." }\end{array}$ \\
\hline \multirow{2}{*}{$\begin{array}{l}\text { Incomplete outcome data } \\
\text { (attrition bias) } \\
\text { All outcomes }\end{array}$} & Low risk & \\
\hline & & $\begin{array}{l}\text { "Of the } 250 \text { included patients, one patient in the circuit training group and sev- } \\
\text { en in the usual care group were excluded from the analysis." }\end{array}$ \\
\hline \multirow{5}{*}{$\begin{array}{l}\text { Selective reporting (re- } \\
\text { porting bias) }\end{array}$} & Low risk & Protocol available \\
\hline & & Cumulative Illness Rating Scale not used in trial paper \\
\hline & & EuroQoL not used in trial paper \\
\hline & & Cost benefits not analysed in this paper \\
\hline & & Slightly different data analysis \\
\hline Other bias & Low risk & No other sources of bias evident \\
\hline
\end{tabular}

Verma 2011

\begin{tabular}{ll} 
Methods & RCT \\
& Mobility CCT plus mental imagery vs conventional therapy (based on Bobath techniques) \\
\hline Participants & $\begin{array}{l}30 \text { participants (intervention }=15, \text { comparison }=15) \text {, mean } 1.5 \text { years post-stroke (lower range from } 3 \\
\text { months), mean age } 54.2 \text { years, Functional Ambulation Classification } 2 \text { or above (i.e. able to walk with } \\
\text { assistance of } 1 \text { person) }\end{array}$ \\
\hline
\end{tabular}

Interventions Intervention: mobility CCT, workstations including balance, stair walking, turning, transfers, and speed walking plus mental imagery

Comparison: conventional lower limb therapy based on Bobath techniques

40-min sessions, 7 days/week for 2 weeks 
Verma 2011 (Continued)

Inpatient and outpatient sessions

Staff:participant ratio: $1: 4$

\begin{tabular}{ll}
\hline Outcomes & $\begin{array}{l}\text { 6mWT, gait speed, Functional Ambulation Classification, Rivermead Visual Gait Assessment, cadence, } \\
\text { step length asymmetry, Barthel Index }\end{array}$ \\
\hline Notes & Adverse events
\end{tabular}

\section{Risk of bias}

\begin{tabular}{|c|c|c|}
\hline Bias & Authors' judgement & Support for judgement \\
\hline \multirow{2}{*}{$\begin{array}{l}\text { Random sequence genera- } \\
\text { tion (selection bias) }\end{array}$} & Low risk & " ... using computer generated random numbers." \\
\hline & & $\begin{array}{l}\text { "A resident physician at the study site conducted the random-number pro- } \\
\text { gram." Resident was blinded to the protocol and was not involved in the study }\end{array}$ \\
\hline $\begin{array}{l}\text { Allocation concealment } \\
\text { (selection bias) }\end{array}$ & Low risk & $\begin{array}{l}\text { "The intervention assignments were enclosed in sealed envelopes, which were } \\
\text { opaque and sequentially numbered." }\end{array}$ \\
\hline \multirow{3}{*}{$\begin{array}{l}\text { Blinding (performance } \\
\text { bias and detection bias) } \\
\text { All outcomes }\end{array}$} & Low risk & "The subjects were blinded for intervention of interest." \\
\hline & & $\begin{array}{l}\text { Personnel delivering the intervention would likely not be blinded due to the } \\
\text { nature of the program, however unlikely to influence outcomes }\end{array}$ \\
\hline & & "... study was an assessor-blinded RCT." \\
\hline \multirow{2}{*}{$\begin{array}{l}\text { Incomplete outcome data } \\
\text { (attrition bias) } \\
\text { All outcomes }\end{array}$} & Low risk & $\begin{array}{l}\text { "An intention-to-treat analysis was used with the last observation carried for- } \\
\text { ward for the missing data." }\end{array}$ \\
\hline & & $\begin{array}{l}\text { "Due to a second stroke, one of the subjects in the experimental group was lost } \\
\text { for a follow-up assessment." }\end{array}$ \\
\hline $\begin{array}{l}\text { Selective reporting (re- } \\
\text { porting bias) }\end{array}$ & Unclear risk & No protocol available \\
\hline Other bias & Low risk & No other sources of bias evident \\
\hline
\end{tabular}

6mWT: 6 Minute Walk Test

ABC: Activities-specific Balance and Confidence Scale

BBS: Berg Balance Scale

BMD: bone mineral density

CCT: circuit class therapy

FIM: Functional Independence Measure

ILAS: Iowa Level of Assistance Scale

JTHFT: Jebsen Taylor Hand Function Test

LOS: length of hospital stay

MAS: Motor Assessment Scale

NHP: Nottingham Health Profile

PADS: Physical Activity and Disability Scale

PASIPD: Physical Acitivity Scale for Individuals with Physical Disabilities

RCT: randomised controlled trial

RMI: Rivermead Mobility Index

TUG: Timed Up and Go

$\mathrm{VO}_{2}$ max: maximum oxygen volume

Characteristics of excluded studies [ordered by study ID] 


\begin{tabular}{|c|c|}
\hline Study & Reason for exclusion \\
\hline Altin 2009 & Intervention: not group format \\
\hline \multirow[t]{2}{*}{ Arya 2012} & Intervention: not group format \\
\hline & Aim: not to improve mobility \\
\hline \multirow[t]{2}{*}{ Boss 2014} & Intervention: not group format, not repetitive practice \\
\hline & Aim: not to improve mobility \\
\hline Bustamante Valles 2016 & Intervention: CCT group used robotic/technology-assisted stations not task-specific training \\
\hline Chu 2004 & Intervention: not task-specific training \\
\hline \multirow[t]{2}{*}{ Dickstein 2014} & Intervention: not group format, not repetitive practice \\
\hline & Aim: not to improve mobility \\
\hline English 2007 & Study design: pseudo randomised \\
\hline English 2014 & Aim: not to improve mobility \\
\hline Faulkner 2014 & Study design: not stroke (TIA) \\
\hline Kim 2010 & Intervention: not group format, no repetitive practice \\
\hline Kim 2012 & Intervention: not group format \\
\hline Kim 2014 & Intervention: not group format, no repetitive practice \\
\hline Kim 2016b & $\begin{array}{l}\text { Intervention: compared group CCT with individualised CCT. However individualised CCT fits defini- } \\
\text { tion of standard CCT. Therefore no useful comparison for this review. }\end{array}$ \\
\hline Kowalczewski 2007 & Intervention: not group format \\
\hline Langhammer 2008 & Intervention: not group format, not task-specific, not circuit \\
\hline \multirow[t]{2}{*}{ Lee 2012} & Intervention: not repetitive practice \\
\hline & Aim: not to improve mobility \\
\hline Lee 2015 & Aim: not to improve mobility \\
\hline \multirow[t]{2}{*}{ McDonnell 2014} & Intervention: not repetitive practice \\
\hline & Aim: not to improve mobility \\
\hline Mead 2007 & Intervention: not task-specific \\
\hline Olney 2006 & Intervention: not task-specific \\
\hline Park 2016 & Intervention: not group format \\
\hline Puckree 2014 & Intervention: not group format \\
\hline Pyöriä 2007 & Intervention: not group format \\
\hline
\end{tabular}




\begin{tabular}{|c|c|}
\hline Study & Reason for exclusion \\
\hline \multirow[t]{2}{*}{ Quaney 2009} & Intervention: not group format, not repetitive practice \\
\hline & Aim: not to improve mobility \\
\hline Rimmer 2000 & Intervention: not task-specific \\
\hline \multirow[t]{2}{*}{ Saeys 2012} & Intervention: not group format, not repetitive practice \\
\hline & Aim: not to improve mobility \\
\hline Salbach 2004 & Intervention: not group format \\
\hline Scianni 2010 & Intervention: not group format \\
\hline Sherrington 2008 & Intervention: not task-specific \\
\hline Shin 2011 & Study design: not group format \\
\hline Sullivan 2007 & Intervention: not circuit format \\
\hline Sunnerhagen 2007 & Intervention: not task-specific \\
\hline Tanne 2008 & Intervention: not task-specific \\
\hline Teixeira-Salmela 1999 & Intervention: not task-specific \\
\hline Yang 2006 & Intervention: not group format \\
\hline
\end{tabular}

CCT: circuit class therapy

Characteristics of studies awaiting assessment [ordered by study ID]

Mota 2011

\begin{tabular}{ll}
\hline Methods & Experimental design \\
\hline Participants & Victims of stroke \\
\hline Interventions & Physiotherapy intervention using aerobic exercises \\
\hline Outcomes & Gait parameters \\
\hline Notes & Not in English \\
\hline
\end{tabular}

\section{Scholten 2014}

\begin{tabular}{ll}
\hline Methods & Possibly a systematic review with 22 RCTs \\
\hline Participants & Unknown \\
\hline Interventions & Fitness training \\
\hline Outcomes & Physical fitness \\
\hline \hline
\end{tabular}


Scholten 2014 (Continued)
Notes
Not in English

Characteristics of ongoing studies [ordered by study ID]

Floel 2014

\begin{tabular}{ll}
\hline Trial name or title & PHYS-STROKE \\
\hline Methods & Phase III RCT \\
\hline Participants & 215 adults with moderate to severe limitations of walking and ADLs 5-45 days after stroke \\
\hline Interventions & $\begin{array}{l}\text { Physical fitness training plus standard rehabilitation; control relaxation sessions plus standard re- } \\
\text { habilitation }\end{array}$ \\
\hline Outcomes & Gait speed, Barthel Index, QoL, sleep, mood, cognition, arm function, cardiovascular factors. \\
\hline Starting date & October 2013 \\
\hline Contact information & Correspondence: agnes.floeel@charite.de \\
\hline Notes & \\
\hline
\end{tabular}

\section{Lawal 2015}

\begin{tabular}{ll}
\hline Trial name or title & CCT in Nigeria \\
\hline Methods & Four-arm RCT \\
\hline Participants & 68 stroke survivors, community dwelling \\
\hline Interventions & CCT of three different durations (60 min, 90 min, 120 min) versus usual care \\
\hline Outcomes & Measures of impairment, activity and participation \\
\hline Starting date & 2014 \\
\hline Contact information & Correspondence: isalawal30@yahoo.com \\
\hline Notes &
\end{tabular}

\section{DATA AND ANALYSES}


Comparison 1. Circuit class therapy versus other

\begin{tabular}{|c|c|c|c|c|}
\hline $\begin{array}{l}\text { Outcome or subgroup } \\
\text { title }\end{array}$ & No. of studies & $\begin{array}{l}\text { No. of partici- } \\
\text { pants }\end{array}$ & Statistical method & Effect size \\
\hline $16 \mathrm{mWT}$ early and late & 10 & 835 & Mean Difference (IV, Fixed, 95\% CI) & $60.86[44.55,77.17]$ \\
\hline 1.1 Early & 4 & 487 & Mean Difference (IV, Fixed, 95\% CI) & $46.56[21.35,71.77]$ \\
\hline 1.2 Late & 6 & 348 & Mean Difference (IV, Fixed, 95\% CI) & $71.15[49.76,92.54]$ \\
\hline $\begin{array}{l}2 \text { Gait speed early and } \\
\text { late }\end{array}$ & 8 & 744 & Mean Difference (IV, Fixed, 95\% CI) & $0.15[0.10,0.19]$ \\
\hline 2.1 Early & 2 & 437 & Mean Difference (IV, Fixed, 95\% CI) & $0.17[0.10,0.25]$ \\
\hline 2.2 Late & 6 & 307 & Mean Difference (IV, Fixed, 95\% CI) & $0.13[0.07,0.19]$ \\
\hline 3 Cadence & 2 & 50 & Mean Difference (IV, Random, 95\% CI) & $13.57[7.52,19.62]$ \\
\hline 4 Timed Up and Go & 5 & 488 & Mean Difference (IV, Fixed, 95\% CI) & $-3.62[-6.09,-1.16]$ \\
\hline $\begin{array}{l}5 \text { Rivermead Mobility } \\
\text { Index }\end{array}$ & 2 & 296 & Mean Difference (IV, Fixed, 95\% CI) & $0.56[0.17,0.95]$ \\
\hline $\begin{array}{l}6 \text { Functional Ambula- } \\
\text { tion Classification }\end{array}$ & 3 & 469 & Odds Ratio (M-H, Random, 95\% Cl) & $1.91[1.01,3.60]$ \\
\hline 7 Berg Balance Scale & 4 & 171 & Mean Difference (IV, Random, 95\% CI) & $1.21[-0.62,3.04]$ \\
\hline 8 Step Test & 3 & 190 & Mean Difference (IV, Fixed, 95\% CI) & $0.98[-0.40,2.37]$ \\
\hline $\begin{array}{l}9 \text { Activities-specific Bal- } \\
\text { ance Confidence Scale }\end{array}$ & 2 & 103 & Mean Difference (IV, Fixed, 95\% CI) & $7.76[0.66,14.87]$ \\
\hline $\begin{array}{l}10 \text { Stroke Impact Scale } \\
\text { (physical) }\end{array}$ & 2 & 437 & Mean Difference (IV, Random, 95\% CI) & $2.91[0.00,5.82]$ \\
\hline 11 VO2 peak & 2 & 103 & Mean Difference (IV, Fixed, 95\% CI) & $2.81[0.90,4.72]$ \\
\hline 12 Steps per day & 2 & 206 & Mean Difference (IV, Fixed, 95\% CI) & $\begin{array}{l}1325.66 \text { [411.09, } \\
2240.22]\end{array}$ \\
\hline 13 Length of stay & 2 & 217 & Mean Difference (IV, Random, 95\% CI) & $-16.35[-37.69,4.99]$ \\
\hline 14 Sensitivity: $6 \mathrm{mWT}$ & 3 & 393 & Mean Difference (IV, Fixed, 95\% CI) & $46.32[17.40,75.24]$ \\
\hline
\end{tabular}

Analysis 1.1. Comparison 1 Circuit class therapy versus other, Outcome $16 \mathrm{mWT}$ early and late.

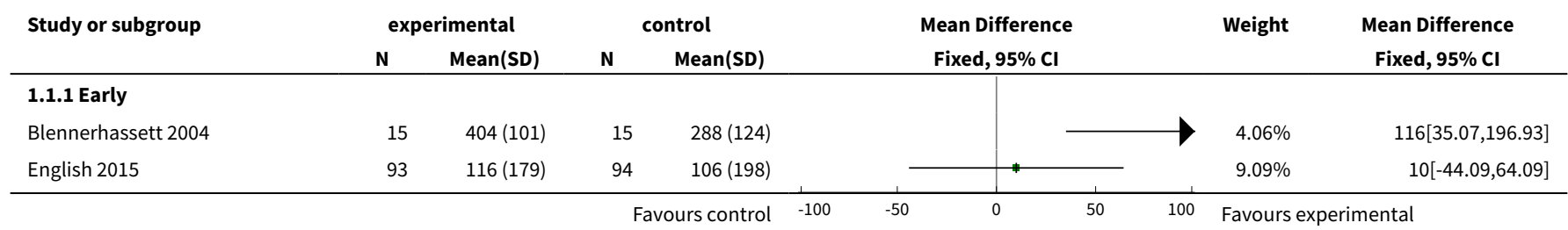




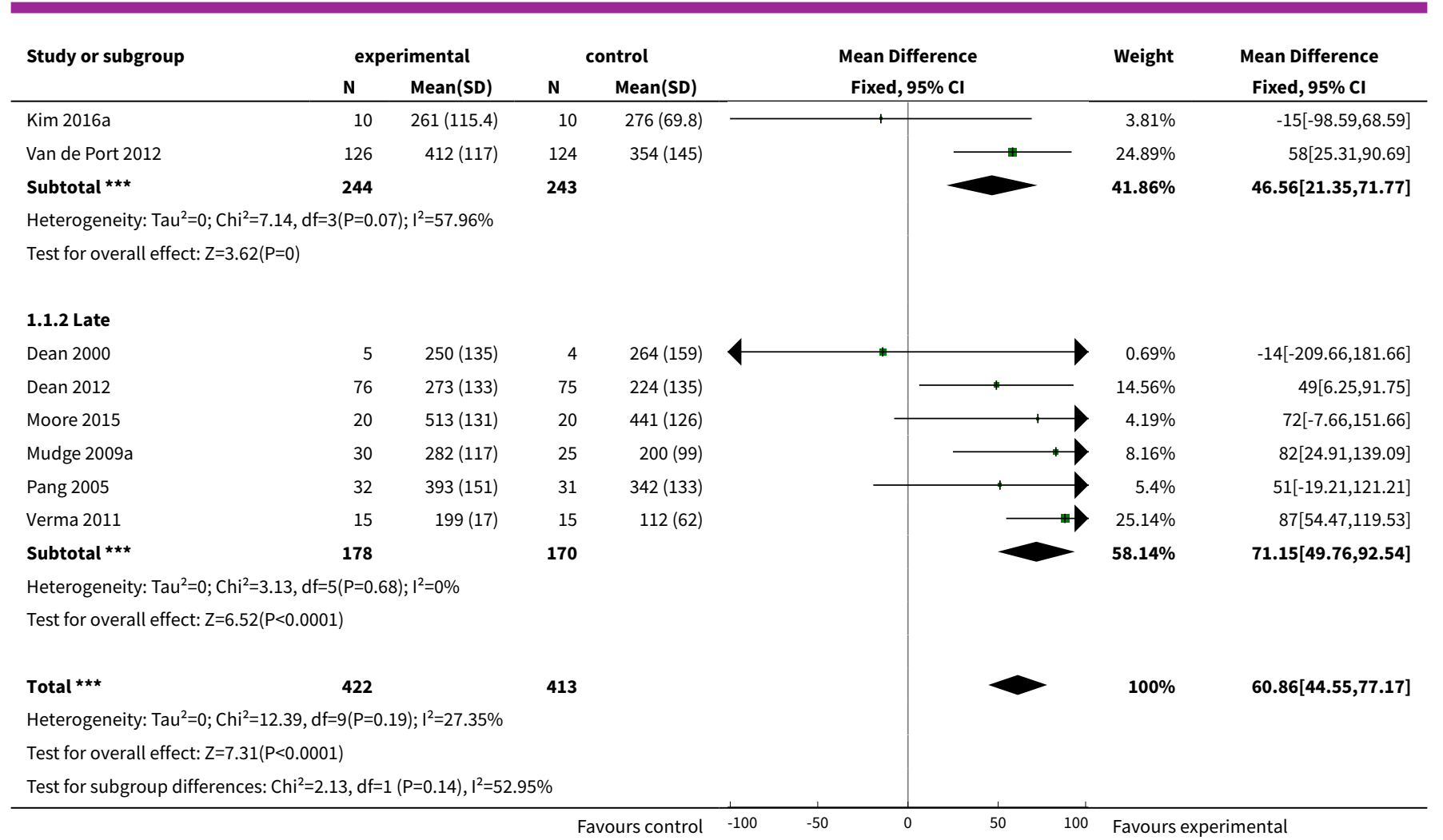

\section{Analysis 1.2. Comparison 1 Circuit class therapy versus other, Outcome 2 Gait speed early and late.}

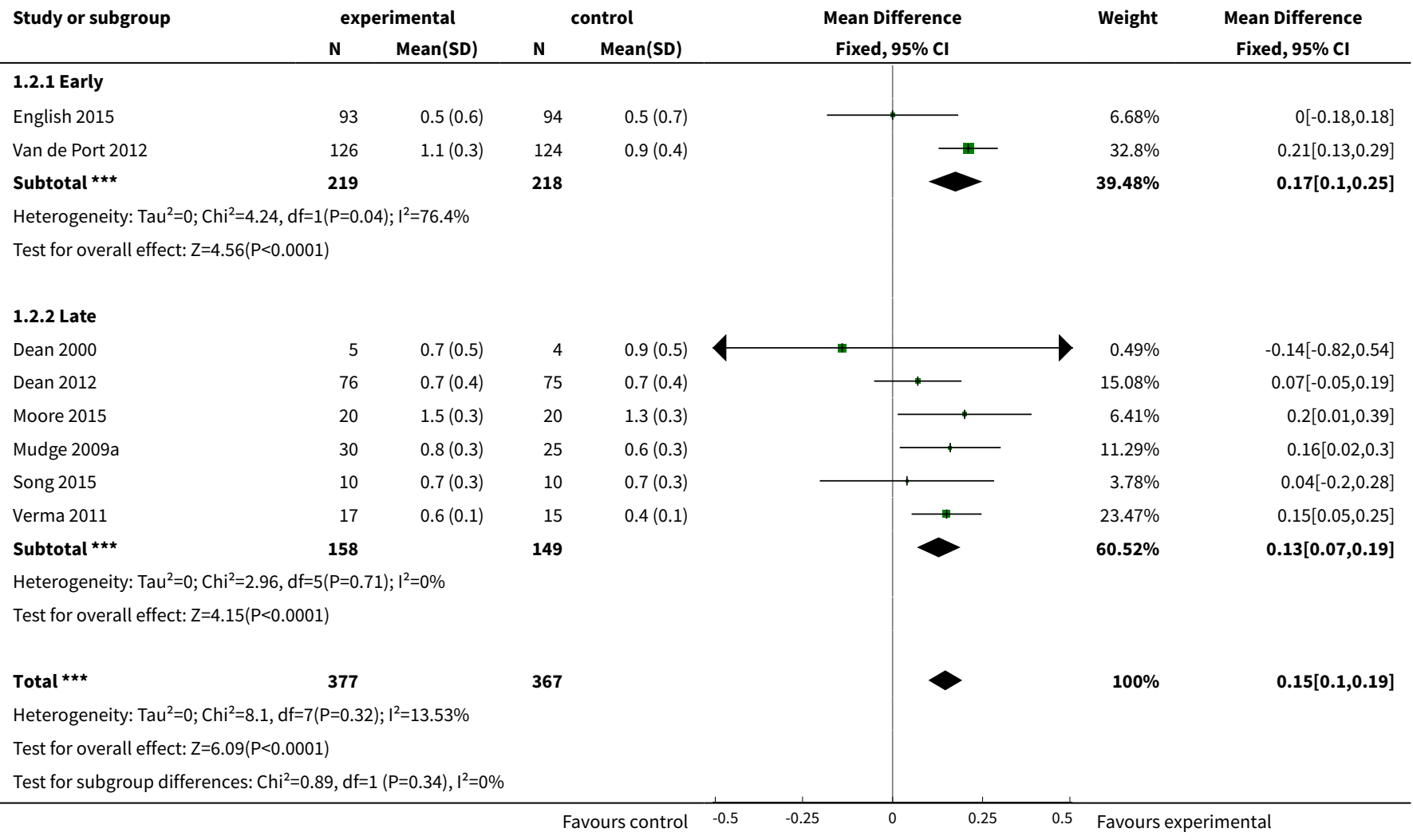


Analysis 1.3. Comparison 1 Circuit class therapy versus other, Outcome 3 Cadence.

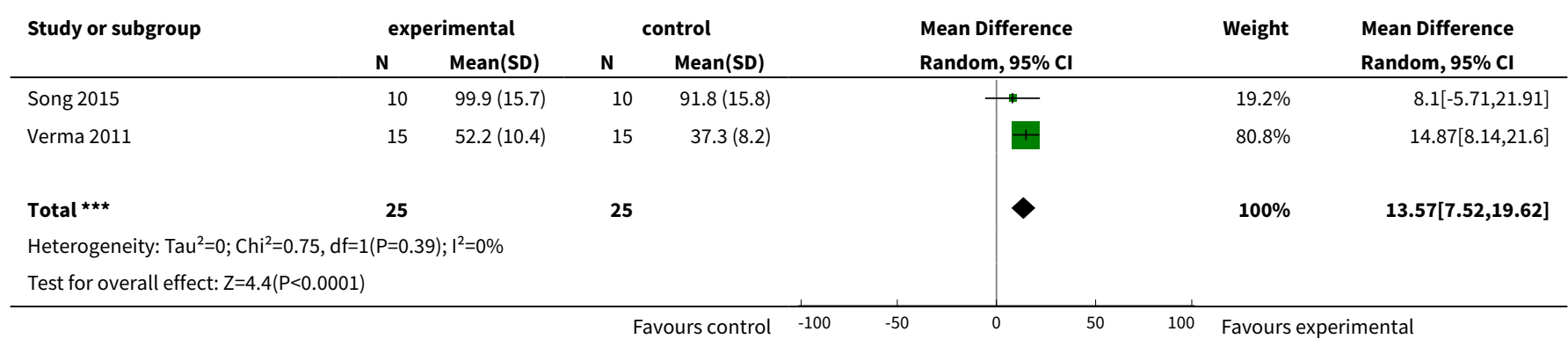

\section{Analysis 1.4. Comparison 1 Circuit class therapy versus other, Outcome 4 Timed Up and Go.}

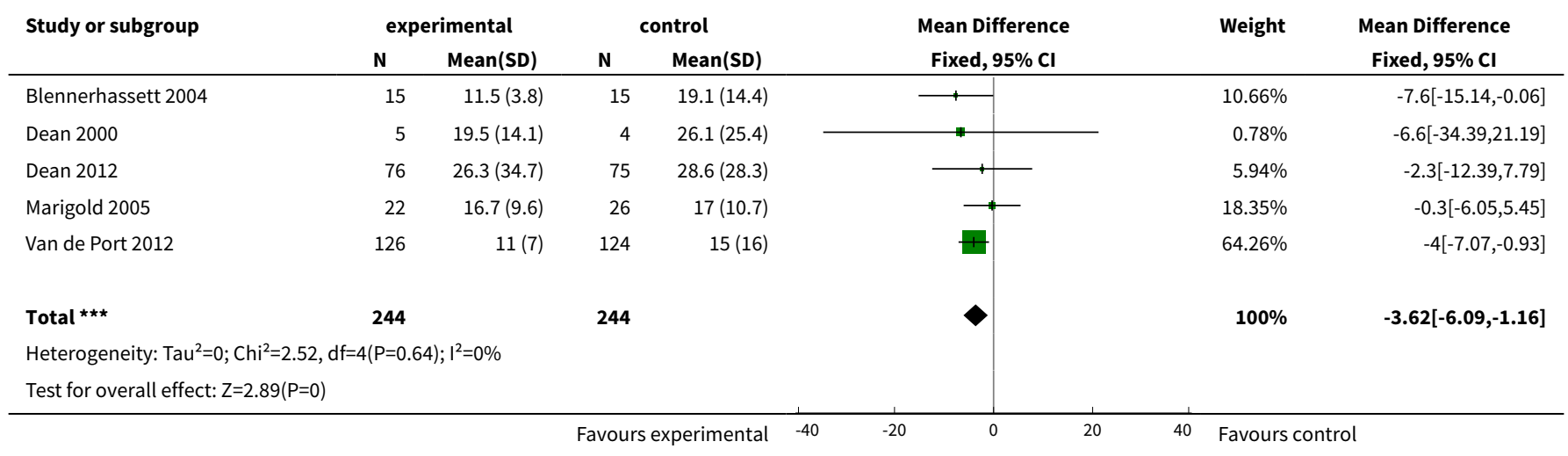

Analysis 1.5. Comparison 1 Circuit class therapy versus other, Outcome 5 Rivermead Mobility Index.

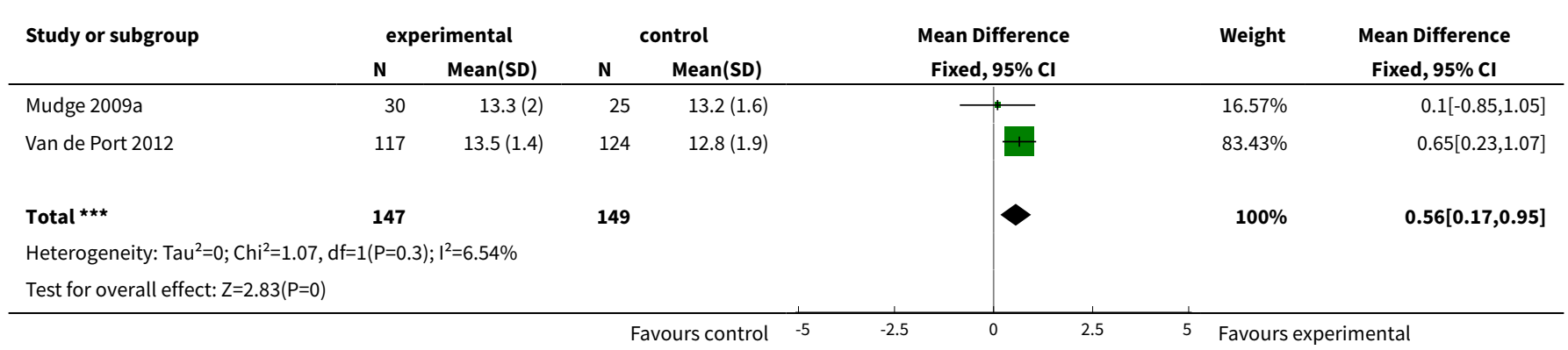

Analysis 1.6. Comparison 1 Circuit class therapy versus other, Outcome 6 Functional Ambulation Classification.

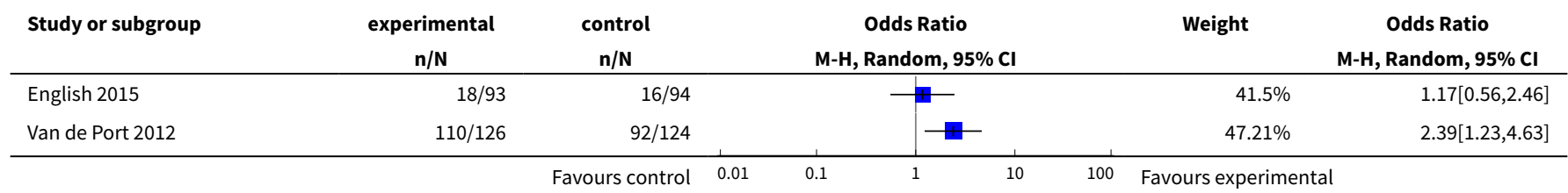




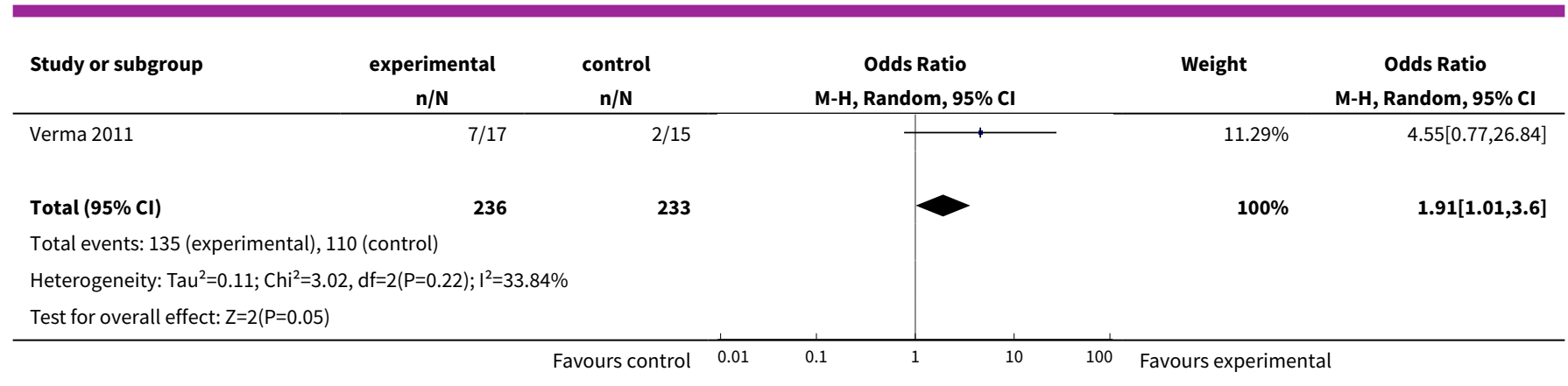

Analysis 1.7. Comparison 1 Circuit class therapy versus other, Outcome 7 Berg Balance Scale.

\begin{tabular}{|c|c|c|c|c|c|c|c|}
\hline \multirow[t]{2}{*}{ Study or subgroup } & \multicolumn{2}{|c|}{ experimental } & \multicolumn{2}{|c|}{ control } & \multirow{2}{*}{$\begin{array}{l}\text { Mean Difference } \\
\text { Random, } 95 \% \mathrm{Cl}\end{array}$} & \multirow[t]{2}{*}{ Weight } & \multirow{2}{*}{$\begin{array}{l}\text { Mean Difference } \\
\text { Random, } 95 \% \mathrm{Cl}\end{array}$} \\
\hline & $\mathbf{N}$ & Mean(SD) & $\mathbf{N}$ & Mean(SD) & & & \\
\hline Kim 2016a & 10 & $46.7(9.4)$ & 10 & $49.8(4.6)$ & $\rightarrow$ & $7.28 \%$ & $-3.1[-9.59,3.39]$ \\
\hline Marigold 2005 & 22 & $49.1(5)$ & 26 & $48.1(5.7)$ & 7 & $25.53 \%$ & $1[-2.03,4.03]$ \\
\hline Moore 2015 & 20 & $55(2)$ & 20 & $52(5)$ & $\#$ & $35.14 \%$ & $3[0.64,5.36]$ \\
\hline Pang 2005 & 32 & $49.6(4.4)$ & 31 & $49.2(5.8)$ & \# & $32.05 \%$ & $0.4[-2.15,2.95]$ \\
\hline \multicolumn{8}{|c|}{ Heterogeneity: $\operatorname{Tau}^{2}=1.03 ; \mathrm{Chi}^{2}=4.27, \mathrm{df}=3(\mathrm{P}=0.23) ; \mathrm{I}^{2}=29.75 \%$} \\
\hline \multicolumn{8}{|c|}{ Test for overall effect: $Z=1.3(P=0.19)$} \\
\hline
\end{tabular}

Analysis 1.8. Comparison 1 Circuit class therapy versus other, Outcome 8 Step Test.

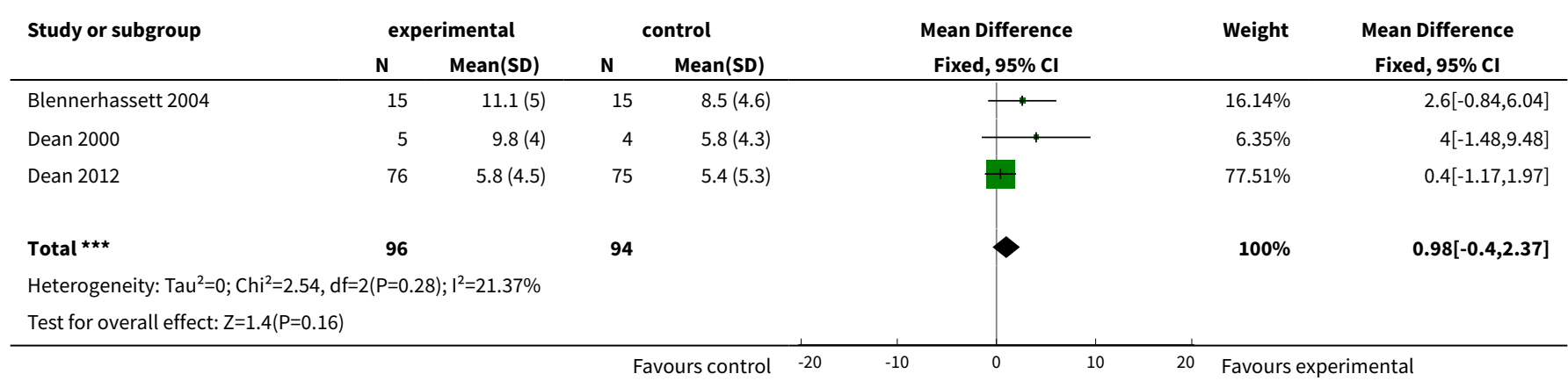

Analysis 1.9. Comparison 1 Circuit class therapy versus other, Outcome 9 Activities-specific Balance Confidence Scale.

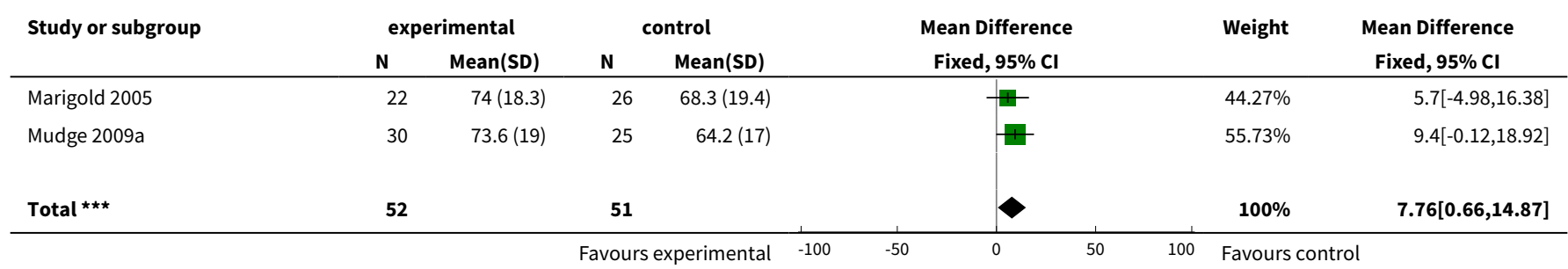




\begin{tabular}{|c|c|c|c|c|c|c|c|c|c|}
\hline \multirow[t]{2}{*}{ Study or subgroup } & experimental & \multicolumn{2}{|c|}{ control } & \multirow{2}{*}{\multicolumn{3}{|c|}{$\begin{array}{c}\text { Mean Difference } \\
\text { Fixed, } 95 \% \mathrm{Cl}\end{array}$}} & \multirow{2}{*}{\multicolumn{2}{|c|}{ Weight }} & \multirow{2}{*}{$\begin{array}{c}\text { Mean Difference } \\
\text { Fixed, } 95 \% \mathrm{Cl} \\
\end{array}$} \\
\hline & N $\quad$ Mean(SD) & $\mathbf{N}$ & $\operatorname{Mean}(S D)$ & & & & & & \\
\hline \multicolumn{10}{|c|}{ Heterogeneity: Tau $^{2}=0 ; \mathrm{Chi}^{2}=0.26, \mathrm{df}=1(\mathrm{P}=0.61) ; \mathrm{I}^{2}=0 \%$} \\
\hline \multicolumn{10}{|c|}{ Test for overall effect: $Z=2.14(P=0.03)$} \\
\hline
\end{tabular}

Analysis 1.10. Comparison 1 Circuit class therapy versus other, Outcome 10 Stroke Impact Scale (physical).

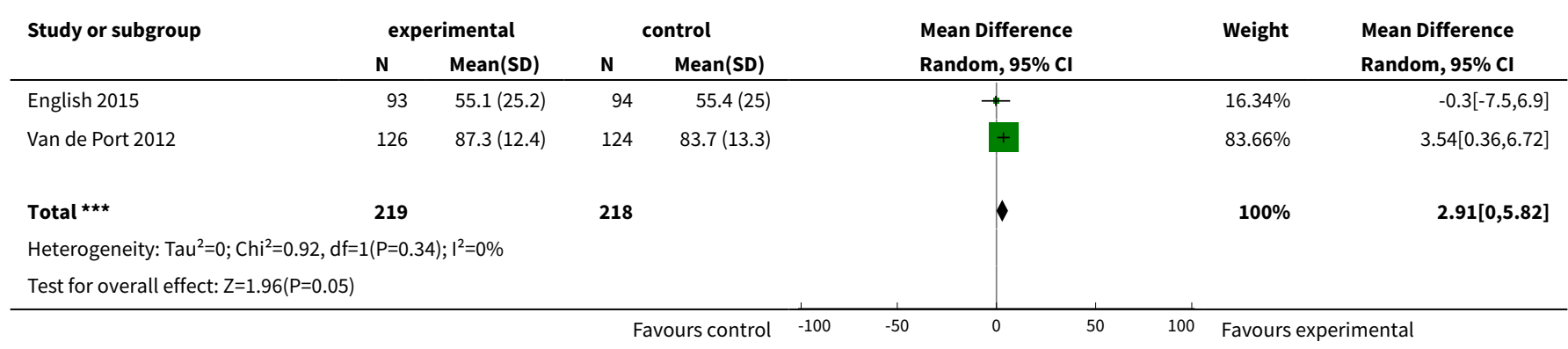

Analysis 1.11. Comparison 1 Circuit class therapy versus other, Outcome 11 v02 peak.

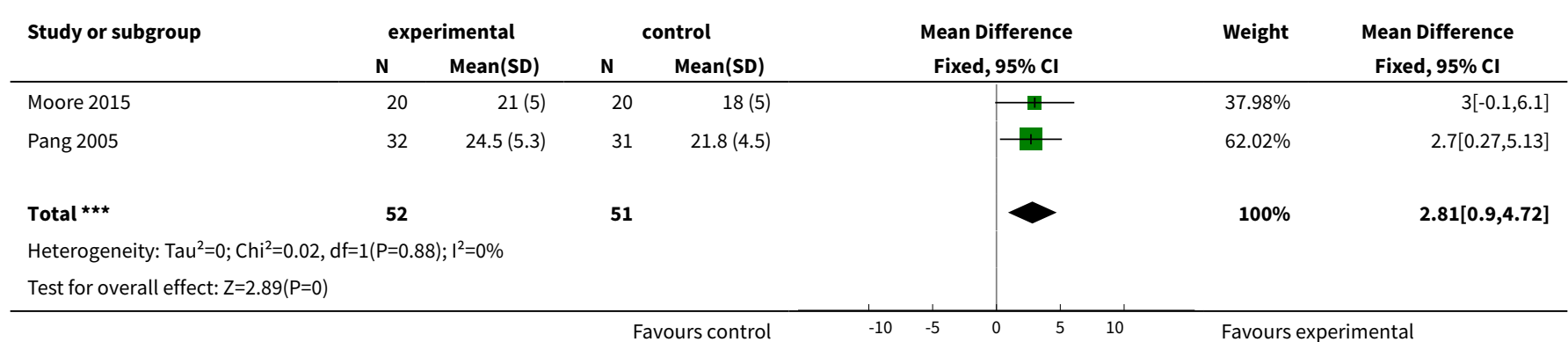

Analysis 1.12. Comparison 1 Circuit class therapy versus other, Outcome 12 Steps per day.

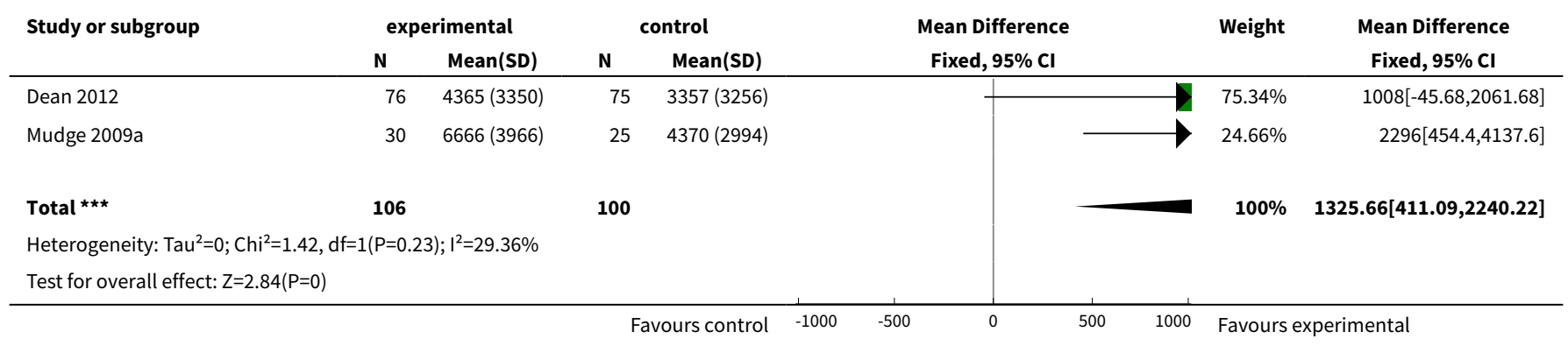


Analysis 1.13. Comparison 1 Circuit class therapy versus other, Outcome 13 Length of stay.

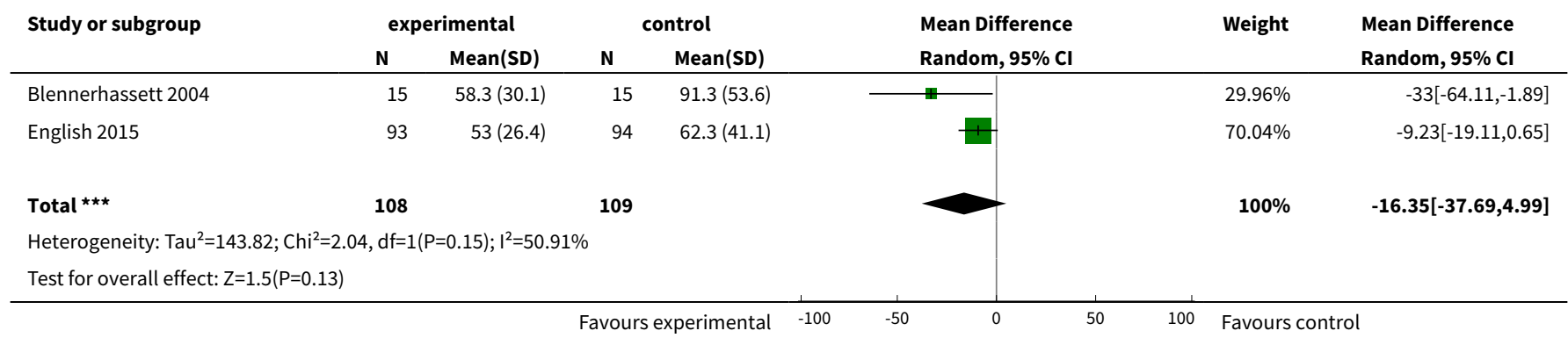

Analysis 1.14. Comparison 1 Circuit class therapy versus other, Outcome 14 Sensitivity: 6mWT.

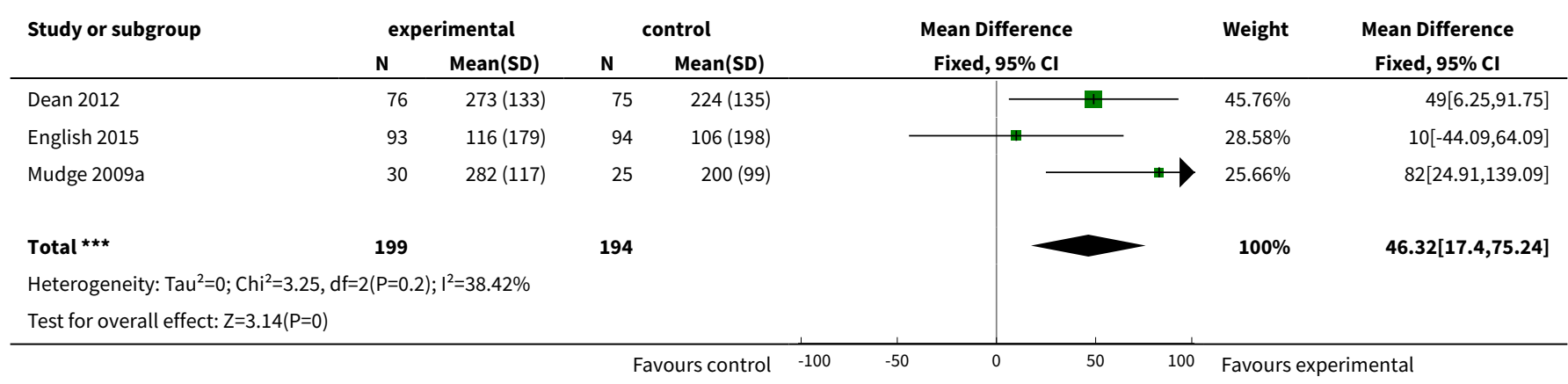

\section{Comparison 2. CCT + education versus no therapy}

\begin{tabular}{lllll}
\hline $\begin{array}{l}\text { Outcome or subgroup ti- } \\
\text { tle }\end{array}$ & No. of studies & $\begin{array}{l}\text { No. of partici- } \\
\text { pants }\end{array}$ & Statistical method & Effect size \\
\hline 1 Timed Up and Go & 2 & 269 & Mean Difference (IV, Fixed, 95\% CI) & $0.90[-0.94,2.75]$ \\
\hline 2 Carer Strain Index & 2 & 174 & Mean Difference (IV, Fixed, 95\% Cl) & $1.06[0.39,1.73]$ \\
\hline
\end{tabular}

Analysis 2.1. Comparison 2 CCT + education versus no therapy, Outcome 1 Timed Up and Go.

\begin{tabular}{|c|c|c|c|c|c|c|c|}
\hline \multirow[t]{2}{*}{ Study or subgroup } & \multicolumn{2}{|c|}{ Experimental } & \multicolumn{2}{|c|}{ Control } & \multirow{2}{*}{$\begin{array}{c}\text { Mean Difference } \\
\text { Fixed, } 95 \% \mathrm{Cl}\end{array}$} & \multirow[t]{2}{*}{ Weight } & \multirow{2}{*}{$\begin{array}{c}\text { Mean Difference } \\
\text { Fixed, } 95 \% \mathrm{Cl}\end{array}$} \\
\hline & $\mathbf{N}$ & Mean(SD) & $\mathbf{N}$ & Mean(SD) & & & \\
\hline Harrington 2010 & 119 & $17.4(7.5)$ & 124 & $16.4(7.5)$ & & $95.45 \%$ & $1[-0.89,2.89]$ \\
\hline Marsden 2010 & 12 & $13.5(7.1)$ & 14 & $14.6(14.6)$ & 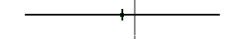 & $4.55 \%$ & $-1.1[-9.74,7.54]$ \\
\hline 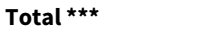 & 131 & & 138 & & & $100 \%$ & $0.9[-0.94,2.75]$ \\
\hline \multicolumn{8}{|c|}{ Heterogeneity: Tau $^{2}=0 ; \mathrm{Chi}^{2}=0.22, \mathrm{df}=1(\mathrm{P}=0.64) ; \mathrm{I}^{2}=0 \%$} \\
\hline
\end{tabular}


Analysis 2.2. Comparison 2 CCT + education versus no therapy, Outcome 2 Carer Strain Index.

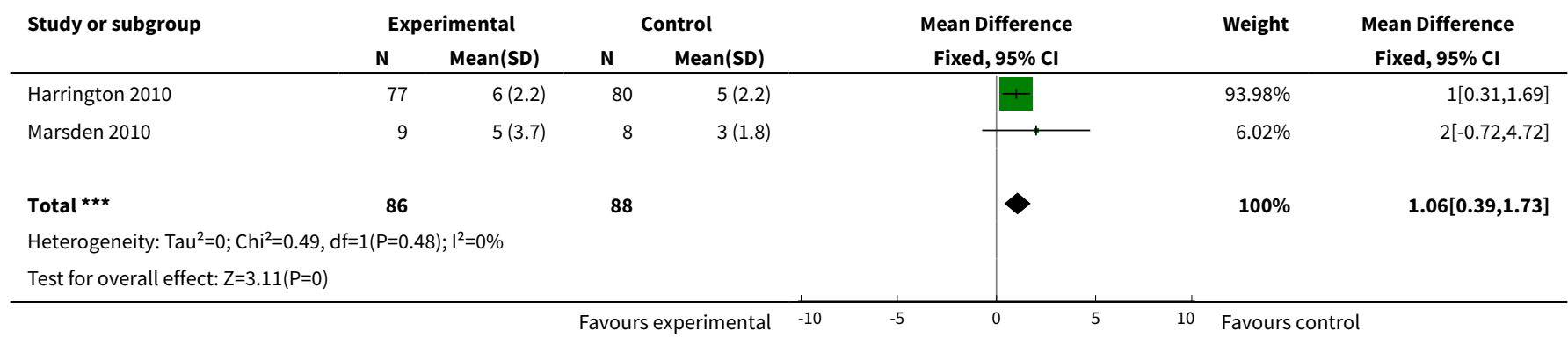

Comparison 3. $\mathrm{CCT}+/$ - education versus any other intervention

\begin{tabular}{lllll}
\hline Outcome or subgroup title & No. of studies & $\begin{array}{l}\text { No. of partici- } \\
\text { pants }\end{array}$ & Statistical method & Effect size \\
\hline 1 Adverse events (falls) & 8 & 815 & $\begin{array}{l}\text { Risk Difference (M-H, Random, 95\% } \\
\text { Cl) }\end{array}$ & 0.03 [-0.02, 0.08] \\
\hline
\end{tabular}

Analysis 3.1. Comparison $3 \mathrm{CCT}+/$ - education versus any other intervention, Outcome 1 Adverse events (falls).

\begin{tabular}{|c|c|c|c|c|c|}
\hline Study or subgroup & $\begin{array}{c}\text { Experimental } \\
n / N\end{array}$ & $\begin{array}{c}\text { Control } \\
n / N\end{array}$ & $\begin{array}{c}\text { Risk Difference } \\
\text { M-H, Random, 95\% Cl }\end{array}$ & Weight & $\begin{array}{c}\text { Risk Difference } \\
\text { M-H, Random, 95\% CI }\end{array}$ \\
\hline Dean 2012 & $0 / 76$ & $0 / 75$ & " & $23.73 \%$ & $0[-0.03,0.03]$ \\
\hline English 2015 & $10 / 93$ & $1 / 94$ & $\rightarrow$ & $17.06 \%$ & $0.1[0.03,0.16]$ \\
\hline Moore 2015 & $0 / 20$ & $0 / 20$ & $\rightarrow$ & $13.03 \%$ & $0[-0.09,0.09]$ \\
\hline Outermans 2010 & $0 / 23$ & $0 / 21$ & + & $14.14 \%$ & $0[-0.08,0.08]$ \\
\hline Pang 2005 & $5 / 32$ & $1 / 31$ & $\longrightarrow$ & $7.93 \%$ & $0.12[-0.02,0.26]$ \\
\hline Van de Port 2012 & $29 / 126$ & $26 / 124$ & $\longrightarrow$ & $11.67 \%$ & $0.02[-0.08,0.12]$ \\
\hline Verma 2011 & $0 / 15$ & $0 / 15$ & $\rightarrow$ & $9.68 \%$ & $0[-0.12,0.12]$ \\
\hline Total $(95 \% \mathrm{Cl})$ & 410 & 405 & $\gamma$ & $100 \%$ & $0.03[-0.02,0.08]$ \\
\hline \multicolumn{6}{|c|}{ Total events: 55 (Experimental), 37 (Control) } \\
\hline \multicolumn{6}{|c|}{ Heterogeneity: $\mathrm{Tau}^{2}=0 ; \mathrm{Chi}^{2}=17.29, \mathrm{df}=7(\mathrm{P}=0.02) ; \mathrm{I}^{2}=59.51 \%$} \\
\hline
\end{tabular}

ADDITIONAL TABLES

Table 1. Summary of circuit class content in all trials

\begin{tabular}{llll}
\hline Study ID & What & Who & How \\
& (CCT content) & $\begin{array}{l}\text { (timing, number and } \\
\text { duration of sessions) }\end{array}$ \\
\hline
\end{tabular}


Table 1. Summary of circuit class content in all trials (Continued)

\begin{tabular}{|c|c|c|c|}
\hline $\begin{array}{l}\text { Blennerhassett } \\
2004\end{array}$ & $\begin{array}{l}\text { Mobility CCT in addition to usual care; } \\
\text { functional tasks, strengthening exercis- } \\
\text { es }\end{array}$ & Physiotherapist & $\begin{array}{l}\text { 1-hour sessions } \\
5 \text { days per week for } 4 \\
\text { weeks }\end{array}$ \\
\hline
\end{tabular}

\begin{tabular}{lllll}
\hline Dean 2000 & $\begin{array}{l}\text { Multiple task-specific training strength- } \\
\text { ening LL; practice locomotor-related } \\
\text { tasks }\end{array}$ & Physiotherapists & $\begin{array}{l}\text { 1-hour sessions, } 3 \text { days } \\
\text { per week for 4 weeks }\end{array}$ & $\begin{array}{l}\text { Community set- } \\
\text { ting }\end{array}$ \\
\hline Dean 2012 & $\begin{array}{l}\text { Progressive balance and strengthening } \\
\text { exercises; walking and stair climbing. } \\
\text { Home exercise programme and advice } \\
\text { to increase walking }\end{array}$ & Physiotherapist & $\begin{array}{l}\text { 45 to 60 minutes per } \\
\text { week for 40 weeks over } \\
\text { a one-year period }\end{array}$ & $\begin{array}{l}\text { Community set- } \\
\text { ting }\end{array}$ \\
\end{tabular}

\begin{tabular}{|c|c|c|c|c|}
\hline English 2015 & $\begin{array}{l}\text { Task-specific, part- as well as whole- } \\
\text { practice of tasks; emphasis on repeti- } \\
\text { tion and feedback }\end{array}$ & $\begin{array}{l}\text { Physiotherapists, as- } \\
\text { sistants, and physio- } \\
\text { therapy students }\end{array}$ & $\begin{array}{l}\text { 90-minute sessions, } 5 \\
\text { times per week for } 4 \\
\text { weeks }\end{array}$ & $\begin{array}{l}\text { Inpatient reha- } \\
\text { bilitation }\end{array}$ \\
\hline Harrington 2010 & $\begin{array}{l}\text { Individual, easily progressed; balance, } \\
\text { endurance, strength, flexibility, function } \\
\text { and well-being. Home exercise manuals } \\
\text { and encouraged for on-going exercise }\end{array}$ & $\begin{array}{l}\text { Instructor and phys- } \\
\text { iotherapist with sup- } \\
\text { port from volunteers } \\
\text { (partners, carers, } \\
\text { family members) }\end{array}$ & $\begin{array}{l}2 \text { sessions per week for } \\
8 \text { weeks. } \\
\text { (1 hour exercise plus } 1 \\
\text { hour interactive educa- } \\
\text { tion }\end{array}$ & $\begin{array}{l}\text { Community set- } \\
\text { ting }\end{array}$ \\
\hline Holmgren 2010 & $\begin{array}{l}\text { Individualised physical activity, func- } \\
\text { tional performance; educational group } \\
\text { discussions about fall risk and security }\end{array}$ & $\begin{array}{l}\text { Physiotherapist and } \\
\text { occupational thera- } \\
\text { pist }\end{array}$ & $\begin{array}{l}7 \text { sessions per week di- } \\
\text { vided over } 3 \text { days for } 5 \\
\text { weeks }\end{array}$ & $\begin{array}{l}\text { Community set- } \\
\text { ting }\end{array}$ \\
\hline Kim 2016a & $\begin{array}{l}\text { Progressive, focused on mobility and } \\
\text { gait training as well as physical fitness }\end{array}$ & Physiotherapist & $\begin{array}{l}\text { 90-minute sessions, } \\
5 \text { days per week for } 4 \\
\text { weeks }\end{array}$ & $\begin{array}{l}\text { Inpatient reha- } \\
\text { bilitation }\end{array}$ \\
\hline Marigold 2005 & $\begin{array}{l}\text { Focused on walking, standing, balance, } \\
\text { and sit-to-stand tasks }\end{array}$ & $\begin{array}{l}\text { Physical therapist, } \\
\text { kinesiologist, and } \\
\text { recreation therapist }\end{array}$ & $\begin{array}{l}\text { 1-hour sessions, } 3 \text { times } \\
\text { per week for } 10 \text { weeks }\end{array}$ & $\begin{array}{l}\text { Community set- } \\
\text { ting }\end{array}$ \\
\hline Marsden 2010 & $\begin{array}{l}\text { Education and exercises for LL function: } \\
\text { functional tasks, strength training and } \\
\text { balance training }\end{array}$ & $\begin{array}{l}\text { Multidisciplinary } \\
\text { team including a } \\
\text { physiotherapist, so- } \\
\text { cial worker, dietician, } \\
\text { clinical nurse consul- } \\
\text { tant, speech patholo- } \\
\text { gist and occupation- } \\
\text { al therapist }\end{array}$ & $\begin{array}{l}\text { 2-hour sessions ( } 1 \text { hour } \\
\text { education }+1 \text { hour ex- } \\
\text { ercise) weekly for } 7 \\
\text { weeks }\end{array}$ & $\begin{array}{l}\text { Community set- } \\
\text { ting }\end{array}$ \\
\hline Moore 2015 & $\begin{array}{l}\text { Functional movement including stretch- } \\
\text { ing, functional strengthening, balance, } \\
\text { agility and fitness }\end{array}$ & $\begin{array}{l}\text { Physiotherapist and } \\
\text { physical activity in- } \\
\text { structor }\end{array}$ & $\begin{array}{l}3 \times 45 \text { - to } 60 \text {-minute ses- } \\
\text { sions per week for } 19 \\
\text { weeks }\end{array}$ & $\begin{array}{l}\text { Community set- } \\
\text { ting }\end{array}$ \\
\hline Mudge 2009a & $\begin{array}{l}\text { Task-oriented gait or standing balance } \\
\text { activity, strengthening LL }\end{array}$ & $\begin{array}{l}\text { Physiotherapist and } \\
2 \text { physiotherapy stu- } \\
\text { dents }\end{array}$ & $\begin{array}{l}\text { 50- to } 60 \text {-minute ses- } \\
\text { sions, } 3 \text { times a week } \\
\text { for } 4 \text { weeks }\end{array}$ & $\begin{array}{l}\text { Community set- } \\
\text { ting }\end{array}$ \\
\hline Outermans 2010 & $\begin{array}{l}\text { Postural control and gait-related activi- } \\
\text { ties: stair climbing, walking and turning }\end{array}$ & Therapists & $\begin{array}{l}\text { 45-minute sessions, } 3 \\
\text { times per week for } 4 \\
\text { weeks }\end{array}$ & $\begin{array}{l}\text { Inpatient and } \\
\text { outpatient set- } \\
\text { tings }\end{array}$ \\
\hline
\end{tabular}




\section{Table 1. Summary of circuit class content in all trials (Continued)}

\begin{tabular}{|c|c|c|c|c|}
\hline Pang 2005 & $\begin{array}{l}\text { Fitness and mobility exercise: cardiores- } \\
\text { piratory fitness, mobility, leg muscle } \\
\text { strength, balance, and hip bone mineral } \\
\text { density }\end{array}$ & $\begin{array}{l}\text { Physical therapist, } \\
\text { occupational thera- } \\
\text { pist, and exercise in- } \\
\text { structor }\end{array}$ & $\begin{array}{l}\text { 1-hour sessions, } 3 \text { times } \\
\text { per week for } 19 \text { weeks }\end{array}$ & $\begin{array}{l}\text { Community set- } \\
\text { ting }\end{array}$ \\
\hline Song 2015 & Functional training tasks & Physiotherapists & $\begin{array}{l}\text { 30-minute sessions, } 3 \\
\text { times per week for } 4 \\
\text { weeks }\end{array}$ & $\begin{array}{l}\text { Inpatient reha- } \\
\text { bilitation }\end{array}$ \\
\hline Tang 2014 & $\begin{array}{l}\text { Brisk level and inclined overground } \\
\text { walking, upright and recumbent cycle } \\
\text { ergometry, functional movements }\end{array}$ & 3 instructors & $\begin{array}{l}\text { 60-minute classes, } 3 \\
\text { times per week for } 6 \\
\text { months }\end{array}$ & $\begin{array}{l}\text { Community set- } \\
\text { ting }\end{array}$ \\
\hline Van de Port 2012 & $\begin{array}{l}\text { Meaningful tasks related to walking } \\
\text { competency }\end{array}$ & $\begin{array}{l}\text { Physiotherapist and } \\
\text { sports therapists }\end{array}$ & $\begin{array}{l}\text { 90-minute sessions, } 2 \\
\text { times per week for } 12 \\
\text { weeks }\end{array}$ & $\begin{array}{l}\text { Community set- } \\
\text { ting }\end{array}$ \\
\hline Verma 2011 & $\begin{array}{l}\text { Meaningful tasks related to walking } \\
\text { competency: balance control, stair } \\
\text { walking, turning, transfers, and speed } \\
\text { walking }\end{array}$ & $\begin{array}{l}\text { Physiotherapist or } \\
\text { occupational thera- } \\
\text { pist } \\
1 \text { caretaker to ensure } \\
\text { safety }\end{array}$ & $\begin{array}{l}\text { 40-minute sessions, } \\
7 \text { days per week for } 2 \\
\text { weeks }\end{array}$ & $\begin{array}{l}\text { Inpatient and } \\
\text { outpatient set- } \\
\text { tings }\end{array}$ \\
\hline
\end{tabular}

CCT: circuit class therapy

LL: lower limb

\section{A P P E N D I C S}

\section{Appendix 1. CENTRAL search strategy}

1. [mh $\wedge^{\prime \prime c e r e b r o v a s c u l a r ~ d i s o r d e r s "] ~ o r ~[m h ~ " b a s a l ~ g a n g l i a ~ c e r e b r o v a s c u l a r ~ d i s e a s e "] ~ o r ~[m h ~ " b r a i n ~ i s c h e m i a "] ~ o r ~[m h ~ " c a r o t i d ~ a r t e r y ~}$ diseases"] or [mh "intracranial arterial diseases"] or [mh "intracranial arteriovenous malformations"] or [mh "intracranial embolism and thrombosis"] or [mh "intracranial hemorrhages"] or [mh^stroke] or [mh "brain infarction"] or [mh ^"stroke, lacunar"] or [mh ^"vasospasm, intracranial"] or [mh ${ }^{\wedge}$ "vertebral artery dissection"]

2. (stroke or poststroke or post-stroke or cerebrovasc* or brain next vasc* or cerebral next vasc* or cva* or apoplex* or SAH):ti,ab,kw (Word variations have been searched)

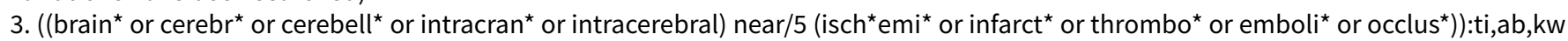
(Word variations have been searched)

4. ((brain* or cerebr $^{\star}$ or cerebell ${ }^{\star}$ or intracerebral or intracranial or subarachnoid) near $/ 5$ (haemorrhage* or hemorrhage* or haematoma* or hematoma* or bleed*)):ti,ab,kw (Word variations have been searched)

5. [mh ^hemiplegia] or [mh paresis]

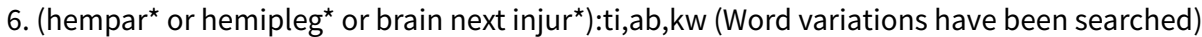

7. [mh "gait disorders, neurologic"]

8. $\{$ or \#1-\#6\}

9. [mh $\wedge^{\wedge}$ "exercise movement techniques"] or [mh $\wedge^{\wedge}$ "exercise therapy"] or [mh $\wedge^{\prime \prime m u s c l e ~ s t r e t c h i n g ~ e x e r c i s e s "] ~ o r ~[m h ~}{ }^{\wedge} "$ plyometric exercise"] or [mh^"resistance training"] or [mh^^walking]

10. [mh^"physical fitness"] or [mh ^"physical exertion"] or [mh^"physical endurance"] or [mh locomotion]

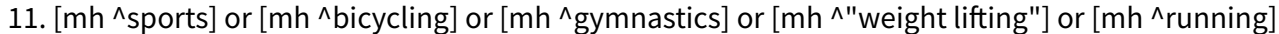

12. [mh $\wedge^{\wedge}$ task performance and analysis"] or [mh ^"athletic performance"] or [mh ${ }^{\wedge}$ "mobility limitation"]

13. [mh ${ }^{\wedge}$ "physical therapy modalities"] or [mh ^"physical therapy specialty"]

14. (physical near $/ 3$ (exercise ${ }^{\star}$ or therap ${ }^{\star}$ or conditioning or activit ${ }^{\star}$ or fitness or endurance)):ti,ab,kw (Word variations have been searched) 15. (exercise near/3 (train* or intervention ${ }^{\star}$ or protocol ${ }^{\star}$ or program ${ }^{\star}$ or therap ${ }^{\star}$ or activit ${ }^{\star}$ or regim $\left.{ }^{\star}\right)$ ):ti, ab,kw (Word variations have been searched)

16. (fitness near/3 (train* or intervention* or protocol* or program* or therap* or activit* or regim)):ti,ab,kw (Word variations have been searched)

17 ((training or conditioning) near/3 (intervention* or protocol* or program or activit* or regim*)):ti,ab,kw (Word variations have been searched) 
18. (sport or cycl $^{\star}$ or bicycl* or treadmill* or run* or walk*):ti,ab,kw (Word variations have been searched)

19. muscle strengthening:ti,ab,kw (Word variations have been searched)

20. ((weight or strength or resistance) near (train* or lift* or exercise*)):ti,ab,kw (Word variations have been searched)

21. \{or \#9-\#20\}

22. [mh ${ }^{\wedge}$ "fitness centers"] or [mh ${ }^{\wedge}$ "sports equipment"]

23. (circuit near/3 (class or classes or therapy or training or program* or exercise* or arranged or arrangement)):ti,ab,kw (Word variations have been searched)

24. (sport ${ }^{\star}$ equipment or station or work station):ti,ab,kw (Word variations have been searched)

25. (fitness near/3 (center ${ }^{\star}$ or centre* or group* or class or classes or training or program $\left.{ }^{\star}\right)$ ):ti, ab,kw (Word variations have been searched)

26. (exercise* near/3 (routine* or group* or class or classes)):ti,ab,kw (Word variations have been searched)

27. ((task-related or sequential) near/3 exercise):ti,ab,kw (Word variations have been searched)

28. group environment:ti,ab,kw (Word variations have been searched)

29. (repetitive pract* or functional task $\left.^{\star}\right): \mathrm{ti}, \mathrm{ab}, \mathrm{kw}$ (Word variations have been searched)

30. $\{$ or \#22-\#29\}

31. [mh $\wedge^{\prime \prime c e r e b r o v a s c u l a r ~ d i s o r d e r s " / R H] ~ o r ~[m h ~ " b a s a l ~ g a n g l i a ~ c e r e b r o v a s c u l a r ~ d i s e a s e " / R H] ~ o r ~[m h ~ " b r a i n ~ i s c h e m i a " / R H] ~ o r ~[m h ~}$ "carotid artery diseases"/RH] or [mh "intracranial arterial diseases"/RH] or [mh "intracranial arteriovenous malformations"/RH] or [mh "intracranial embolism and thrombosis"/RH] or [mh "intracranial hemorrhages"/RH] or [mh ^stroke/RH] or [mh "brain infarction"/RH] or [mh ${ }^{\wedge}$ "stroke, lacunar"/RH] or [mh ^"vasospasm, intracranial"/RH] or [mh ${ }^{\wedge}$ "vertebral artery dissection"/RH]

32. \#8 and \#21

33. \#31 or \#32

34. \#30 and \#33

\section{Appendix 2. MEDLINE search strategy}

We used the following search strategy for MEDLINE (Ovid) and adapted it to search the other databases. As the subject area of this review is quite specific we did not include a trials filter. This increased the sensitivity of the search.

\section{MEDLINE (Ovid)}

1. cerebrovascular disorders/ or exp basal ganglia cerebrovascular disease/ or exp brain ischemia/ or exp carotid artery diseases/or exp intracranial arterial diseases/ or exp "intracranial embolism and thrombosis"/ or exp intracranial hemorrhages/or stroke/ or exp brain infarction/ or vasospasm, intracranial/ or vertebral artery dissection/

2. (stroke or poststroke or post-stroke or cerebrovasc\$ or brain vasc\$ or cerebral vasc\$ or cva $\$$ or apoplex\$ or SAH).tw.

3. ((brain $\$$ or cerebr\$ or cerebell\$ or intracran\$ or intracerebral) adj5 (isch?emi or infarct $\$$ or thrombo $\$$ or emboli\$ or occlus\$)).tw.

4. ((brain $\$$ or cerebr $\$$ or cerebell\$ or intracerebral or intracranial or subarachnoid) adj5 (haemorrhage $\$$ or hemorrhage $\$$ or haematoma

\$or hematoma\$ or bleed\$)).tw.

5. hemiplegia/ or exp paresis/

6. (hemipleg\$ or hemipar\$ or paresis or paretic).tw.

7. exp gait disorders, neurologic/

8. or/1-7

9. exercise movement techniques/ or exercise therapy/ or muscle stretching exercises/ or plyometric exercise/ or resistance training/ or walking/

10. physical fitness/ or physical exertion/ or physical endurance/ or exp locomotion/

11. sports/ or bicycling/ or gymnastics/ or weight lifting/ or running/

12. "task performance and analysis"/ or athletic performance/ or mobility limitation/

13. physical therapy modalities/or physical therapy specialty/

14. (physical adj3 (exercise $\$$ or therap\$ or conditioning or activit\$ or fitness or endurance)).tw.

15. (exercise adj3 (train $\$$ or intervention $\$$ or protocol\$ or program $\$$ or therap $\$$ or activit $\$$ or regim $\$$ )).tw.

16. (fitness adj3 (train\$ or intervention $\$$ or protocol\$ or program $\$$ or therap\$ or activit $\$$ or regim $\$$ )).tw.

17. ((training or conditioning) adj3 (intervention\$ or protocol\$ or program\$ or activit\$ or regim\$)).tw.

18. (sport\$ or cycl\$ or bicycl\$ or treadmill\$ or run\$ or walk\$).tw.

19. muscle strengthening.tw.

20. ((weight or strength or resistance) adj (train\$ or lift\$ or exercise\$)).tw.

21.9 or 10 or 11 or 12 or 13 or 14 or 15 or 16 or 17 or 18 or 19 or 20

22. fitness centers/ or sports equipment/

23. (circuit adj3 (class or classes or therapy or training or program $\$$ or exercise $\$$ or arranged or arrangement)).tw.

24. (sport\$ equipment or station or work station).tw.

25. (fitness adj3 (center $\$$ or centre $\$$ or group\$ or class or classes or training or program\$)).tw.

26. (exercise $\mathbf{a d j 3}$ (routine $\$$ or group $\$$ or class or classes)).tw.

27. ((task-related or sequential) adj3 exercise\$).tw.

28. group environment.tw.

29. (repetitive pract\$ or functional task\$).tw.

30.22 or 23 or 24 or 25 or 26 or 27 or 28 or 29 
31. cerebrovascular disorders/rh or exp basal ganglia cerebrovascular disease/rh or exp brain ischemia/rh or exp carotid artery diseases/ rh or exp intracranial arterial diseases/rh or exp "intracranial embolism and thrombosis"/rh or exp intracranial hemorrhages/rh or stroke/ rh or exp brain infarction/rh or vasospasm, intracranial/rh or vertebral artery dissection/rh

32. 8 and 21

33. 31 or 32

34. 30 and 33

35. limit 34 to human

\section{Appendix 3. Embase search strategy}

1. cerebrovascular disease/ or brain disease/ or exp basal ganglion hemorrhage/ or exp brain hemangioma/ or exp brain hematoma/ or exp brain hemorrhage/ or exp brain infarction/ or exp brain ischemia/ or exp carotid artery disease/ or exp cerebral artery disease/ or exp cerebrovascular accident/ or exp cerebrovascular malformation/ or exp intracranial aneurysm/ or exp occlusive cerebrovascular disease/ or exp vertebrobasilar insufficiency/

2. (stroke\$ or poststroke or apoplex\$ or cerebral vasc\$ or brain vasc\$ or cerebrovasc\$ or cva\$ or SAH).tw.

3. ((brain or cerebr $\$$ or cerebell\$ or vertebrobasil\$ or hemispher $\$$ or intracran $\$$ or intracerebral or infratentorial or supratentorial or middle cerebral artery or MCA\$ or anterior circulation or posterior circulation or basilar artery or vertebral artery or space-occupying) adj5 (isch? emi\$ or infarct\$ or thrombo or emboli\$ or occlus\$ or hypoxi\$)).tw.

4. ((brain $\$$ or cerebr\$ or cerebell\$ or intracerebral or intracran\$ or parenchymal or intraparenchymal or intraventricular or infratentorial or supratentorial or basal gangli\$ or putaminal or putamen or posterior fossa or hemispher\$ or subarachnoid) adj5 (h?emorrhag\$ or h? ematoma\$ or bleed\$)).tw.

5. hemiparesis/ or hemiplegia/ or paresis/

6. (hemipleg\$ or hemipar\$ or paresis or paretic).tw.

7. 1 or 2 or 3 or 4 or 5 or 6

8. exp kinesiotherapy/ or stretching exercise/ or muscle stretching/ or muscle exercise/ or plyometrics/ or resistance training/ or walking/ or exercise/ or circuit training/ or endurance training/

9. fitness/ or exercise intensity/ or endurance/ or exp locomotion/

10. physical activity/ or sport/ or body building/ or cycling/ or endurance sport/ or jogging/ or running/ or weight lifting/

11. task performance/ or physical performance/ or athletic performance/ or walking difficulty/

12. physiotherapy/

13. (physical adj3 (exercise $\$$ or therap\$ or conditioning or activit\$ or fitness or endurance)).tw.

14. (exercise adj3 (train\$ or intervention $\$$ or protocol\$ or program $\$$ or therap\$ or activit $\$$ or regim $\$$ )).tw.

15. (fitness adj3 (train $\$$ or intervention $\$$ or protocol\$ or program\$ or therap\$ or activit\$ or regim\$)).tw.

16. ((training or conditioning) adj3 (intervention\$ or protocol\$ or program\$ or activit\$ or regim\$)).tw.

17. (sport\$ or cycl\$ or bicycl\$ or treadmill\$ or run\$ or walk\$).tw.

18. muscle strengthening.tw.

19. ((weight or strength or resistance) adj (train\$ or lift\$ or exercise\$)).tw.

20.8 or 9 or 10 or 11 or 12 or 13 or 14 or 15 or 16 or 17 or 18 or 19

21. health center/ or exp sports equipment/

22. (circuit adj3 (class or classes or therapy or training or program $\$$ or exercise\$ or arranged or arrangement)).tw.

23. (sports equipment or station or work station).tw.

24. (fitness adj3 (center\$ or centre\$ or group\$ or class or classes or training or program\$)).tw.

25. (exercise\$ adj3 (routine\$ or group\$ or class or classes)).tw.

26. ((task-related or sequential) adj3 exercise\$).tw.

27. group environment.tw.

28. (repetitive pract\$ or functional task\$).tw.

29.21 or 22 or 23 or 24 or 25 or 26 or 27 or 28

30. cerebrovascular disease/rh or brain disease/rh or exp basal ganglion hemorrhage/rh or exp brain hemangioma/rh or exp brain hematoma/rh or exp brain hemorrhage/rh or exp brain infarction/rh or exp brain ischemia/rh or exp carotid artery disease/rh or exp cerebral artery disease/rh or exp cerebrovascular accident/rh or exp cerebrovascular malformation/rh or exp intracranial aneurysm/rh or exp occlusive cerebrovascular disease/rh or exp vertebrobasilar insufficiency/rh

31.7 and 20

32. 30 or 31

33. 29 and 32

\section{Appendix 4. CINAHL search strategy}

S1 (MH "Cerebrovascular Disorders") OR (MH "Basal Ganglia Cerebrovascular Disease+") OR (MH "Carotid Artery Diseases+") OR (MH "Cerebral Ischemia+") OR (MH "Cerebral Vasospasm") OR (MH "Intracranial Arterial Diseases+") OR (MH "Intracranial Embolism and Thrombosis") OR (MH "Intracranial Hemorrhage+") OR (MH "Stroke") OR (MH "Vertebral Artery Dissections") S2 (MH "Stroke Patients") OR (MH "Stroke Units")

S3 TI ( stroke* or poststroke or apoplex* or cerebral vasc* or brain vasc* or cerebrovasc* or cva* or SAH ) or AB ( stroke $^{\star}$ or poststroke or apoplex ${ }^{\star}$ or cerebral vasc ${ }^{\star}$ or brain vasc ${ }^{\star}$ or cerebrovasc ${ }^{\star}$ or cva* $^{\star}$ or SAH ) 
S4 TI ( brain or cerebr ${ }^{\star}$ or cerebell* or vertebrobasil* or hemispher* or intracran* or intracerebral or infratentorial or supratentorial or middle cerebral artery or $\mathrm{MCA}^{\star}$ or anterior circulation or posterior circulation or basilar artery or vertebral artery or space-occupying ) or $\mathrm{AB}$ ( brain or cerebr ${ }^{\star}$ or cerebell ${ }^{\star}$ or vertebrobasil ${ }^{\star}$ or hemispher ${ }^{\star}$ or intracran* or intracerebral or infratentorial or supratentorial or middle cerebral artery or $\mathrm{MCA}^{\star}$ or anterior circulation or posterior circulation or basilar artery or vertebral artery or space-occupying )

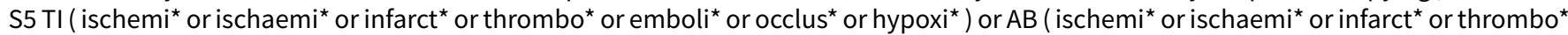
or emboli* or occlus* or hypox* $^{\star}$ )

S6 S4 and S5

S7 TI ( brain $^{\star}$ or cerebr ${ }^{\star}$ or cerebell ${ }^{\star}$ or intracerebral or intracran ${ }^{\star}$ or parenchymal or intraparenchymal or intraventricular or infratentorial or supratentorial or basal gangli* or putaminal or putamen or posterior fossa or hemispher* or subarachnoid) or AB (brain* or cerebr* or cerebell $^{\star}$ or intracerebral or intracran* or parenchymal or intraparenchymal or intraventricular or infratentorial or supratentorial or basal gangli* or putaminal or putamen or posterior fossa or hemispher ${ }^{\star}$ or subarachnoid )

S8 TI ( haemorrhage* or hemorrhage* or haematoma* or hematoma* or bleed ${ }^{\star}$ ) or AB ( haemorrhage* or hemorrhage* or haematoma* or hematoma* or bleed*)

S9 S7 and S8

S10 (MH "Hemiplegia")

$\mathrm{S} 11 \mathrm{TI}$ ( hemipleg* or hemipar* or paresis or paretic ) or AB ( hemipleg* or hemipar* or paresis or paretic)

S12 S1 OR S2 OR S3 OR S6 OR S9 OR S10 OR S11

S13 (MH "Exercise") OR (MH "Therapeutic Exercise") OR (MH "Muscle Strengthening") OR (MH "Stretching") OR (MH "Plyometrics") OR (MH "Group Exercise") OR (MH "Muscle Strengthening") OR (MH "Resistance Training")

S14 (MH "Physical Fitness") OR (MH "Physical Performance") OR (MH "Physical Activity") OR (MH "Physical Endurance+") OR (MH "Muscle Strength") OR (MH "Locomotion+")

S15 (MH "Sports") OR (MH "Cycling") OR (MH "Gymnastics") OR (MH "Weight Lifting") OR (MH "Running") OR (MH "Jogging")

S16 (MH "Task Performance and Analysis") OR (MH "Athletic Performance") OR (MH "Physical Mobility")

S17 (MH "Physical Therapy")

S18 ( TI physical AND TI ( (exercise* or therap* or conditioning or activit* or fitness or endurance) ) ) OR ( AB physical AND AB ( (exercise* or therap* or conditioning or activit* or fitness or endurance) ) )

S19 ( TI exercise AND TI ( (train* or intervention* or protocol* or program* or therap* or activit* or regim*) ) ) OR ( AB exercise AND AB ( ( train $^{\star}$ or intervention* or protocol $^{\star}$ or program $^{\star}$ or therap* or activit ${ }^{\star}$ or regim $\left.\left.^{\star}\right)\right)$ )

S20 ( TI fitness AND TI ( (train* or intervention* or protocol* or program* or therap* or activit* or regim) ) ) OR ( AB fitness AND AB ( (train* or intervention ${ }^{\star}$ or protocol* or program ${ }^{\star}$ or therap* or activit $^{\star}$ or regim*) ))

S21 ( TI ( (training or conditioning) ) AND TI ( (intervention* or protocol* or program* or activit* or regim $\left.{ }^{\star}\right)$ ) ) OR ( AB ( (training or conditioning) ) AND AB ( (intervention* or protocol* or program* or activit* or regim* $\left.{ }^{\star}\right)$ ) )

S22 TI ( (sport* or cycl ${ }^{\star}$ or bicycl* or treadmill* or run* or walk*)) OR AB ( (sport ${ }^{\star}$ or cycl* or bicycl or treadmill* or run $^{\star}$ or walk $\left.^{\star}\right)$ )

S23 TI muscle strengthening OR AB muscle strengthening

S24 ( TI ( (weight or strength or resistance) ) AND TI ( (train* or lift* or exercise*) ) ) OR ( $\mathrm{AB}$ ( (weight or strength or resistance) ) AND AB

( ( train $^{\star}$ or lift ${ }^{\star}$ or exercise $\left.\left.{ }^{\star}\right)\right)$ )

S25 S13 OR S14 OR S15 OR S16 OR S17 OR S18 OR S19 OR S20 OR S21 OR S22 OR S23 OR S24

S26 (MH "Fitness Centers") OR ( (MH "Sports Equipment and Supplies") )

S27 ( TI circuit AND TI ( (class or classes or therapy or training or program* or exercise* or arranged or arrangement)) ) OR ( AB circuit AND $\mathrm{AB}$ ( (class or classes or therapy or training or program* or exercise* or arranged or arrangement) ) )

S28 TI ( (sports equipment or station or work station) ) OR AB ( (sports equipment or station or work station))

S29 ( TI fitness AND TI ( (center* or centre* or group* or class or classes or training or program)) ) OR ( AB fitness AND AB ( (center ${ }^{\star}$ or

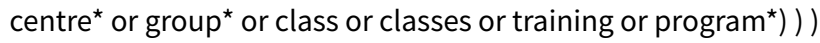

S30 ( $\mathrm{Tl}$ exercise ${ }^{\star}$ AND TI ( (routine* or group* or class or classes) ) ) OR ( AB exercise* AND AB ( (routine* or group* or class or classes) ) )

S31 ( TI ( (task-related or sequential) ) AND TI exercise* ) OR ( AB ( (task-related or sequential) ) AND AB exercise* )

S32 TI group environment OR AB group environment

S33 TI ( (repetitive pract* or functional task*) ) OR AB ( (repetitive pract* or functional task*))

S34 S26 OR S27 OR S28 OR S29 OR S30 OR S31 OR S32 OR S33

S35 (MH "Cerebrovascular Disorders/RH") OR (MH "Basal Ganglia Cerebrovascular Disease+/RH") OR (MH "Carotid Artery Diseases+/RH") OR (MH "Cerebral Ischemia+/RH") OR (MH "Cerebral Vasospasm/RH") OR (MH "Intracranial Arterial Diseases+/RH") OR (MH "Intracranial Embolism and Thrombosis/RH") OR (MH "Intracranial Hemorrhage+/RH") OR (MH "Stroke/RH") OR (MH "Vertebral Artery Dissections/RH") S36 S9 AND S25

S37 S35 OR S36

S38 S34 AND S37

\section{Appendix 5. PsycINFO search strategy}

1. cerebrovascular disorders/ or cerebral hemorrhage/ or cerebral ischemia/ or cerebrovascular accidents/

2. (stroke or poststroke or post-stroke or cerebrovasc\$ or brain vasc\$ or cerebral vasc\$ or cva\$ or apoplex\$ or SAH).tw.

3. ((brain $\$$ or cerebr\$ or cerebell\$ or intracran\$ or intracerebral) adj5 (isch?emi\$ or infarct\$ or thrombo $\$$ or emboli\$ or occlus\$)).tw.

4. ((brain $\$$ or cerebr $\$$ or cerebell\$ or intracerebral or intracranial or subarachnoid) adj5 (haemorrhage $\$$ or hemorrhage $\$$ or haematoma \$or hematoma\$ or bleed\$)).tw. 
5. paralysis/ or hemiplegia/

6. (hemipleg\$ or hemipar\$ or paresis or paretic).tw.

7. 1 or 2 or 3 or 4 or 5 or 6

8. aerobic exercise/ or physical fitness/ or exercise/ or movement therapy/ or walking/ or locomotion/

9. physical activity/ or physical mobility/ or physical agility/ or physical dexterity/ or physical therapy/

10. athletic training/ or athletic performance/ or sports medicine/ or sports/ or weightlifting/

11. (physical adj3 (exercise\$ or therap\$ or conditioning or activit\$ or fitness or endurance)).tw.

12. (exercise adj3 (train $\$$ or intervention $\$$ or protocol\$ or program $\$$ or therap $\$$ or activit $\$$ or regim $\$)$ ).tw.

13. (fitness adj3 (train $\$$ or intervention $\$$ or protocol $\$$ or program $\$$ or therap $\$$ or activit $\$$ or regim $\$$ )).tw.

14. ((training or conditioning) adj3 (intervention\$ or protocol\$ or program\$ or activit\$ or regim\$)).tw.

15. (sport\$ or cycl\$ or bicycl\$ or treadmill\$ or run\$ or walk\$).tw.

16. muscle strengthening.tw.

17. ((weight or strength or resistance) adj (train\$ or lift\$ or exercise\$)).tw.

18. or/8-17

19. apparatus/

20. (circuit adj3 (class or classes or therapy or training or program $\$$ or exercise $\$$ or arranged or arrangement)).tw.

21. (sport\$ equipment or station or work station).tw.

22. (fitness adj3 (center $\$$ or centre $\$$ or group $\$$ or class or classes or training or program\$)).tw.

23. (exercise $\$$ adj3 (routine or group $\$$ or class or classes)).tw.

24. ((task-related or sequential) adj3 exercise\$).tw.

25. group environment.tw.

26. (repetitive pract\$ or functional task\$).tw.

27. or/19-26

28. 27 and 18 and 7

\section{Appendix 6. AMED search strategy}

1. cerebrovascular disorders/or cerebral hemorrhage/ or cerebral infarction/or cerebral ischemia/ or cerebrovascular accident/ or stroke/

2. (stroke or poststroke or post-stroke or cerebrovasc\$ or brain vasc\$ or cerebral vasc\$ or cva $\$$ or apoplex\$ or SAH).tw.

3. ((brain $\$$ or cerebr\$ or cerebell\$ or intracran\$ or intracerebral) adj5 (isch?emi\$ or infarct\$ or thrombo $\$$ or emboli\$ or occlus\$)).tw.

4. ((brain $\$$ or cerebr\$ or cerebell\$ or intracerebral or intracranial or subarachnoid) adj5 (haemorrhage or hemorrhage\$ or haematoma

\$ or hematoma\$ or bleed\$)).tw.

5. hemiplegia/

6. (hemipleg\$ or hemipar\$ or paresis or paretic).tw.

7. 1 or 2 or 3 or 4 or 5 or 6

8. exp exercise/ or physical fitness/ or exertion/ or lifting/ or exp physical endurance/ or immobility/ or resistance training/

9. sports/ or bicycling/ or gymnastics/ or exp locomotion/

10. physical therapy modalities/ or physical therapy speciality/

11. (physical adj3 (exercise\$ or therap\$ or conditioning or activit\$ or fitness or endurance)).tw.

12. (exercise adj3 (train $\$$ or intervention $\$$ or protocol $\$$ or program $\$$ or therap $\$$ or activit $\$$ or regim $\$)$ ).tw.

13. (fitness adj3 (train $\$$ or intervention $\$$ or protocol\$ or program $\$$ or therap $\$$ or activit $\$$ or regim $\$$ )).tw.

14. ((training or conditioning) adj3 (intervention $\$$ or protocol\$ or program $\$$ or activit $\$$ or regim $\$)$ ).tw.

15. (sport\$ or cycl\$ or bicycl\$ or treadmill\$ or run\$ or walk\$).tw.

16. muscle strengthening.tw.

17. ((weight or strength or resistance) adj (train\$ or lift\$ or exercise\$)).tw.

18.8 or 9 or 10 or 11 or 12 or 13 or 14 or 15 or 16 or 17

19. (circuit adj3 (class or classes or therapy or training or program $\$$ or exercise $\$$ or arranged or arrangement)).tw.

20. (sports equipment or station or work station).tw.

21. (fitness adj3 (center\$ or centre $\$$ or group $\$$ or class or classes or training or program\$)).tw.

22. (exercise $\$$ adj3 (routine $\$$ or group $\$$ or class or classes)).tw.

23. ((task-related or sequential) adj3 exercise\$).tw.

24. group environment.tw.

25. (repetitive pract\$ or functional task\$).tw.

26. 19 or 20 or 21 or 22 or 23 or 24 or 25

27.7 and 18 and 26

\section{Appendix 7. SPORTDiscus}

S1 DE "CEREBROVASCULAR disease" OR DE "BRAIN -- Hemorrhage" OR DE "CEREBRAL embolism \& thrombosis" OR DE "STROKE" OR DE "BRAIN -- Wounds \& injuries" OR DE "BRAIN damage" OR DE "CEREBROVASCULAR disease -- Patients"

S2 TI ( stroke or poststroke or post-stroke or cerebrovasc* or brain vasc* or cerebral vasc or cva or apoplex or SAH) or AB ( stroke or poststroke or post-stroke or cerebrovasc ${ }^{\star}$ or brain vasc* or cerebral vasc or cva or apoplex or SAH ) 
S3 ( $\mathrm{TI}$ ( brain* or cerebr ${ }^{\star}$ or cerebell* or intracran* or intracerebral ) or AB ( brain ${ }^{\star}$ or cerebr ${ }^{\star}$ or cerebell ${ }^{\star}$ or intracran* or intracerebral ) ) and ( $\mathrm{TI}$ ( ischemi ${ }^{\star}$ or ischaemi ${ }^{\star}$ or infarct ${ }^{\star}$ or thrombo* or emboli* or occlus ${ }^{\star}$ ) or AB (ischemi* or ischaemi* or infarct ${ }^{\star}$ or thrombo $^{\star}$ or emboli* or occlus*))

S4 ( $\mathrm{TI}$ ( brain $^{\star}$ or cerebr ${ }^{\star}$ or cerebell ${ }^{\star}$ or intracerebral or intracranial or subarachnoid) or AB ( brain ${ }^{\star}$ or cerebr $^{\star}$ or cerebell ${ }^{\star}$ or intracerebral or intracranial or subarachnoid ) ) and ( $\mathrm{TI}$ ( haemorrhage* or hemorrhage* or haematoma* or hematoma* or bleed ${ }^{\star}$ ) or $\mathrm{AB}^{(\text {haemorrhage* }}$ or hemorrhage* or haematoma* or hematoma* or bleed*))

S5 DE "HEMIPLEGIA" OR DE "HEMIPLEGICS" OR DE "GAIT disorders"

S6 TI ( hemipleg* or hemipar ${ }^{\star}$ or paresis or paretic ) or AB ( hemipleg $^{\star}$ or hemipar $^{\star}$ or paresis or paretic )

S7 S1 OR S2 OR S3 OR S4 OR S5 OR S6

S8 DE "EXERCISE" OR DE "EXERCISE -- Equipment \& supplies" OR DE "EXERCISE intensity" OR DE "EXERCISE physiology" OR DE "EXERCISE therapy"

S9 (((DE "MUSCLE strength" OR DE "MUSCLE weakness") OR (DE "PLYOMETRICS")) OR (DE "RESISTANCE training (Physical training \& conditioning)")) AND (DE "WALKING" OR DE "WALKING (Sports)" OR DE "WALKING (Sports) -- Training")

S10 ((DE "PHYSICAL fitness") OR (DE "ENDURANCE sports" OR DE "ULTRAENDURANCE sports")) OR (DE "LOCOMOTION")

S11 (DE "WEIGHT lifting" OR DE "BENCH press" OR DE "DEAD lift (Weight lifting)" OR DE "POWERLIFTING" OR DE "SQUAT (Weight lifting)" OR DE "WEIGHT lifting competitions") OR (DE "RUNNING")

S12 (DE "PHYSICAL therapy" OR DE "SPORTS physical therapy" OR DE "RECOVERY training") OR (DE "CIRCUIT training")

S13 ( TI physical AND TI ( (exercise* or therap* or conditioning or activit* or fitness or endurance) ) ) OR ( AB physical AND AB ( (exercise or therap* or conditioning or activit* or fitness or endurance) ))

S14 ( TI exercise AND TI ( (train* or intervention* or protocol* or program* or therap* or activit* or regim ${ }^{\star}$ ) ) ) OR ( AB exercise AND AB ( $\left(\right.$ train $^{\star}$ or intervention* or protocol $^{\star}$ or program $^{\star}$ or therap* $^{\star}$ or activit ${ }^{\star}$ or regim $\left.\left.{ }^{\star}\right)\right)$ )

S15 ( TI fitness AND TI ( (train* or intervention* or protocol ${ }^{\star}$ or program* or therap ${ }^{\star}$ or activit* or regim $\left.{ }^{\star}\right)$ ) ) OR ( AB fitness AND AB ( (train* or intervention* or protocol ${ }^{\star}$ or program* or therap* or activit* or regim*) ) )

S16 ( TI ( (training or conditioning) ) AND TI ( (intervention* or protocol* or program* or activit* or regim $\left.{ }^{\star}\right)$ )) OR ( AB ( (training or conditioning) ) AND AB ( (intervention* or protocol* or program* or activit* or regim $\left.{ }^{\star}\right)$ ))

S17 TI ( (sport* or cycl ${ }^{\star}$ or bicycl* or treadmill* or run* or walk*) ) OR AB ( (sport* or cycl* or bicycl ${ }^{\star}$ or treadmill* or run* or walk*) )

S18 TI muscle strengthening OR AB muscle strengthening

S19 ( TI ( (weight or strength or resistance) ) AND TI ( (train* or lift* or exercise*) ) ) OR ( AB ( (weight or strength or resistance) ) AND AB

( ( train $^{\star}$ or lift* or exercise*) ))

S20 S8 OR S9 OR S10 OR S11 OR S12 OR S13 OR S14 OR S15 OR S16 OR S17 OR S18 OR S19

S21 DE "PHYSICAL fitness centers" OR DE "WEIGHT training facilities" OR DE "GYMNASIUMS" OR DE "HEALTH facilities" OR DE "EXERCISE -- Equipment \& supplies"

S22 ( TI circuit AND TI ( (class or classes or therapy or training or program* or exercise* or arranged or arrangement) ) ) OR ( AB circuit AND $\mathrm{AB}$ ( (class or classes or therapy or training or program* or exercise* or arranged or arrangement) ))

S23 TI ( (sports equipment or station or work station) ) OR AB ( (sports equipment or station or work station))

S24 ( TI fitness AND TI ( (center* or centre* or group* or class or classes or training or program ${ }^{\star}$ )) ) OR ( AB fitness AND AB ( (center ${ }^{\star}$ or centre* or group ${ }^{\star}$ or class or classes or training or program $\left.\left.{ }^{\star}\right)\right)$ )

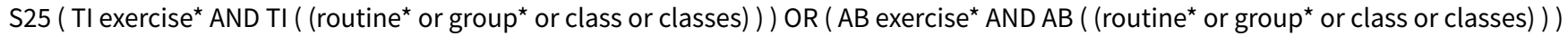

S26 ( TI ( (task-related or sequential) ) AND TI exercise* ) OR ( AB ( (task-related or sequential) ) AND AB exercise* $)$

S27 TI group environment OR AB group environment

S28 TI ( (repetitive pract* or functional task $\left.{ }^{\star}\right)$ ) OR AB ( (repetitive pract* or functional task $\left.{ }^{\star}\right)$ )

S29 S21 OR S22 OR S23 OR S24 OR S25 OR S26 OR S27 OR S28

S30 S7 AND S20 AND S29

\section{WHAT'S NEW}

\begin{tabular}{lll}
\hline Date & Event & Description \\
\hline 23 June 2017 & Amended & Correction to forest plot axis label (Analysis 1.1) \\
\hline
\end{tabular}

\section{H ISTORY}

Protocol first published: Issue 1, 2009

Review first published: Issue 7, 2010 


\begin{tabular}{lll}
\hline Date & Event & Description \\
\hline 28 May 2017 & $\begin{array}{l}\text { New citation required but conclusions } \\
\text { have not changed }\end{array}$ & $\begin{array}{l}\text { Greater number of studies supporting the main conclusion that } \\
\text { circuit class therapy is effective at improving mobility for people } \\
\text { after stroke. }\end{array}$ \\
\hline 28 January 2017 & New search has been performed & $\begin{array}{l}\text { Searches updated and } 12 \text { new trials involving } 1005 \text { new partici- } \\
\text { pants included. This review now includes } 17 \text { trials and } 1297 \text { par- } \\
\text { ticipants. }\end{array}$ \\
\hline 9 July 2010 & Amended & $\begin{array}{l}\text { Minor correction made to the participant characteristics in the } \\
\text { Results section of the Abstract and under Included studies in the } \\
\text { main Results section of the review. }\end{array}$ \\
\hline
\end{tabular}

\section{CONTRIBUTIONS OFAUTHORS}

Coralie English and Susan Hillier were involved in all stages of the review. Elizabeth Lynch assisted in assessing risk of bias and in drafting the text of the updated review. Coralie English and Elizabeth Lynch have experience in the clinical use of CCT and Susan Hillier and Coralie English have experience as review authors. Coralie English and Susan Hillier are guarantors of the review.

\section{DECLARATIONS OF INTEREST}

Coralie English: has published a trial investigating the use of CCT with people with stroke (English 2015).

Susan Hillier: has published a trial investigating the use of CCT with people with stroke (English 2015).

Elizabeth Lynch: none known

\section{DIFFERENCES BETWEEN PROTOCOLANDREVIEW}

The original protocol included quasi-randomised trials: the updated review excluded these due to sufficient randomised trials being found. The primary outcome has been refined to walking capacity (rather than a general outcome of improved mobility) but is still defined operationally as the $6 \mathrm{mWT}$, which is used the most extensively in stroke trials. We have included a 'Summary of findings' table in the main report, along with the approach to determining this table and the GRADE designations (in methods).

\section{IN DEX TERMS}

\section{Medical Subject Headings (MeSH)}

*Walking Speed; Arm [physiology]; Exercise Therapy [adverse effects] [methods]; Gait [physiology]; Postural Balance [physiology]; Randomized Controlled Trials as Topic; Recovery of Function; Stroke Rehabilitation [ ${ }^{\star}$ methods]; Walk Test

\section{MeSH check words}

Adult; Humans 